\title{
WestVirginiaUniversity
}

THE RESEARCH REPOSITORY @ WVU

Graduate Theses, Dissertations, and Problem Reports

2002

\section{Sport fish consumption advisory for West Virginia}

William Alvin Warnick
West Virginia University

Follow this and additional works at: https://researchrepository.wvu.edu/etd

\section{Recommended Citation}

Warnick, William Alvin, "Sport fish consumption advisory for West Virginia" (2002). Graduate Theses, Dissertations, and Problem Reports. 1563.

https://researchrepository.wvu.edu/etd/1563

This Thesis is protected by copyright and/or related rights. It has been brought to you by the The Research Repository @ WVU with permission from the rights-holder(s). You are free to use this Thesis in any way that is permitted by the copyright and related rights legislation that applies to your use. For other uses you must obtain permission from the rights-holder(s) directly, unless additional rights are indicated by a Creative Commons license in the record and/ or on the work itself. This Thesis has been accepted for inclusion in WVU Graduate Theses, Dissertations, and Problem Reports collection by an authorized administrator of The Research Repository @ WVU. For more information, please contact researchrepository@mail.wvu.edu. 
Sport Fish Consumption Advisory for West Virginia

\author{
William A. Warnick
}

Thesis

Submitted to the Davis College of Agriculture, Forestry and Consumer Sciences at West Virginia University

In partial fulfillment of the requirement for the degree of Master of Science in

Wildlife and Fisheries Resources

\author{
Patricia M. Mazik, Chairperson \\ Kyle J. Hartman \\ Janice Smithson \\ Department of Wildlife and Fisheries Resources
}

\author{
Morgantown, West Virginia \\ 2002
}

Keywords: advisories, aroclor, consumption, fish, polychlorinated biphenyls (PCBs), screening value, mercury 


\section{ABSTRACT \\ Sport Fish Consumption Advisory for West Virginia}

\section{William Alvin Warnick}

The risk based sport fish consumption advisory protocol, West Virginia Sport Fish Consumption Advisory Guide (the Guide), was drafted for the state. Fish were collected from ten West Virginia sites ( 5 previously identified as contaminated, 5 previously identified as uncontaminated). Fish samples were collected, processed and analyzed for total mercury concentration and Aroclors (PCBs). Recommended meal frequencies were calculated from contaminant levels and based on the Guide. Mean fillet sample contaminant levels were compared to composite sample levels and found to require the same level or in one case a more protective of consumption advisory. Ten composite samples had Aroclor concentrations greater than the screening values used to trigger a fish consumption advisory according to Guide. All samples from the ten sites had mercury levels above the Guide screening levels. West Virginia should consider implementing consumption advisories for the sites with samples exceeding screening values and conduct further study to determine the extent of contamination in all the state's watersheds. 


\section{DEDICATION}

I dedicate this work to the people most responsible for who I am. First my late mother Linda Fleming Warnick taught me I could accomplish anything I set my mind to. My Dad, David Warnick taught me I could do anything I wanted in life as long as I was willing to accept the consequences. I always wanted to be like you Dad, I hope I came close. Lizzie, I honestly don't know what I would do with out you. Keslie, I hope I can teach you some of the most important things I've learned, which aren't taught in schools or written in books.

"I have tried to live my life so that my family would love me and my friends respect me. The others can do whatever the hell they please" John Wayne 


\section{ACKNOWLEDGEMENTS}

I want to thank my committee members, Pat Mazik, Kyle Hartman and Janice Smithson for their help in getting this done. Pat thanks for putting up with me since 1998;

hopefully your first student at WVU is done. Thanks to the West Virginia Department of Environmental Protection for funding and the Division of Natural Resources for the fish.

Special thanks to Deo Picart, Meuria Yu and Jim Campbell for sharing your expertise in fish tissue analysis and more importantly your friendship.

Thanks to my fellow students in no particular order, Mike Kaller, John Sweka, Clif Tipton, Jason Freund, Kim Bjorgo, Gary Williams, Jim Hakala, Dorothy Tinkler, and Eric Janney.

Thank you, Captain John F. Jordan U.S. Navy (RET.) for teaching me that you have to play at least as hard as you work to have balance in life.

Thank you, Coach Don Nehlen. If more people put West Virginia University ahead of personal gain and position as you did, WVU would be a much better place.

Last but not least I have to thank my wife Lizzie and daughter Keslie for allowing me to steal time from them to complete my work. 
Table of Contents

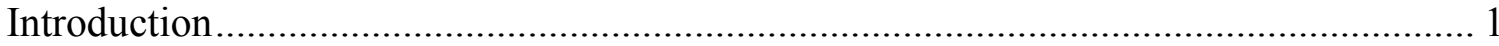

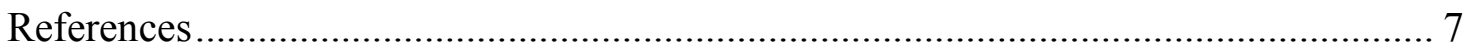

Chapter 1: Guide for West Virginia Sport Fish Consumption Advisories ...................... 10

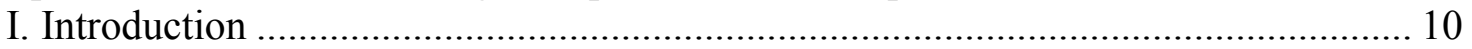

II. General statement about contaminants, benefits and hazards ............................. 12

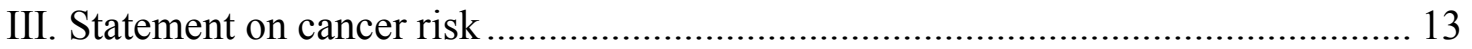

IV. Statement on benefits of fish consumption...................................................... 13

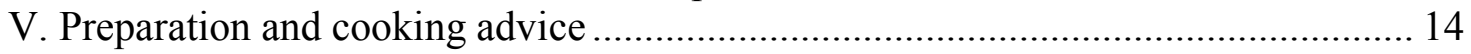

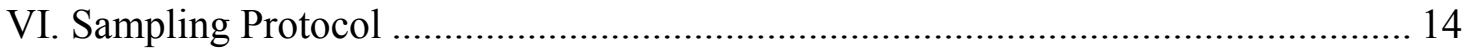

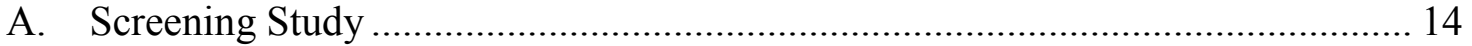

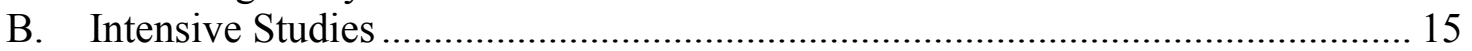

VII. Assumptions ........................................................................................... 15

A. Reference Dose ...................................................................................... 16

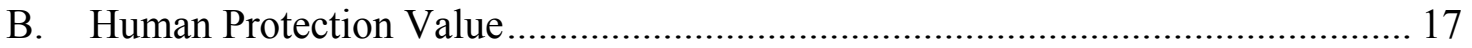

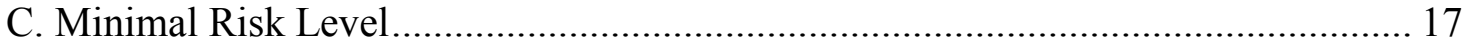

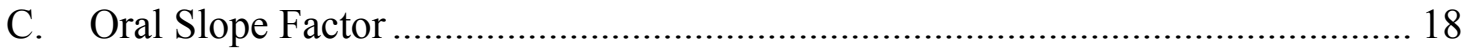

D. Average Body Weight............................................................................ 18

E. Uniform Meal Size..................................................................................... 19

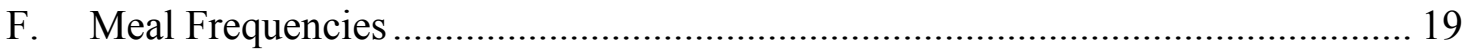

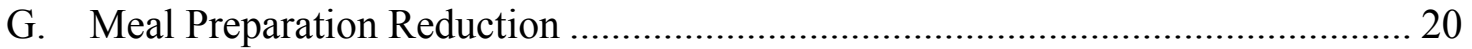

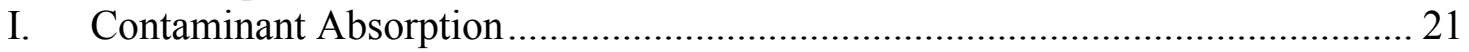

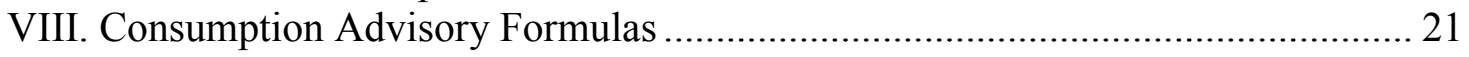

IX. Multiple Contaminants Noncancer Formula ................................................... 22

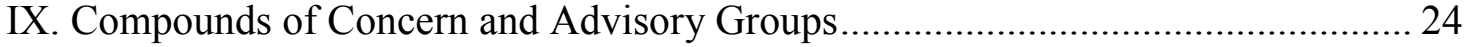

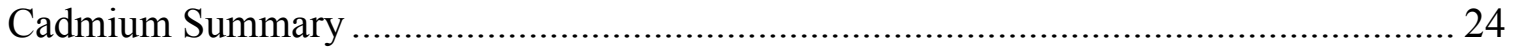

Adult Advisory Assumptions - Cadmium................................................................. 26

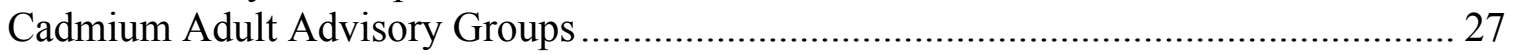

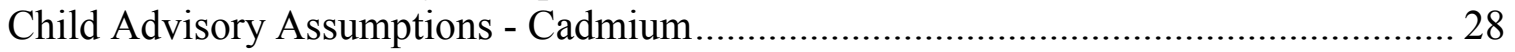

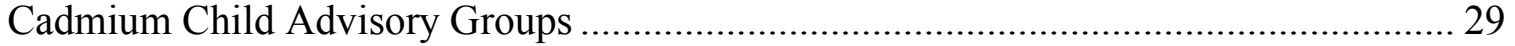

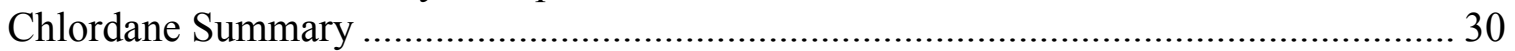

Cancer Effect Assumptions - Chlordane Skin on Fillets ............................................. 32

Cancer Effect Assumptions - Chlordane Skin Off Fillets (Catfish) ................................ 32

Chlordane Cancer Effect Advisory Groups - Skin On Fillet .......................................... 33

Chlordane Cancer Effect Advisory Groups - Skin Off Fillet ........................................ 34

Advisory Assumptions - Chlordane Skin on Fillets ............................................... 35

Advisory Assumptions - Chlordane Skin Off Fillets (Catfish) .................................... 35

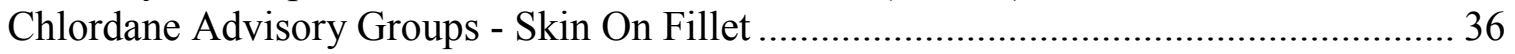

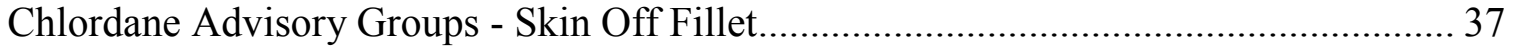

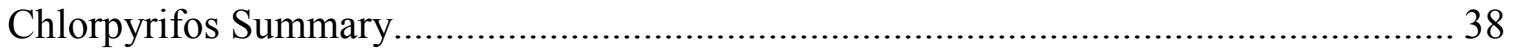

Adult Advisory Assumptions - Chlorpyrifos Skin On Fillet ........................................ 39

Adult Advisory Assumptions - Chlorpyrifos Skin Off Fillet ...................................... 39

Chlorpyrifos Adult Advisory Groups - Skin On Fillets............................................. 40

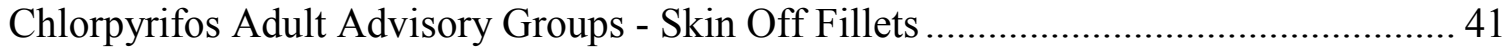

Child Advisory Assumptions - Chlorpyrifos Skin On Fillet ......................................... 42 
Child Advisory Assumptions - Chlorpyrifos Skin Off Fillet.......................................... 42

Chlorpyrifos Child Advisory Groups - Skin On Fillets ................................................. 43

Chlorpyrifos Child Advisory Groups - Skin Off Fillets ................................................... 44

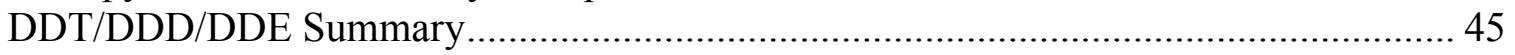

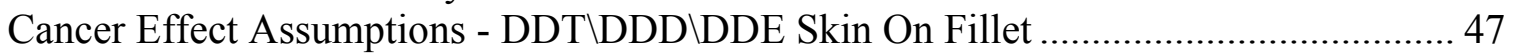

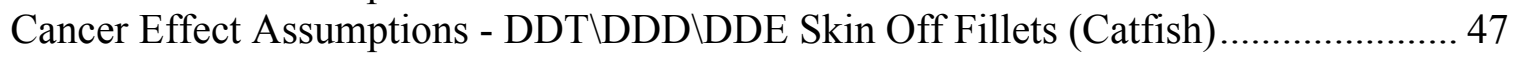

DDT/DDD/DDE Cancer Effect Advisory Groups - Skin On Fillet ................................. 48

DDT/DDD/DDE Cancer Effect Advisory Groups Skin Off Fillet ................................... 49

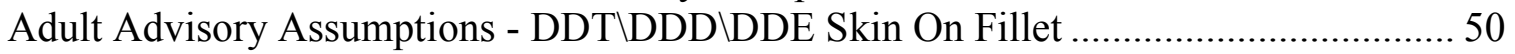

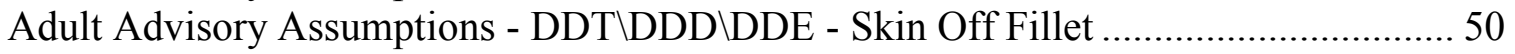

DDT/DDD/DDE Adult Advisory Groups - Skin On Fillet ........................................... 51

DDT/DDD/DDE Adult Advisory Groups Skin Off Fillet .............................................. 52

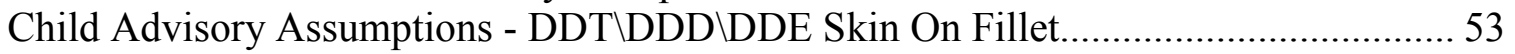

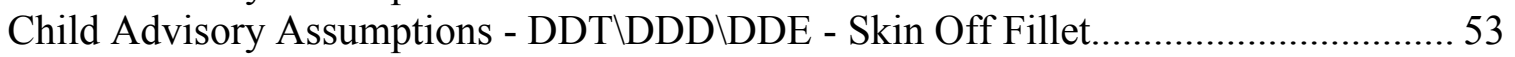

DDT/DDD/DDE Child Advisory Groups - Skin On Fillet.............................................. 54

DDT/DDD/DDE Child Advisory Groups Skin Off Fillet .............................................. 55

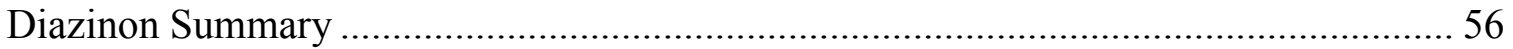

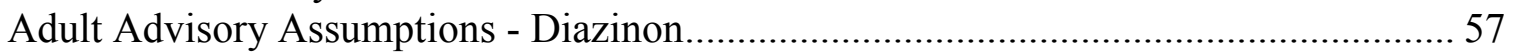

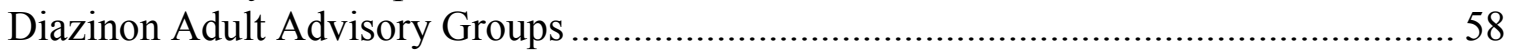

Children Advisory Assumptions - Diazinon.............................................................. 59

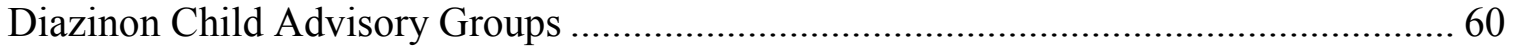

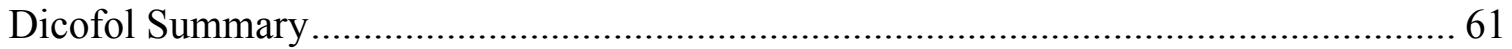

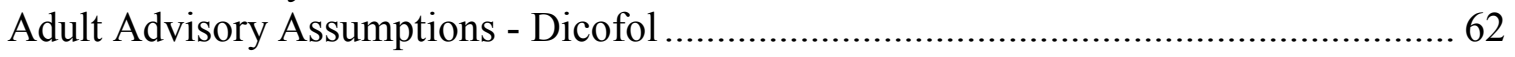

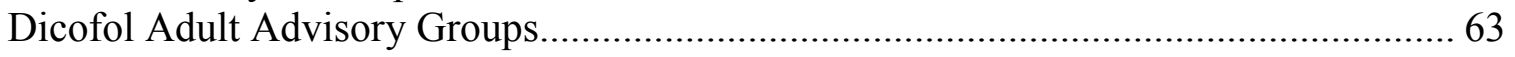

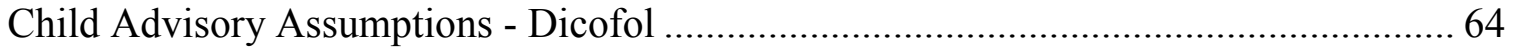

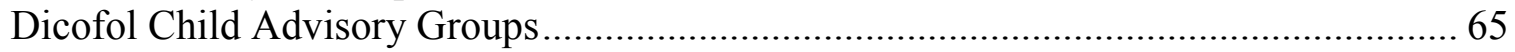

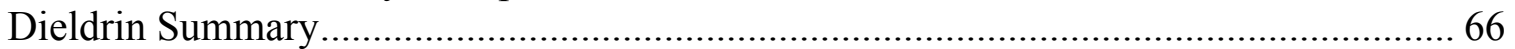

Cancer Effect Assumptions - Dieldrin Skin On Fillets...................................................... 68

Cancer Effect Assumptions - Dieldrin Skin Off Fillets (Catfish)...................................... 68

Dieldrin Cancer Effect Advisory Groups - Skin On Fillet ............................................... 69

Dieldrin Cancer Effect Advisory Groups - Skin Off Fillets ............................................. 70

Adult Advisory Assumptions - Dieldrin Skin On Fillets................................................ 71

Adult Advisory Assumptions - Dieldrin Skin Off Fillets ................................................ 71

Dieldrin Adult Advisory Groups - Skin On Fillet ...................................................... 72

Dieldrin Adult Advisory Groups - Skin Off Fillets ........................................................ 73

Children Advisory Assumptions - Dieldrin Skin On Fillets ............................................. 74

Children Advisory Assumptions - Dieldrin Skin Off Fillets ............................................. 74

Dieldrin Child Advisory Groups - Skin On Fillet............................................................ 75

Dieldrin Child Advisory Groups - Skin Off Fillets ....................................................... 76

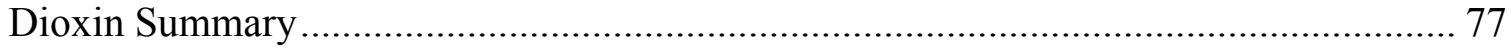

Cancer Effect Assumptions - Dioxin Skin Off Fillets (Catfish) ........................................ 78

Dioxin Cancer Effect Advisory Groups - Skin On Fillet................................................. 79

Dioxin Cancer Effect Advisory Groups - Skin Off Fillets ............................................. 80

Adult Advisory Assumptions - Dioxin Skin On Fillets .................................................. 81

Adult Advisory Assumptions - Dioxin Skin Off Fillets ……………………………..... 81

Dioxin Adult Advisory Groups - Skin On Fillet............................................................. 82 
Dioxin Adult Advisory Groups - Skin Off Fillet........................................................ 83

Children Advisory Assumptions - Dioxin Skin On Fillets ............................................ 84

Children Advisory Assumptions - Dioxin Skin Off Fillets ............................................. 84

Dioxin Child Advisory Groups - Skin On Fillet........................................................... 85

Dioxin Child Advisory Groups - Skin Off Fillet ........................................................ 86

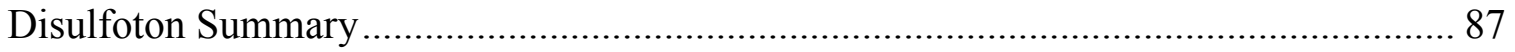

Adult Advisory Assumptions - Disulfoton ................................................................. 88

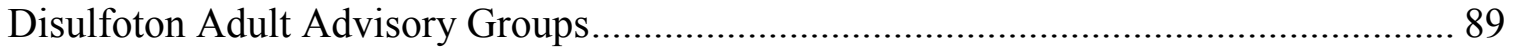

Children Advisory Assumptions - Disulfoton .............................................................. 90

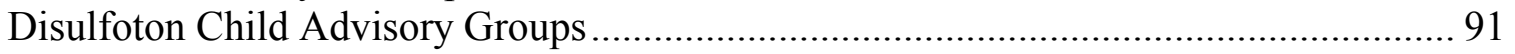

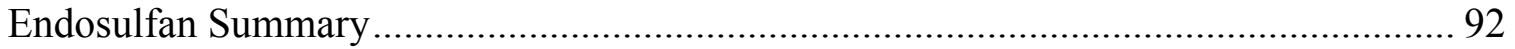

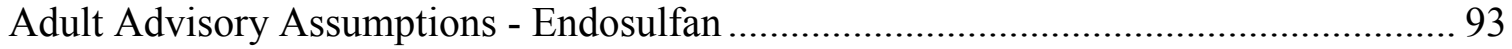

Endosulfan Adult Advisory Groups........................................................................... 94

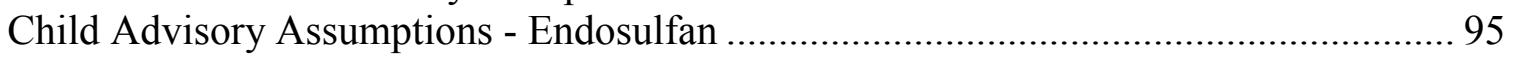

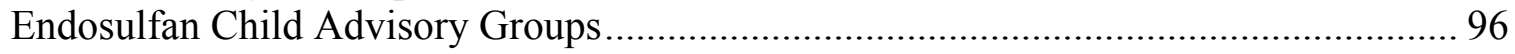

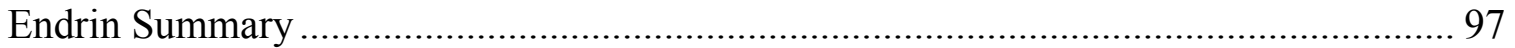

Adult Advisory Assumptions - Endrin Skin On Fillet...................................................... 98

Adult Advisory Assumptions - Endrin Skin Off Fillet ................................................... 98

Endrin Adult Advisory Groups Skin On Fillet ........................................................... 99

Endrin Adult Advisory Groups Skin Off Fillet........................................................... 100

Children Advisory Assumptions - Endrin Skin On Fillet................................................ 101

Children Advisory Assumptions - Endrin Skin Off Fillet ............................................. 101

Endrin Child Advisory Groups Skin On Fillet ……….............................................. 102

Endrin Child Advisory Groups Skin Off Fillet.......................................................... 103

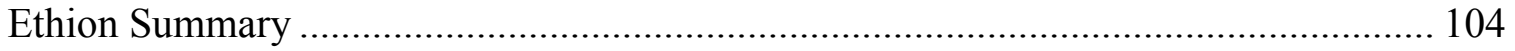

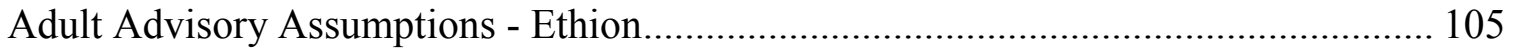

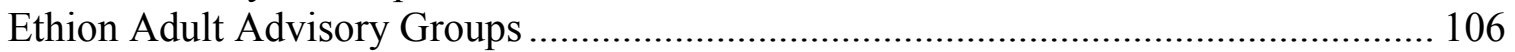

Children Advisory Assumptions - Ethion................................................................. 107

Ethion Child Advisory Groups .............................................................................. 108

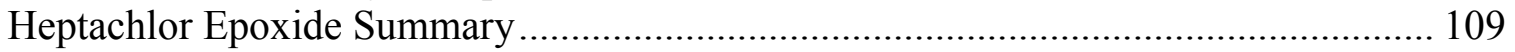

Cancer Effect Assumptions - Heptachlor Epoxide Skin On Fillets................................ 110

Cancer Effect Assumptions - Heptachlor Epoxide Skin Off Fillets (Catfish) ................ 110

Heptachlor Epoxide Cancer Effect Advisory Groups - Skin On Fillets .......................... 111

Heptachlor Epoxide Cancer Effect Advisory Groups - Skin Off Fillets ......................... 112

Adult Advisory Assumptions - Heptachlor Epoxide Skin On Fillets .............................. 113

Adult Advisory Assumptions - Heptachlor Epoxide Skin Off Fillets ............................. 113

Heptachlor Epoxide Adult Advisory Groups - Skin On Fillets ....................................... 114

Heptachlor Epoxide Adult Advisory Groups - Skin Off Fillets ...................................... 115

Child Advisory Assumptions - Heptachlor Epoxide Skin On Fillets .............................. 116

Heptachlor Epoxide Child Advisory Groups - Skin On Fillets ....................................... 117

Heptachlor Epoxide Child Advisory Groups - Skin Off Fillets....................................... 118

Hexachlorobenzene Summary ................................................................................ 119

Cancer Effect Assumptions - Hexachlorobenzene Skin On Fillets ................................. 120

Cancer Effect Assumptions - Hexachlorobenzene Skin Off Fillets (Catfish) ................ 120

Hexachlorobenzene Cancer Effect Advisory Groups - Skin On Fillets .......................... 121

Hexachlorobenzene Cancer Effect Advisory Groups - Skin Off Fillets......................... 122 
Adult Advisory Assumptions - Hexachlorobenzene Skin On Fillet ............................. 123

Adult Advisory Assumptions - Hexachlorobenzene Skin Off Fillet ............................. 123

Hexachlorobenzene Adult Advisory Groups - Skin On Fillets .................................... 124

Hexachlorobenzene Adult Advisory Groups - Skin Off Fillets ................................... 125

Children Advisory Assumptions - Hexachlorobenzene Skin On Fillet ........................ 126

Children Advisory Assumptions - Hexachlorobenzene Skin Off Fillet ........................ 126

Hexachlorobenzene Child Advisory Groups - Skin On Fillets................................... 127

Hexachlorobenzene Child Advisory Groups - Skin Off Fillets ................................... 128

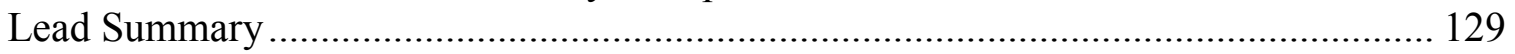

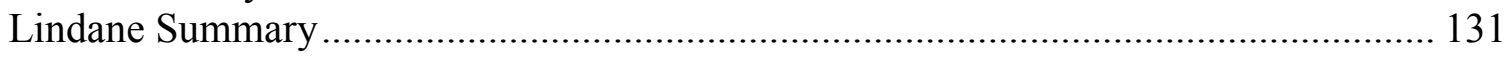

Adult Advisory Assumptions - Lindane Skin On Fillet ........................................... 132

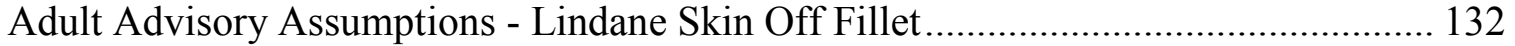

Lindane Adult Advisory Groups - Skin On Fillet...................................................... 133

Lindane Adult Advisory Groups - Skin Off Fillet ..................................................... 134

Children Advisory Assumptions - Lindane Skin On Fillet.......................................... 135

Children Advisory Assumptions - Lindane Skin Off Fillet ....................................... 135

Lindane Child Advisory Groups - Skin On Fillet......................................................... 136

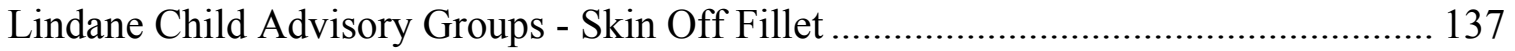

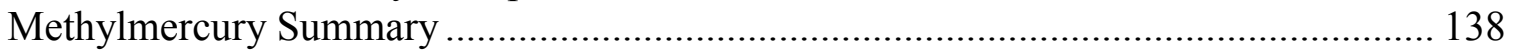

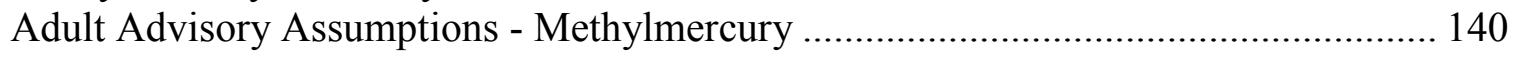

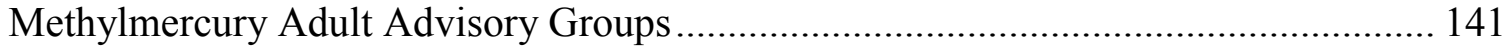

Children Advisory Assumptions - Methylmercury.................................................. 142

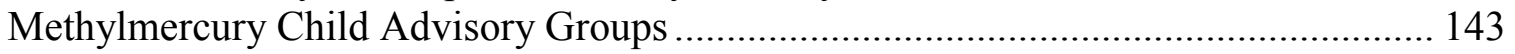

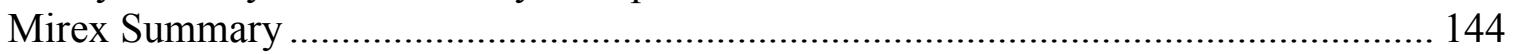

Adult Advisory Assumptions - Mirex Skin On Fillet .............................................. 145

Adult Advisory Assumptions - Mirex Skin Off Fillet ................................................ 145

Mirex Adult Advisory Groups Skin On Fillet ........................................................... 146

Mirex Adult Advisory Groups Skin Off Fillet........................................................... 147

Children Advisory Assumptions - Mirex Skin On Fillet ............................................ 148

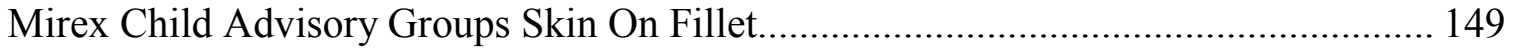

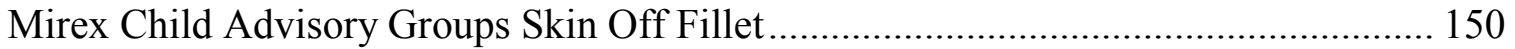

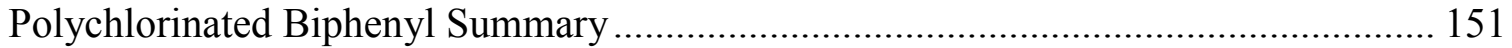

Advisory Assumptions - PCB Skin On Fillet ......................................................... 153

Advisory Assumptions - PCB Skin Off Fillet.......................................................... 153

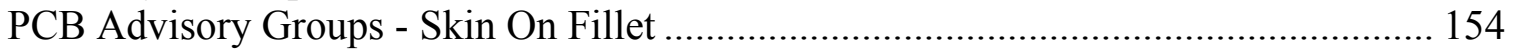

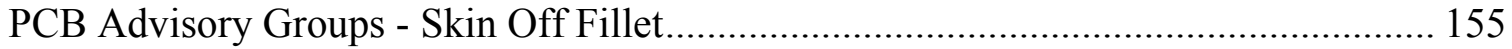

Polycyclic Aromatic Hydrocarbons ......................................................................... 156

Cancer Effect Assumptions - Polycyclic Aromatic Hydrocarbons Skin On Fillets ....... 157

Cancer Effect Assumptions - Polycyclic Aromatic Hydrocarbons Skin Off Fillets

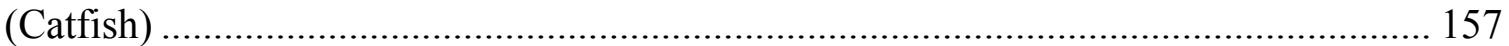

Polycyclic Aromatic Hydrocarbons Cancer Effect Advisory Groups - Skin On Fillets. 158

Polycyclic Aromatic Hydrocarbons Cancer Effect Advisory Groups -........................ 159

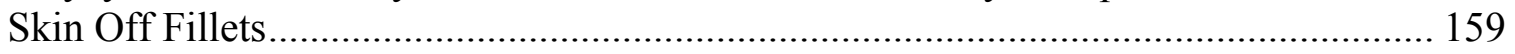

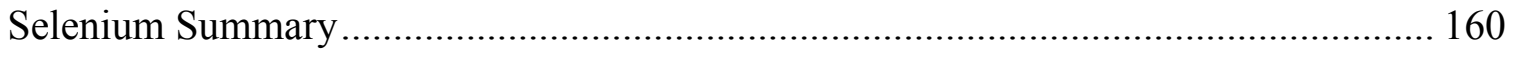

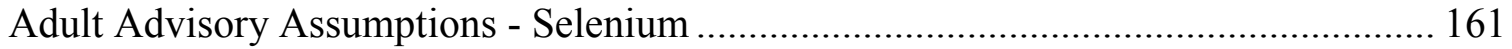

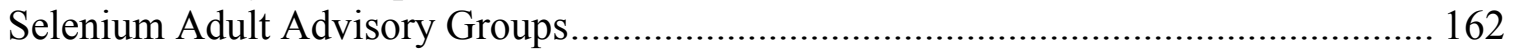




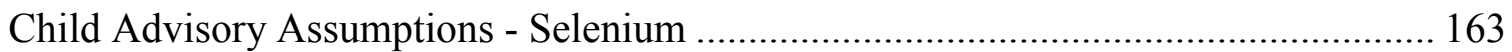

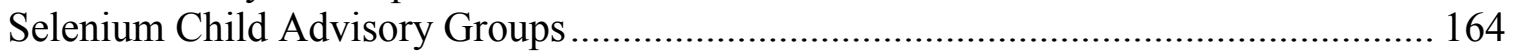

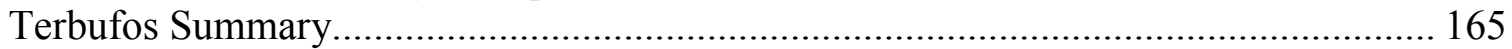

Adult Advisory Assumptions - Terbufos ................................................................... 166

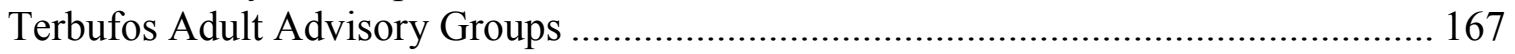

Children Advisory Assumptions - Terbufos ………………..................................... 168

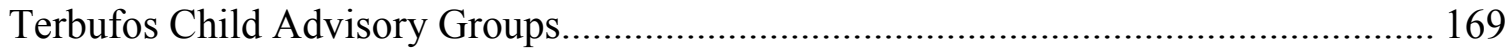

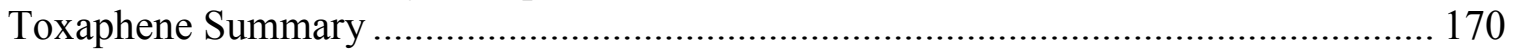

Cancer Effect Assumptions - Toxaphene Skin On Fillets .............................................. 171

Cancer Effect Assumptions - Toxaphene Skin Off Fillets (Catfish) .............................. 171

Toxaphene Cancer Effect Advisory Groups - Skin On Fillets ...................................... 172

Toxaphene Cancer Effect Advisory Groups - Skin Off Fillets...................................... 173

Adult Advisory Assumptions -Toxaphene Skin On Fillet.............................................. 174

Adult Advisory Assumptions -Toxaphene Skin Off Fillet .......................................... 174

Toxaphene Adult Advisory Groups Skin On Fillet ................................................... 175

Toxaphene Adult Advisory Groups Skin Off Fillet...................................................... 176

Child Advisory Assumptions -Toxaphene Skin On Fillet .............................................. 177

Child Advisory Assumptions -Toxaphene Skin Off Fillet ............................................ 177

Toxaphene Child Advisory Groups Skin On Fillet................................................... 178

Toxaphene Child Advisory Groups Skin Off Fillet.................................................... 179

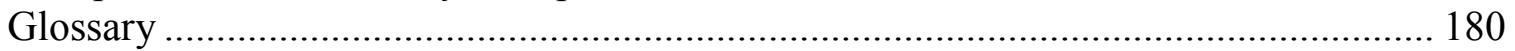

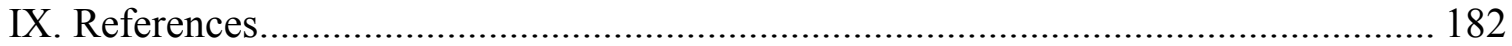

Table 1.Maximum Daily Ingestion for Compounds of Concern .................................... 188

Table 2. Compound RfD, HPV, MRL and References................................................ 189

Table 3. West Virginia Sport Fish Consumption Cancer Contaminant Advisory Levels Summarized*.. 191

Table 4. West Virginia Sport Fish Adult Consumption Contaminant Advisory Levels Summarized*.... 192

Table 5. West Virginia Sport Fish Children Advisory Consumption Contaminant Levels Summarized* 193

Chapter 2: Mercury Levels in Fish Fillets from Selected West Virginia Fisheries ........ 194

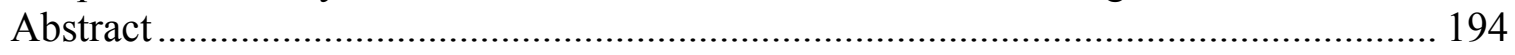

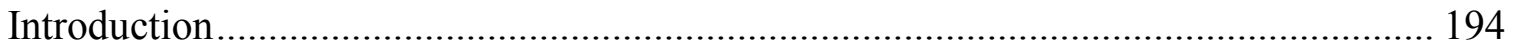

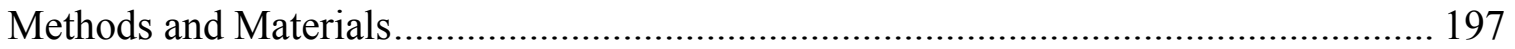

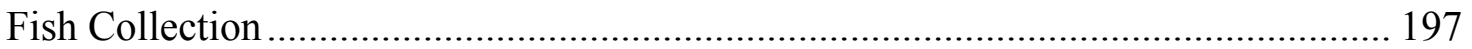

Fish Processing and Analysis................................................................................... 197

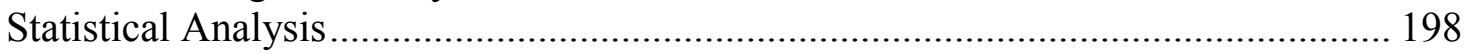

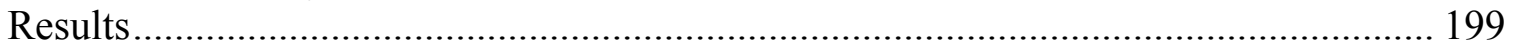

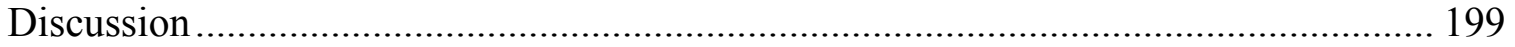

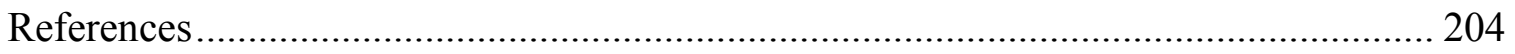

Table 1. Methylmercury Child Advisory Groups ................................................ 207

Table 2. Methylmercury Adult Advisory Groups.................................................. 208

Table 3. Results of Students T-Test comparing Mean Hg levels and Composite Hg levels in fish samples at Ten West Virginia sites. ................................................. 209 Table 4. Composite Hg levels compared to children's one meal per week screening value of $0.028 \mathrm{ug} / \mathrm{g}$, one meal per month value of $0.12 \mathrm{ug} / \mathrm{g}$, adult's one meal per week value of $0.05 \mathrm{ug} / \mathrm{g}$ and one meal per month value of $0.22 \mathrm{ug} / \mathrm{g}$.

Table 5. 1998 National Ranking of Coal Production and Power Plant Mercury Release Rankings for West Virginia and Surrounding States ................................ 211 
Chapter 3: Aroclor 1260 levels in Fish Fillets from Selected West Virginia Sites ........ 212

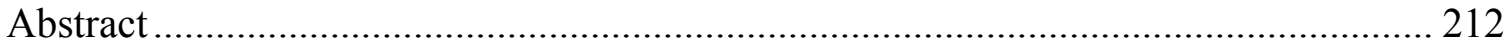

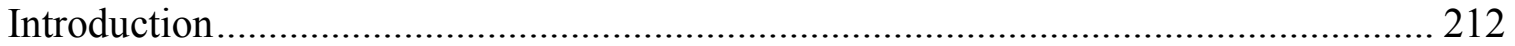

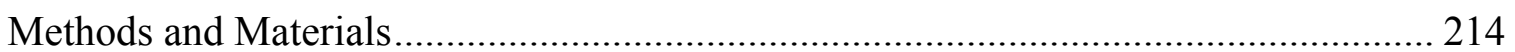

Fish Collection ............................................................................................... 214

Fish Processing and Analysis............................................................................. 215

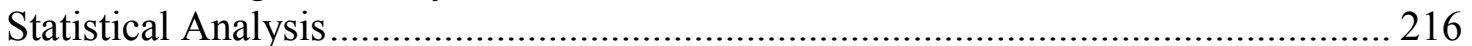

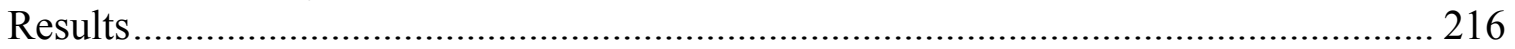

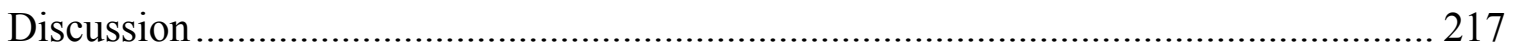

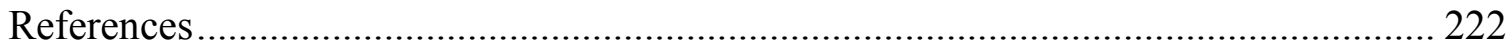

Table 1. PCB Advisory Groups - Skin Off Fillet and Skin On Fillet ........................................ 225

Table 2. Results of Students T-Test comparing Mean Aroclor levels and Composite

Aroclor levels in fish samples at West Virginia Sites........................................ 226

Table 3. Composite Aroclor levels compared to one meal per week screening value

0f $0.05 \mathrm{ug} / \mathrm{g}$ - Skin on Fillet and one meal per month value 0f $0.22 \mathrm{ug} / \mathrm{g}$ - Skin on

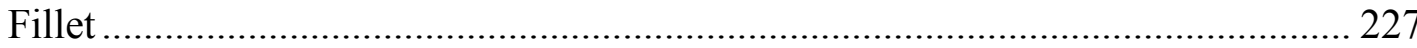

Table 4. Composite Aroclor levels compared to one meal per week screening value

0f $0.036 \mathrm{ug} / \mathrm{g}$ - Skin off Fillet and one meal per month value of $0.16 \mathrm{ug} / \mathrm{g} \ldots \ldots \ldots \ldots . .228$

Table 5. Ohio River Fish Consumption Advisory .............................................. 229 


\section{Introduction}

Human activities have resulted in the discharge of chemicals, trace metals and other contaminants into the aquatic environment. West Virginia's history of industry, mining, and oil and gas extraction has resulted in the impairment of portions of West Virginia's waters. Fish and other aquatic organisms accumulate and bioconcentrate these contaminants to levels much higher than those in the water and sediments. Human consumption of sport-caught fish represents a significant route of exposure to aquatic contaminants (Humphrey 1987). West Virginia has a large number of resident and nonresident fishermen and women. Prior to accepting the West Virginia Sportfish Consumption Advisory Guide (the Guide) which follows as chapter one, the state based sport fish consumption advisories for all contaminants, except PCB's in the Ohio River, on U.S. Food and Drug Administration (FDA) tolerances. FDA tolerances are a maximum level of a contaminant allowed in fish and fishery products in interstate commerce, formulated for the general population who purchase fish, not the sub-population of sustenance fishermen and women. This could result in an underestimation of the fish consumption level and health risk. Many states have moved to risk-based sport fish consumption advisories and the U.S. Environmental Protection Agency (EPA) has provided guidance documents to assist in designing risk-based consumption advisories (USEPA 1995a, USEPA 1995b, USEPA 1996 and USEPA 1997).

West Virginia's rural heritage and low per capita income provide for a resident population with the inclination and incentive to catch and keep fish for food. The scenic beauty and abundant fishery draw many nonresidents to fish as well. West Virginia has a total population of $1,808,344$ (U.S. Census Bureau 2000). The per capita income in 2000 was $\$ 15,714$ ranking 51st 
out of the states and Washington, D.C. (Stateline 2000). In 1991 the U.S. Fish and Wildife Service (USFWS) estimated that 235,200 of West Virginia residents age 16 and over accounted for a total of 3.4 million days of fishing and $\$ 33$ million in fishing expenditures. Another 104,000 nonresidents were estimated to spend 667,000 days fishing and \$22 million on fishing (USFWS 1991). Fifty five percent of West Virginia anglers had an annual household income of less than $\$ 25,000$. Men were $78 \%$ of anglers and women were $22 \%$ (U.S. Fish and Wildlife Service 1993). By 1996, the number of fishing West Virginians over 16 had grown to 250,000, fishing 4.6 million days.

There is conflicting guidance concerning allowable levels of chemical contaminants in fish consumed by humans. Much of the discrepancies come from assumptions used by the federal agencies. The FDA uses a ratio of the body weights to extrapolate toxicity data from small animals to humans (Reinert et al.1996). The FDA authority and regulations are aimed at fish and fishery products in interstate commerce consumed by the general public and consider the impact on the commercial fishing industry (USFDA 1984). The FDA uses an average adult body weight of $60 \mathrm{~kg}$ to calculate an acceptable daily intake (USFDA 2002).

The EPA uses a ratio of animal to human surface area to transfer toxicity data to human levels (Reinert et al.1996). The EPA is only concerned with recreationally caught fish. The EPA uses the no observable adverse effect level and the most sensitive population when recommending limits. The EPA also recommends using an average body weight of 70 kilograms for adults and an average body weight of $14.5 \mathrm{~kg}$ for children under 6 (USEPA 1997).

Until 2000, West Virginia did not have a Sportfish Consumption Advisory Guide. The Guide is risk-based and was written following the EPA guidance documents (USEPA 1995, USEPA 1995, USEPA 1996 and USEPA 1997) and Protocol for a Uniform Great Lakes Sport 
Fish Consumption Advisory (The Great Lakes Protocol). These documents were used because their content is based upon recreational anglers (Great Lakes Sport Fish Advisory Task Force 1993). The EPA guidance is more protective in general and the most protective of sensitive subpopulations, specifically children and unborn children. The Great Lakes Protocol was used in West Virginia for PCB advisories to maintain uniformity of advisories with neighboring Ohio and Pennsylvania and eliminate confusion for anglers fishing waters shared by the three states. The Guide provides information for advisories based on carcinogenic and chronic effects as appropriate. Contaminant absorption, uptake and transport are highly variable and there is little quantitative data available concerning distribution, metabolism and excretion of individual contaminants. Therefore all consumption limit calculations in the Guide assume $100 \%$ absorption of contaminants. In most cases this assumption provides an added margin of safety. The Guide assumes a representative adult body weight of 70 kilograms and a representative child body weight of 14.5 kilograms. Average adult meal size is 227 grams, while average child meal size is 52.5 grams of uncooked fish. The Guide also takes into account cooking reductions for lipophilic contaminants. Scaled fish, which traditionally are cooked and eaten with the skin on, and catfish fish, which usually are cooked and eaten skinless, have different advisory calculations for contaminants known to accumulate in fat. Five advisory groups are used in the Guide: 1) unrestricted or 225 meals per year, 2) one meal per week, 3) one meal per month, 4) six meals per year and 5) no consumption.

There are currently 2,618 fish consumption advisories in effect in 48 states (U.S. EPA 2001). According to the EPA, approximately $80 \%$ of advisories have been issued due to mercury contamination. Mercury, polychlorinated biphenyls (PCBs), chlordane, dioxins, and 1,1,1-trichloro-2, 2-bis(p-chlorophenyl)ethane (DDT) caused 99\% of all fish consumption 
advisories in effect in 2000 (USEPA 2000). Mercury, PCB, dioxin and DDT advisories increased from 1999 to 2000, while chlordane advisories stayed the same. A 1997 survey by the EPA indicated States followed different consumption advisories. Twenty-three States followed risk-based methods, 16 used risk based and FDA guidelines, 9 used only FDA guidelines and 2 had no fish consumption advisories. The five states bordering West Virginia display these differing methods. Ohio uses the Great Lakes Protocol for PCB's and uses the Great Lakes Protocol for all other contaminants unless levels exceed FDA limits. Kentucky and Pennsylvania use the Great Lakes Protocol for PCB's and FDA Action Levels for other contaminants. Maryland and Virginia both use a combination of risk assessment and FDA limits, although neither have a written guidance. These differing methods can confuse anglers fishing in adjacent states and may lead to consumption advisories being ignored. This type of confusion in the Great Lakes region prompted the formation of the Great Lakes Sport Fish Advisory Task Force and their work on the Great Lakes Protocol.

The Department of Natural Resources (DNR) Division of Water Resources (DWR) began West Virginia's fish tissue program in the late 1970's with analysis of whole fish samples as a measure of contamination in water bodies, not with consumption advisories in mind. Most of the samples were collected from bodies of water with known sources of contamination and some contained high concentrations of contaminants. The DWR biologists began testing fish fillets for residue levels. Fish consumption advisories were first issued in the early 1980's based on FDA action levels with the Bureau for Public Health (BPH), DNR-Division of Wildlife and DWR working to prepare advisories (Smithson 2000). In 1984, the EPA conducted the national Dioxin Study and levels of dioxin in samples prompted a FDA based "do not eat" consumption advisory for all fish in the Kanawha River, Pocatalico River and Amour Creek in West Virginia. By the 
early 1990's, the first editions of the EPA Guidance documents were released and the EPA encouraged risk-based advisories (USEPA 1995a). In 1992, the Department of Natural Resources was split and the DWR was placed in the new Division of Environmental Protection and renamed the Office of Water Resources (DWR). The Ohio River Valley Water Sanitation Commission (ORSANCO) was also seeking a consistent fish consumption advisory for the entire Ohio River. In 1995, Ohio released its fish consumption advisory following the Great Lakes Protocol and West Virginia released a different advisory using FDA limits for the Ohio River (Smithson 1996). In 1996, West Virginia revised the Ohio River advisory using the Great Lakes Sport Fish Advisory Task Force's protocol. EPA continued to encourage states to issue risk-based advisories and began examining mercury contamination in West Virginia. The mercury levels found in West Virginia fish did not trigger an advisory based on FDA levels (1ppm), however four of the five states surrounding West Virginia had mercury advisories. In 2000, Governor Underwood signed an executive order requiring the BPH, DNR and DEP to prepare an agreement creating a Fish Advisory technical committee. The three agencies formed the Interagency Technical Committee under a Memorandum of Agreement which defined the agencies roles in issuing consumption advisories, the mechanics of informing the public, defines how to remove advisories, and standardized components of the consumption advisory formula.

The objectives of this study were: 1) to write the West Virginia Sport Fish Consumption Advisory Guide (the Guide) and 2) compare the Guide to mercury and PCBs levels in 5 rivers of known contamination and 5 rivers of unknown contamination. The limited fish tissue data previously collected by the OWR continued to indicate the presence of contaminants including mercury. Although these contaminant levels did not exceed the FDA limits, this prompted the OWR to secure a grant to fund this project to write a guidance document for risk based sport fish 
consumption advisories. In 1998 the West Virginia Division of Environmental Protection funded this project to write and field test the risk-based consumption advisory guidance document for the State, The West Virginia Sport Fish Consumption Advisory Guide. The Guide follows as Chapter 2, and is not in the format of a scientific paper. The Guide is written for the Interagency Technical Committee to use to set fish consumption advisories and for the general public to better understand the advisories. 


\section{References}

Bevelhimer, M.A. 1995. Recent Advances in Contaminant Assessment Offer Proactive Alternatives for Managing Contaminated Fisheries. Fisheries. 20(12):6-10.

Foran, J.A. and D. VanderPloeg. 1989. Consumption Advisories for Sport Fish in the Great Lakes Basin: Jurisdictional Inconsistencies. Journal of Great Lakes Research. 15(3):476-485.

Great Lakes Sport Fish Advisory Task Force. 1993. Protocol for a Uniform Great Lakes Sport Fish Consumption Advisory. GLSFAT, Madison, WI.

Humphrey, H.E.B. 1987. The human population - An Ultimate Receptor for Aquatic Contaminants. Hydrobiologia. 149: 75-80.

Reinert, R.E., Knuth, B.A., Kamrin, M.A. and Q.J. Stober. 1991. Risk Assessment, Risk Management, and Fish Consumption Advisories in the United States. Fisheries. 16(6): 5-12.

Reinert, R.E., Knuth, B.A., Kamrin, M.A. and Q.J. Stober. 1996. A review of the Basic Principles and Assumptions used to issue Fish Consumption Advisories. American Fisheries Society Symposium. 16:98-106.

Smithson, J.E. 1996. Ohio River Consumption Advisories. WVDEP, Charleston, WV.

Smithson, J.E. 2000. History of West Virginia Fish Tissue Program. WVDEP, Charleston, WV.

Stateline. 2002. Per Capita Income 2000. www1.stateline.org/fact.do?factId=211881.

Stow, C., Carpenter, S.R., Madenjian, C.P., Eby, L.A. and L.J. Jackson. 1995. Fisheries Management to Reduce Contaminant Consumption. Bioscience. 45(11): 752-758.

U.S. Bureau of the Census. 2002. State and County QuickFacts West Virginia. http:quickfacts.census.gov/qfd/states/54000.html

U.S. Environmental Protection Agency. 1995a. Guidance for Assessing Chemical Contaminant Data for Use In Fish Consumption Advisories, Volume I: Fish Sampling and Analysis. USEPA, EPA 823-R-95-007, Washington, D.C.

U.S. Environmental Protection Agency. 1997. Guidance for Assessing Chemical Contaminant Data for Use In Fish Consumption Advisories, Volume II: Risk Assessment and Fish Consumption Limits. USEPA, EPA 823-B-97-009, Washington, D.C.

U.S. Environmental Protection Agency. 1996. Guidance for Assessing Chemical Contaminant Data for Use In Fish Consumption Advisories, Volume III: Overview of Risk Management. USEPA, EPA 823-B-96-006, Washington, D.C. 
U.S. Environmental Protection Agency. 1995b. Guidance for Assessing Chemical Contaminant Data for Use In Fish Consumption Advisories, Volume IV: Overview of Risk Management. USEPA, EPA 823-R-95-001, Washington, D.C.

U.S. Environmental Protection Agency. 2002. Integrated Risk Information System. http://www.epa.gov/iris/subst/0649.htm\#reforal

U.S. Environmental Protection Agency. 2000. Update:National Listing of Fish and Wildlife Advisories USEPA, EPA 823-F-01-010, Washington, D.C.

U.S. Environmental Protection Agency. 2001. Update:National Listing of Fish and Wildlife Advisories USEPA, EPA 823-F-02-007, Washington, D.C.

U.S. Environmental Protection Agency. 1998. Listing of fish and Wildlife Advisories Summary report. USEPA, Washington, D.C.

U.S. Environmental Protection Agency. 1991. Methods for the Determination of Metals in Environmental Samples. USEPA, EPA 600491010, Washington, D.C.

U.S. Environmental Protection Agency. 1994. Methods for the Determination of Metals in Environmental Samples, Supplement 1. USEPA, EPA 600491010, Washington, D.C.

U.S. Food and Drug Administration. 2002. Guideline for Establishing a Safe Concentration. http://www.cfsan.fda.gov/ frf/guid-as.html

U.S. Food and Drug Administration. 1984. Polychlorinated biphenyls in fish and shellfish: reduction of tolerances; final decision. Federal Register 49:10:21514-21520, Washington, D.C.

U.S. Food and Drug Administration. 1997. Pesticide Analytical Manual(PAM) Volume I. FDA, Washington, D.C.

U.S. Food and Drug Administration. 1997. Pesticide Analytical Manual(PAM) Volume II. FDA, Washington, D.C.

West Virginia Division of Natural Resources. 2002. West Virginia Fishing, Favorite Fishing Waters. http://www.dnr.state.wv.us/wvfishing/waters.htm. 
Figure 1. West Virginia Sport Fish Consumption Advisory Sampling Sites

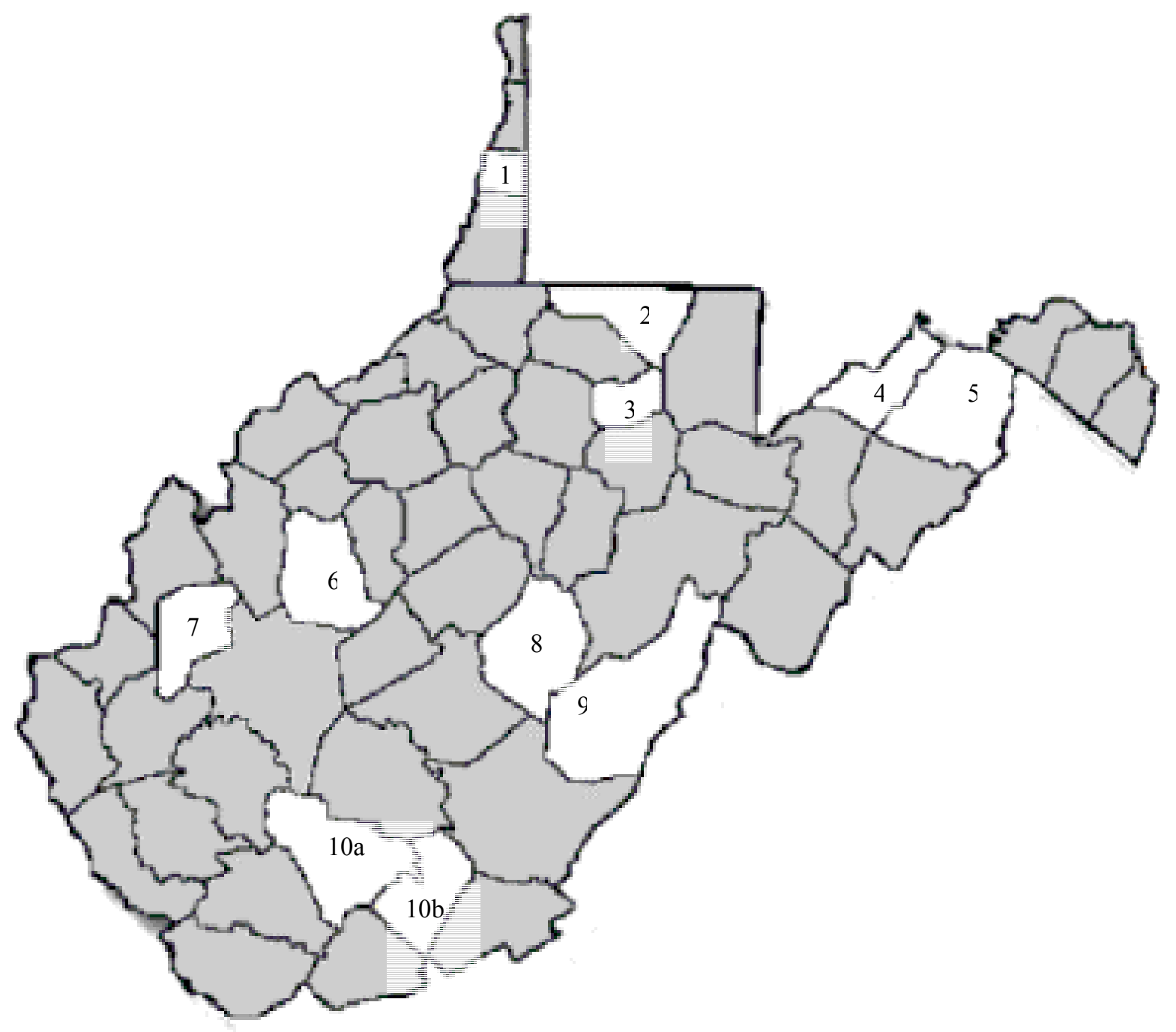

Known Contamination

1) Ohio River, Ohio County

2) Monongahela River, Monongalia County

4) North Branch of the Potomac River, Mineral County

6) Flat Fork Creek, Roane County

7) Kanawha River, Putnam County
Unknown Contamination

3) Tygart Lake, Taylor County

8) Summersville Lake, Nicholas County

5) South Branch of the Potomac River, Hampshire County

9) Cranberry River, Pocahontas County

10a) New River, Raleigh County

10b) Bluestone Lake, Summers County 


\section{Chapter 1: Guide for West Virginia Sport Fish Consumption Advisories}

This guide (Chapter 1) was written as a separate document for government agencies of West Virginia to use in implementing fish consumption advisories for the state. The guide is also intended to help the general public to better understand the benefit and risk of eating fish caught from bodies of water in West Virginia. The West Virginia Bureau for Public Health, Department of Environmental Protection and Division of Natural Resources have accepted the format, assumptions, and methods used.

\section{Introduction}

Human activities have resulted in the discharge of chemicals, trace metals and other contaminants into the aquatic environment. West Virginia's history of industry, mining and oil and gas extraction has resulted in the pollution of portions of West Virginia's waters. Fish and other aquatic organisms accumulate and bioconcentrate these contaminants to levels much higher than those in the water and sediments. Human consumption of sport-caught fish represents a significant route of exposure to aquatic contaminants (Humphrey 1987) West Virginia has a number of resident and nonresident fishermen and women. Prior to accepting the West Virginia Sportfish Consumption Advisory Guide (the Guide), the state based sport fish consumption advisories for all contaminants, except polychlorinated biphenyls (PCB's) in the Ohio River, on U.S. Food and Drug Administration (FDA) tolerances. These tolerances are a maximum level of a contaminant allowed in fish and fishery products in interstate commerce. FDA tolerances were formulated for the general population who purchase fish, not the sub-population of recreational fishermen and women. This results in a considerable underestimation of the fish consumption level and of the health risk by fishermen. Many states have moved to risk based sport fish 
consumption advisories and the U.S. Environmental Protection Agency has(EPA) provided guidance documents to assist in designing risk based consumption advisories.

West Virginia's rural heritage and low per capita income provide for a resident population with the inclination and incentive to catch and keep fish for food. The scenic beauty and abundant fishery draw many nonresidents to fish as well. West Virginia has a total population of $1,808,344$ (U.S. Census Bureau 2000). The per capita income was $\$ 15,714$ ranking $51^{\text {st }}$ out of the states and Washington, D. C. (Stateline.org 2000). In 1991 the U.S. Fish and Wildlife Service (USFWS) estimated that 235,200 of West Virginia Residents age 16 and over accounted for a total of 3.4 million days of fishing and $\$ 33$ million in fishing expenditures. Another 104,000 nonresidents were estimated to spend 667,000 days fishing and \$22 million on fishing. Fifty five percent of West Virginia anglers had an annual household income of less than $\$ 25,000$. Men were $78 \%$ of anglers and women were $22 \%$ (U.S. Fish and Wildlife Service 1993). By 1996, the number of fishing West Virginians over 16 had grown to 250,000 and they were fishing 4.6 million days.

There is conflicting guidance concerning allowable levels of chemical contaminants in fish consumed by humans. Many of the discrepancies come from assumptions, the EPA uses a ratio of animal to human surface area to extrapolate from small animals to humans and the FDA uses a ratio of the body weights (Reinert et al.1996). The FDA authority and regulations are aimed at fish in interstate commerce and considers economic impact on the commercial fishing industry, while the EPA and Great Lakes Task Force are concerned only with recreationally caught fish. For example, the FDA has set a limit of 2 ppm PCB in the edible portion of all fish species, a level that will result in regulatory action. The EPA set levels of concern at $2.0 \mathrm{ppm}$ PCB per day for carcinogenicity. The Great Lakes Task Force human protection value of 0.05 
ppb per day considers cancer, reproductive and developmental risk.

A nationwide survey by the EPA in 1997 regarding fish consumption advisories shows

23 states followed risk based methods, 16 used risk based and FDA guidelines, 9 used only FDA guidelines and 2 had no fish consumption advisories. The five states bordering West Virginia display these differing methods. Ohio uses the Great Lakes Protocol for PCB's and uses the same formula for all other contaminants unless levels exceed FDA limits. Kentucky and Pennsylvania use the Great Lakes Protocol for PCB's and FDA Action Levels for other contaminants. Maryland and Virginia both use a combination of risk assessment and FDA limits, although neither have a written protocol. These differing methods can confuse anglers fishing in neighboring states and may lead to consumption advisories being ignored. This confusion resulting from differing advisories in the Great Lakes prompted the formation of the Great Lakes Sport Fish Advisory Task Force and their work on the Great Lakes Protocol.

\section{General statement about contaminants, benefits and hazards}

Fish are usually a healthy and nutritious food. Human activities have resulted in the discharge of chemicals, trace metals and other contaminants into some of the state's waters. Fish can accumulate and concentrate these contaminants to levels much higher than the surrounding water and sediments. Over long periods of time these same contaminants can build up in humans who eat these fish. In large enough quantities over a long period of time, these contaminants could cause health problems. Fishermen and women should pay careful attention to West Virginia Sport Fish Consumption Advisories to minimize their intake of contaminants and maintain good health. This advisory should not discourage people from eating all fish, only fish with high levels of contaminants. Women of child-bearing years, infants, children, the 
elderly and those suffering from immune deficiencies should take care to space fish meals to avoid contaminants from building up to harmful levels. Consuming excessive amounts of contaminants may cause health problems such as birth defects and cancer.

\section{Statement on cancer risk}

Some contaminants cause cancer in laboratory animals, and may increase the lifetime risk of cancer. Eating contaminated fish may or may not increase an individual's risk of cancer. It is impossible to estimate the potential increased cancer risk with certainty. Cancer affects about one out of four people by age 70. The two leading causes of cancer in the United States are smoking and nutrition related effects.

IV. Statement on benefits of fish consumption

Eating fish is part of a healthy diet. Fish is high in quality protein, low in saturated fats and provides valuable vitamins and minerals. Fish contain omega-3 fatty acids, which reduce blood clotting and plaque from forming in the arteries. Recent studies have shown eating as little a one meal of fish a week can significantly reduce the risk of a fatal heart attack. Another study linked a significantly lower risk of stroke for those who ate more than one meal of fish a week. Fish contain nutrients essential for proper development of infants. Eating fish may also lower lung disease in smokers, and may help relieve symptoms of arthritis. Consumption advisories are designed to provide the health benefits of eating fish, while offering protection from contaminants. 


\section{Preparation and cooking advice}

Fish should be cleaned and dressed as soon as possible. Smaller, younger fish within the legal limits are less likely to have harmful levels of pollutants. Some contaminants accumulate in the fat of fish. Fatty fish and bottom feeding species, which usually have higher levels of contaminants, should be eaten less frequently. The head, guts, kidney and liver should be removed prior to cooking. Filleting the fish and removing the skin and fat before cooking can lower your exposure to contaminants. Grilling, baking, or broiling fish, and allowing the fat to drain, can reduce the amount of pollutants in a meal. The drippings or broth, which usually contain higher levels of contaminants should not be included in the meal. Frying and deep frying fish will remove fewer contaminants and may seal contaminants in the fish. Fish should be filleted and skinned before smoking.

\section{Sampling Protocol}

\section{A. Screening Study}

Screening studies are used to identify water bodies having chemical contaminant levels that can impact human health due to fish consumption. Ideally screening studies should be conducted in all waters of the State that are fished. Screening studies are a way to direct resources toward sites with a greater potential for risk. Composite skin-off fillet samples for catfish and skin-on fillet samples for other species should be collected and analyzed for all compounds in the Guide for an initial screening. If the sample contaminant level exceeds a screening value, an Intensive Study should be conducted. Screening values for noncancer effects are shown in Table 2. Cancer related screening values are in Table 3. Consumption advisories should be based on intensive studies when possible. If consumption advisories are 
based on screening studies, frequently consumed target species in the largest size class available, should be analyzed. This procedure will ensure that advice will be given based on the greatest potential risk to recreational fishermen and women. A minimum of one sample would be required for an advisory to be issued, but an intensive study or at least one follow up sample is recommended.

\section{B. Intensive Studies}

Intensive studies are conducted when screening studies indicate the presence of contaminant levels, which may pose a risk to human health. Intensive studies can be used to determine the extent of fish contamination, species and size classes of fish under consumption advisories. Fish within each species are collected without regard to size class and individually analyzed. Regressions for each species should be performed to determine the relationship between fish length and chemical concentrations. Size classes of species in consumption categories should be determined by regression with the highest $\mathrm{r}^{2}$ greater than 0.60 (GLSFATF 1993) Regressions, listing and shifting size class will be conducted according to the Great Lakes Protocol Appendix V. It is recommended that 2 consecutive years of data below screening values be collected before removing a fish consumption advisory.

\section{Assumptions}

The following is a brief explanation of the assumptions used in calculating the contaminant tolerances for fish consumption advisories that follow in Part IX. The West Virginia Bureau for Public Health, Department of Environmental Protection and Division of Natural Resources agreed upon these assumptions. 


\section{A. Reference Dose}

The reference dose (RfD) was developed to replace the traditionally used Acceptable Daily Intake (ADI) approach. The ADI was calculated by dividing an experimental No Observed Adverse Effect Level (NOAEL) by a Safety Factor (SF). Many times SFs were inconsistently applied, and variability in numbers of test animals and experiments to determine NOAEL bought the soundness of the ADI method into question. The public also incorrectly interpreted that the use of Safety Factors meant consumption at or below ADIs posed no health risk.

The reference doses used here are benchmark doses calculated by the U.S. EPA. The RFD is an estimate of a daily exposure to the human population (including sensitive subgroups) that is likely to be without an appreciable risk of deleterious effects during a lifetime. (EPA 1993). A RfD is calculated by first reviewing the literature and determining the proper no observed adverse effects level (NOAEL) or lowest observed adverse effects level (LOAEL). After the literature review is completed, the results of the studies are evaluated for the following categories:

- Category $\mathrm{H}$ - variability of human response

- Category A - extrapolation of data from humans to animals

- Category $\mathrm{S}$ - gaps in the size of the data

- Category L - the availability of NOAEL and LOAEL data

Then uncertainty factors (UF) are assigned to each of these categories. Uncertainty factors can range from 1 - 10,000, but are usually 10. A modifying factor (MF) ranging from 1 - 10, is assigned based on professional judgement concerning varying chemical tolerances and absorption rates, and critical endpoints of studies. The NOAEL or LOAEL is divided by the 
product of the uncertainty factors and modifying factor, resulting in the RfD. Reference doses determined by the EPA will be used to calculate fish consumption advisories when available.

\section{B. Human Protection Value}

The human protection value (HPV) set by the Great Lakes Sport Fish Advisory Task Force (GLSFAT) will be used for polychlorinated biphenyl (PCB) consumption advisories. The GLSFAT used a weight of evidence procedure and evaluated all values and studies. The value was created with the idea that by considering all the data, the most robust and stable HPV possible would emerge (GLSFATF 1993). The RfD is calculated from a single determining study, the HPV for PCBs is a consensus of the best professional judgement based on all available PCB studies.

\section{Minimal Risk Level}

Minimal Risk Levels (MRL) are calculated by the Agency for Toxic Substance and Disease Registry. An MRL is an estimate of the Daily Human exposure to a contaminant that is likely to be without appreciable risk of adverse noncancer health effects only (ATSDR 1997). MRLs are calculated in a manner similar to RfDs. UFs are determined as necessary for the following categories:

- Category $\mathrm{H}$ - variability of human response

- Category A - extrapolation of data from humans to animals

- Category $\mathrm{S}$ - gaps in the size of the data

- Category L - the availability of NOAEL and LOAEL data

MRLs are determined for acute, intermediate and chronic effects. The best definitive study is selected for each effect level based on experimental design. Chronic MRLs should be used in 
the absence of an RfD or HPV.

\section{Oral Slope Factor}

The oral slope factors used here are extrapolated by the EPA from high doses used in animal experiments or from epidemiological studies to lower doses the public is more likely to encounter. Dosing is estimated by using the ratio of animal to human surface area. The surface area is converted to a dose in milligrams per kilogram $(\mathrm{kg})$ per day assuming surface area equals 2/3 power of body weight. The EPA used an average body weight of $70 \mathrm{kgs}$ for calculating the slope factors.

D. Average Body Weight

Representative adult body weight is assumed to be $70 \mathrm{kgs}$ (154.35 pounds).

Representative child body weight is assumed to be $14.5 \mathrm{kgs}$ (31.97 pounds). These weights were determined through several studies including the most comprehensive study on the subject ever performed, a four year study including approximately 28,000 people from age 6 months to 74 years done by the National Center for Health Statistics (NCHS). Data from the NCHS study was used to calculate mean adult weights (Burmaster et al 1994). This data included information on 5916 men and 6588 women representing the general U.S. population. The average adult male weighed $78.1 \mathrm{kgs}$ (171.99 pounds), while the average adult female weighed $65.4 \mathrm{kgs}$ (144.207 pounds). The Exposure Factors Handbook reports the average adult weight as $71.8 \mathrm{kgs}$, which has been rounded down to $70 \mathrm{kgs}$. The $70 \mathrm{~kg}$ figure was used by the EPA to derive cancer slope factors and is recommended for fish consumption advisories by the EPA (USEPA 1997). The 70 $\mathrm{kg}$ average body weight is used by 28 states, while 3 use a average weight of $60 \mathrm{kgs}$ (Reinert et al 1991). The average child from 0-6 weighed $14.5 \mathrm{kgs}$, the average male child weighed 14.8 
and the average female child weighed $14.2 \mathrm{kgs}$. The EPA uses and recommends the $14.5 \mathrm{~kg}$ body weight to calculate all consumption limits for children.

\section{E. Uniform Meal Size}

Average adult meal size is 227 grams or $1 / 2$ pound of uncooked fish per $70 \mathrm{kgs}$ of body weight. Average child meal size is 52.5 grams or 3 ounces per $14.5 \mathrm{kgs}$ of body weight. These are important assumptions which concern body weight and meal size. A majority of dietitians consider the best predictor of meals size to be the weight of the individual (GLSFATF 1993). It is assumed that consumption will decrease as body weight decreases and increases as body weight increases. It is important to ensure this assumption is explained to the fish consuming public, to protect children and smaller consumers. The 227 gram meal size is used by 20 states, 170 grams is used by 12 states, and 114 grams is used by 7 states in developing fish consumption advisories (Reinert et al 1991).

\section{F. Meal Frequencies}

Five adult meal advice groups will be used to establish West Virginia Fish Consumption advisories:

- Group 1 - Unrestricted or up to 225 meals per year (averages to 140 grams per day)

- Group 2 - One meal per week (averages to 32 grams per day)

- $\quad$ Group 3 - one meal per month (averages to 7.4 grams per day)

- $\quad$ Group 4 - Six meals per year (averages to 3.7 grams per day)

- Group 5 - No Consumption

These meal frequencies are based on a sliding scale of consumption rates. Group 1 frequency is 
based on the $90^{\text {th }}$ percentile of consumption by recreation fishermen falling to Group 4 frequency which is slightly more than half of the average consumption by the general population, 6.5 grams per day. These meal frequencies have been used for the sake of uniformity and clarity. States using the Great Lakes Sport Fish Consumption Advisory Protocol are using these five meal advice groups including Ohio and Pennsylvania. The five meal advice groups have been used on the Ohio River PCB consumption advisory in West Virginia since 1996. If advisories are not clear and consistent fishermen and women may ignore the advice and consume unlimited amounts of fish, or refuse to eat fish.

Five child meal advice groups will be used to establish children's fish consumption advisories in West Virginia:

- Group 1 - Unrestricted or up to 225 meals per year (averages to 52.5 grams per day)

- Group 2 - One meal per week (averages to 12.13 grams per day)

- Group 3 - one meal per month (averages to 2.8 grams per day)

- Group 4 - Six meals per year (averages to 1.4 grams per day)

- Group 5 - No Consumption

These meal frequencies are based on a sliding scale of consumption rates.

G. Meal Preparation Reduction

Relying on a combination of trimming and cooking, a thirty percent meal dose reduction will be used on catfish and any other species analyzed as a skin off fillet, and a fifty percent reduction on the remaining species analyzed as skin on fillets for lipophilic contaminants. The literature indicates a contaminant reduction factor of $50 \%$ due to trimming and cooking is appropriate (GLSFATF1993). Many studies have determined significant reductions in 
contaminant levels after cooking (Zabik et al 1995, Zabik and Zabik 1995, Khanna et al 1997, Zabik and Zabik 1995, Zabik et al 1996, Zabik and Zabik 1995). Trimming reductions are also well documented. Raw skin-off fillets have an average of less than half of the residues found in raw skin-on fillets (Zabik et al 1995). The appropriate meal preparation reduction will be applied to contaminants documented to be lipophilic in the literature.

I. Contaminant Absorption

Contaminant absorption, uptake and transport is highly variable. Little quantitative data is available concerning distribution, metabolism and excretion of individual contaminants. Consumption limit calculations assume $100 \%$ absorption of contaminants. In most cases this assumption provides an added margin of safety.

VIII. Consumption Advisory Formulas

Noncancer effects calculations are calculated using a formula derived from the Great Lakes Protocol.

MDCI/DFC/MPR $=\mathrm{Cr}_{\text {lim }}$

MDCI = maximum daily contaminant ingestion (ug/day)

DFC = daily fish consumption (g/day)

MPR = meal preparation reduction $(1,0.5$ or 0.7$)$

$\mathbf{C}_{\mathbf{m a x}}=$ maximum allowable contaminant concentration in raw fish fillet (ppm)

Consumption advisories for cancer health effects are calculated solving the EPA formula, 
$\mathrm{Cr}_{\text {lim }}=(\mathrm{ARL} * \mathrm{BW}) /\left(\mathrm{q} 1 * \mathrm{C}_{\mathrm{m}}\right)$ for $\mathrm{C}_{\mathrm{m}}$. The measured concentration of chemical contaminant in a species of fish, $\mathrm{C}_{\mathrm{m}}$, becomes the maximum allowable contaminant concentration in raw fish fillet, $C_{\max }$, for the consumption rate calculated. The EPA uses three ARLs, $10^{-4}, 10^{-5}$ and $10^{-6}$ in its calculations. Cancer effect consumption advisories in the guide are calculated using a $10^{-4}$ maximum acceptable lifetime risk level, which equates to one additional cancer in a population of 10,000 . The ARL can be adjusted as considered appropriate.

$C_{\max }=(A R L * B W) /\left(q_{1} * \mathbf{C r}_{\text {lim }}\right)$

$\mathbf{A R L}=$ maximum acceptable lifetime risk level (unitless)
$\mathbf{C r}_{\text {lim }}=$ maximum allowable fish consumption rate ( $\mathrm{kg} /$ day)
$\mathbf{C}_{\mathbf{m a x}}=$ maximum allowable contaminant concentration in raw fish fillet (ppm)
$\mathbf{q}_{1} \quad=$ cancer slope factor $(\mathrm{mg} / \mathrm{kg} /$ day)-1

IX. Multiple Contaminants Noncancer Formula

Noncancer fish consumption advisories for similar multiple contaminants in fish samples can be calculated using the following formula:

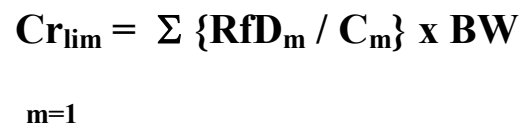

$\mathbf{C r}_{\text {lim }}=$ maximum allowable fish consumption rate $(\mathrm{kg} /$ day $)$

$\mathbf{R f D}_{\mathbf{m}}=\mathrm{RfD}$, HPV, or MRL for chemical m.(mg/kg/day)

$\mathbf{C}_{\mathbf{m}}=$ concentration of chemical $\mathrm{m}$ in fillet $(\mathrm{mg} / \mathrm{kg})$

(USEPA 1997) 
In some sites fish may contain more than one chemical contaminant. Not much information is available on interactions of toxic chemicals (U.S. . Chemical contaminants of similar nature such as organochlorines are considered to have additive effects unless literature states differently.

Presently there are no methods to combine effects of contaminant mixtures of chemicals with different modes of action. Consumption advisories for dissimilar chemicals in the same body of water should be calculated and presented separately. 
IX. Compounds of Concern and Advisory Groups

\section{Cadmium Summary}

Merck Number 1649

CAS Number 7440-43-9

Oral RfD $0.001 \mathrm{mg} / \mathrm{kg} / \mathrm{day}$

Preparation Dose Reduction 1

Fredich Stromeyr discovered cadmium, a byproduct of zinc, copper and lead refining, in

1817. Cadmium is a soft silver-blue metal. It was not widely utilized until the World War II era.

Cadmium is used for pigments, electroplating, plastic stabilizers, in specialty solders and

batteries. Unlike many trace metals, there is no evidence that cadmium is a micronutrient or is

biologically beneficial. Human generated sources of cadmium in the environment are coal and

other fossil fuels, fertilizers, medical waste, manufacture and disposal of batteries, wastewater

and sludge. Volcanic eruptions are the major natural atmospheric source of cadmium.

Cadmium is a teratogen, probable mutagen and carcinogen in fish and wildlife. The U.S.

Environmental Protection Agency lists it as a probable human carcinogen. Pregnant rats

subjected to more than 6 milligrams of cadmium per $\mathrm{kg}$ of body weight daily produced fetuses

with jaw defects, cleft palates, club feet and pulmonary hyperplasia (Ferm and Layton 1981).

Cadmium exposure has produced effects such as unclosed neural tubes in frog embryos; more

edema, microcephala, and malformed tails in bluegill embryos; and tail and leg deformities in

chicks. Mice and hamsters injected with cadmium had changed chromosome numbers within 12

hours. Cadmium also had mutagenic affects on plant seeds and Salmonella. Mice and rats

injected with cadmium developed malignant tumors.

Most information on human exposure comes from occupational exposure. Respiratory exposure to cadmium is associated with lung cancer, emphysema and chronic bronchitis. 
Cadmium was implicated in the Itai-itai(ouch-ouch) disease in Japan shortly after World war II. Cadmium from a mine discharging upstream from rice fields, was taken up by the rice and eaten by the residents in Fuchu. Cadmium in the rice caused joint and muscle pain and spontaneous bone fractures. Humans excrete most inhaled or ingested cadmium in the urine and the kidney is thought to be the most susceptible organ to cadmium exposure. Chronic exposure causes irreversible kidney damage. Cadmium may also be linked to high blood pressure. 


\section{Adult Advisory Assumptions - Cadmium}

\section{Assumptions:}

1) Reference Dose is 1 microgram Cadmium per kilogram per day

2) Average Meal Size is 227 grams or $1 / 2$ pound of uncooked fish.

3) Representative Consumer Body weight is 70 kilograms.

4) Five Advisory Groups: Unrestricted or 225 meals per year; One meal per week; One meal per month; Six meals per year; No Consumption.

5) Assume meal preparation does not reduce residues by $50 \%$ from raw skin on fish fillets used to determine Cadmium residue level.

\section{Maximum Allowable Daily Adult Cadmium Ingestion Calculation}

1 microgram per kilogram per day X 70 kilogram body weight $=70$ micrograms Cadmium allowed per day. 


\section{Cadmium Adult Advisory Groups}

\section{GROUP 1}

Unrestricted Consumption or up to 225 meals per year

(140 grams of sportfish per day)

70 micrograms per day Cadmium / 140 grams of fish per day

Less than 0.5 ppm Cadmium in raw skin on fish fillet

\section{GROUP 2}

Up to 1 meal per week

(32 grams of sportfish per day)

70 micrograms per day Cadmium / 32 grams of fish per day

$0.5 \mathrm{ppm}$ to $2.19 \mathrm{ppm}$ Cadmium in raw skin on fish fillet

\section{GROUP 3}

Up to 1 meal per month

(7.4 grams of sportfish per day)

70 micrograms per day Cadmium / 7.4 grams of fish per day

$2.19 \mathrm{ppm}$ to $9.46 \mathrm{ppm}$ Cadmium in raw skin on fish fillet

\section{GROUP 4}

Up to 6 meals per year

(3.7 grams of sportfish per day)

70 micrograms per day Cadmium / 3.7 grams of fish per day

$9.46 \mathrm{ppm}$ to18.92 ppm Cadmium in raw skin on fish fillet

\section{GROUP 5 \\ DO NOT EAT}

Greater than 18.92 ppm Cadmium in raw skin on fish fillet 


\section{Child Advisory Assumptions - Cadmium}

\section{Assumptions:}

1) Reference Dose is 1 microgram Cadmium per kilogram per day

2) Average Meal Size is 52.5 grams or 3 ounces pound of uncooked fish.

3) Representative Consumer Body weight is 14.5 kilograms.

4) Five Advisory Groups: Unrestricted or 225 meals per year; One meal per week; One meal per month; Six meals per year; No Consumption.

5) Assume meal preparation does not reduce residues by $50 \%$ from raw skin on fish fillets used to determine Cadmium residue level.

\section{Maximum Allowable Daily Child Cadmium Ingestion Calculation}

1 microgram per kilogram per day X 14.5 kilogram body weight $=14.5$ micrograms Cadmium allowed per day. 


\section{Cadmium Child Advisory Groups}

\section{GROUP 1}

Unrestricted Consumption or up to 225 meals per year (52.5 grams of sportfish per day)

14.5 micrograms per day Cadmium / 52.5 grams of fish per day

Less than 0.28 ppm Cadmium in raw skin on fish fillet

\section{GROUP 2}

Up to 1 meal per week

(12.13 grams of sportfish per day)

14.5 micrograms per day Cadmium / 12.13 grams of fish per day

$0.28 \mathrm{ppm}$ to $1.20 \mathrm{ppm}$ Cadmium in raw skin on fish fillet

\section{GROUP 3}

Up to 1 meal per month

(2.8 grams of sportfish per day)

14.5 micrograms per day Cadmium / 2.8 grams of fish per day

$1.20 \mathrm{ppm}$ to $5.18 \mathrm{ppm}$ Cadmium in raw skin on fish fillet

\section{GROUP 4}

Up to 6 meals per year (1.40 grams of sportfish per day)

14.5 micrograms per day Cadmium / 1.40 grams of fish per day

10.36 ppm Cadmium in raw skin on fish fillet

\section{GROUP 5}

DO NOT EAT

More than 10.36 ppm Cadmium in raw skin on fish fillet 


\section{Chlordane Summary}

Merck Number 21299

CAS Number 12789-03-6

Oral RfD $0.00015 \mathrm{mg} / \mathrm{kg} / \mathrm{day}$

Oral Slope Factor $.35 \mathrm{mg} / \mathrm{kg} / \mathrm{day}$

Preparation Dose Reduction .5 Skin On, .7 Skin Off

Chlordane was first produced in 1947. Chlordane is a organochlorine insecticide that kills on contact or ingestion. It is a thick clear or amber liquid with a chlorine odor. Chlordane is persistent in soil, water and sediment and is readily bioconcentrated in aquatic ecosystems. Chlordane has been found worldwide in air, water, sediments, soils, and all types of animals tested including humans. Atmospheric transport is thought to be responsible for its universal nature. It was commercially produced as dusts, concentrates, granules, oil solutions and wettable powders. Chlordane was legally used until 1978 to treat corn, turf grasses, potatoes and tomatoes and the agricultural registration was canceled in 1980. It was used until 1988 for termite control. Chlordane is no longer distributed in the United States. The only permitted use is for fire ants in power transformers. Chlordane residues can be found in crops grown in soils treated before the agricultural registration was revoked.

Chlordane has been shown to be teratogenic, causing permanent effects on the immune system and abnormal behavior in mice. Mutagenicity tests for chlordane have produced conflicting results. Chlordane has been shown to cause cancer in test animals including mice and is listed as a probable carcinogen by the U.S. Environmental Protection Agency. Reduced fertility and growth has been reported in lab animals fed low doses of chlordane. Mammals including humans easily absorb chlordane through the skin, lungs and gastrointestinal tract. Chronic exposure results in weight loss and damage to the liver and central nervous system. Chlordane is stored in fat and in the liver. Chlordane has been found in human milk in the U.S., 
Canada, Japan, Mexico and Spain. Fish tested for chlordane occasionally contain more than the U.S. Food and Drug Administration action level of $0.3 \mathrm{ppm}$. 


\section{Cancer Effect Assumptions - Chlordane Skin on Fillets}

\section{Assumptions:}

1) Slope Factor is 0.35 milligrams Chlordane per kilogram per day

2) Average Meal Size is 227 grams or $1 / 2$ pound of uncooked fish.

3) Representative Consumer Body weight is 70 kilograms.

4) ARL is $10^{-4}$

5) Five Consumption Rates: Unrestricted 225 meals per year(140 g/day); One meal per week(32g/day); One meal per month(7.4 g/day); Six meals per year(3.7 g/day); No Consumption.

6) Assume meal preparation reduces residues by $50 \%$ from raw skin off (catfish) fish fillets used to determine Chlordane residue level.

\section{Cancer Effect Assumptions - Chlordane Skin Off Fillets (Catfish)}

\section{Assumptions:}

1) Slope Factor is 0.35 milligrams Chlordane per kilogram per day

2) Average Meal Size is 227 grams or $1 / 2$ pound of uncooked fish.

3) Representative Consumer Body weight is 70 kilograms.

4) ARL is $10^{-4}$

5) Five Consumption Rates: Unrestricted 225 meals per year(140 g/day); One meal per week(32g/day); One meal per month(7.4 g/day); Six meals per year(3.7 g/day); No Consumption.

6) Assume meal preparation reduces residues by $30 \%$ from raw skin off (catfish) fish fillets used to determine Chlordane residue level. 


\section{Chlordane Cancer Effect Advisory Groups - Skin On Fillet}

\section{GROUP 1}

Unrestricted Consumption or up to 225 meals per year (140 grams of sportfish per day)

Less than $0.29 \mathrm{ppm}$ Chlordane in raw skin on fish fillet

\section{GROUP 2}

Up to 1 meal per week

(32 grams of sportfish per day)

$0.29 \mathrm{ppm}$ to $1.25 \mathrm{ppm}$ Chlordane in raw skin on fish fillet

\section{GROUP 3}

Up to 1 meal per month

(7.4 grams of sportfish per day)

$1.25 \mathrm{ppm}$ to $5.41 \mathrm{ppm}$ Chlordane in raw skin on fish fillet

\section{GROUP 4}

Up to 6 meals per year

(3.7 grams of sportfish per day)

$5.41 \mathrm{ppm}$ to $10.81 \mathrm{ppm}$ Chlordane in raw skin on fish fillet

\section{GROUP 5}

DO NOT EAT

Greater than $10.81 \mathrm{ppm}$ Chlordane in raw skin on fish fillet 


\section{Chlordane Cancer Effect Advisory Groups - Skin Off Fillet}

\section{GROUP 1}

Unrestricted Consumption or up to 225 meals per year

(140 grams of sportfish per day)

Less than $0.20 \mathrm{ppm}$ Chlordane in raw skin off (catfish) fish fillet

\section{GROUP 2}

Up to 1 meal per week

(32 grams of sportfish per day)

$0.20 \mathrm{ppm}$ to $0.89 \mathrm{ppm}$ Chlordane in raw skin off (catfish) fish fillet

\section{GROUP 3}

Up to 1 meal per month

(7.4 grams of sportfish per day)

$0.89 \mathrm{ppm}$ to $3.86 \mathrm{ppm}$ Chlordane in raw skin off (catfish) fish fillet

\section{GROUP 4}

Up to 6 meals per year

(3.7 grams of sportfish per day)

$3.86 \mathrm{ppm}$ to $7.72 \mathrm{ppm}$ Chlordane in raw skin on fish fillet

\section{GROUP 5}

DO NOT EAT

More than $7.72 \mathrm{ppm}$ Chlordane in raw skin off (catfish) fish fillet 


\section{Advisory Assumptions - Chlordane Skin on Fillets}

\section{Assumptions:}

1) Reference Dose is 0.15 micrograms Chlordane per kilogram per day

2) Average Meal Size is 227 grams or $1 / 2$ pound of uncooked fish.

3) Representative Consumer Body weight is 70 kilograms.

4) Five Advisory Groups: Unrestricted or 225 meals per year; One meal per week; One meal per month; Six meals per year; No Consumption.

5) Assume meal preparation reduces residues by 50\% from raw skin on fish fillets used to determine Chlordane residue level.

\section{Maximum Allowable Daily Chlordane Ingestion Calculation}

0.15 micrograms per kilogram per day X 70 kilogram body weight $=10.5$ micrograms Chlordane allowed per day.

\section{Advisory Assumptions - Chlordane Skin Off Fillets (Catfish)}

\section{Assumptions:}

1) Reference Dose is 0.15 micrograms Chlordane per kilogram per day

2) Average Meal Size is 227 grams or $1 / 2$ pound of uncooked fish.

3) Representative Consumer Body weight is 70 kilograms.

4) Five Advisory Groups: Unrestricted or 225 meals per year; One meal per week; One meal per month; Six meals per year; No Consumption.

5) Assume meal preparation reduces residues by 30\% from raw skin off (catfish) fish fillets used to determine Chlordane residue level.

\section{Maximum Allowable Daily Chlordane Ingestion Calculation}

0.15 micrograms per kilogram per day X 70 kilogram body weight $=10.5$ micrograms

Chlordane allowed per day. 


\section{Chlordane Advisory Groups - Skin On Fillet}

\section{GROUP 1}

Unrestricted Consumption or up to 225 meals per year (140 grams of sportfish per day)

10.5 micrograms per day Chlordane / 140 grams of fish per day /.5 preparation reduction

Less than $0.15 \mathrm{ppm}$ Chlordane in raw skin on fish fillet

\section{GROUP 2}

Up to 1 meal per week

(32 grams of sportfish per day)

10.5 micrograms per day Chlordane / 32 grams of fish per day / .5 preparation reduction

$0.15 \mathrm{ppm}$ to $0.66 \mathrm{ppm}$ Chlordane in raw skin on fish fillet

\section{GROUP 3}

Up to 1 meal per month

(7.4 grams of sportfish per day)

10.5 micrograms per day Chlordane / 7.4 grams of fish per day / .5 preparation reduction

$0.66 \mathrm{ppm}$ to $2.84 \mathrm{ppm}$ Chlordane in raw skin on fish fillet

\section{GROUP 4}

Up to 6 meals per year

(3.7 grams of sportfish per day)

10.5 micrograms per day Chlordane / 3.7 grams of fish per day / .5 preparation reduction

$2.84 \mathrm{ppm}$ to $5.68 \mathrm{ppm}$ Chlordane in raw skin on fish fillet

\section{GROUP 5}

DO NOT EAT

Greater than $5.68 \mathrm{ppm}$ Chlordane in raw skin on fish fillet 


\section{Chlordane Advisory Groups - Skin Off Fillet}

\section{GROUP 1}

Unrestricted Consumption or up to 225 meals per year (140 grams of sportfish per day)

10.5 micrograms per day Chlordane / 140 grams of fish per day /.7 preparation reduction

Less than $0.11 \mathrm{ppm}$ Chlordane in raw skin off (catfish) fish fillet

\section{GROUP 2}

Up to 1 meal per week

(32 grams of sportfish per day)

10.5 micrograms per day Chlordane / 32 grams of fish per day / .7 preparation reduction

$0.11 \mathrm{ppm}$ to $0.47 \mathrm{ppm}$ Chlordane in raw skin off (catfish) fish fillet

\section{GROUP 3}

Up to 1 meal per month

(7.4 grams of sportfish per day)

10.5 micrograms per day Chlordane / 7.4 grams of fish per day / .7 preparation reduction

$0.47 \mathrm{ppm}$ to $2.03 \mathrm{ppm}$ Chlordane in raw skin off (catfish) fish fillet

\section{GROUP 4}

Up to 6 meals per year

(3.7 grams of sportfish per day)

10.5 micrograms per day Chlordane / 3.7 grams of fish per day / .7 preparation reduction

$2.03 \mathrm{ppm}$ to $4.05 \mathrm{ppm}$ Chlordane in raw skin on fish fillet

\section{GROUP 5}

DO NOT EAT

Greater than $4.05 \mathrm{ppm}$ Chlordane in raw skin off (catfish) fish fillet 


\section{Chlorpyrifos Summary}

Merck Number 2242

CAS Number 2921-88-2

Oral RfD $0.003 \mathrm{mg} / \mathrm{kg} /$ day

Preparation Dose Reduction .5 Skin On, .7 Skin Off

Chlorpyrifos is an organophosphate insecticide. It is an amber or white crystal form with a sulfur odor. Chlorpyrifos is used to control cutworms, corn root worms, cockroaches, grubs, flea beetles, flies, termites, fire ants, and lice. Although no longer approved, its first use was to control mosquitoes in wetlands. It is registered for use on a variety of food crops, sheep and turkeys, golf courses, non-food crops, in houses, farm outbuildings, storage bins, and commercial buildings. Chlorpyrifos comes in a variety of formulations including granules, wettable powders, dusts, and concentrates. Unless protective clothing is worn, a 24 hour reentry restriction is placed on fields treated with concentrates or wettable powders.

Chlorpyrifos is highly lipophilic and collects in fat. Mutagenic testing of Chlorpyrifos produced varying results with some studies showing increased alkylation of DNA and RNA in mouse livers. Exposure during pregnancy is fetotoxic in many test species, and can result in decreased birth length, increase skeletal deformities including unossified sternum. The U.S. Environmental Protection Agency has not determined the carcinogenic status of Chlorpyrifos, and there is no current evidence it increases cancer rates. Chronic exposure can cause numbness, tingling, weakness, cramping and can develop into a loss of coordination and paralysis. Memory loss, nausea, confusion, head ache, slurred speech, and slowed reaction also can result from long term exposure. Reference dose is in part based on a study with adult human males as test subjects. 


\section{Adult Advisory Assumptions - Chlorpyrifos Skin On Fillet}

\section{Assumptions:}

1) Reference Dose is 3 micrograms Chlorpyrifos per kilogram per day

2) Average Meal Size is 227 grams or $1 / 2$ pound of uncooked fish.

3) Representative Consumer Body weight is 70 kilograms.

4) Five Advisory Groups: Unrestricted or 225 meals per year; One meal per week; One meal per month; Six meals per year; No Consumption.

5) Assume meal preparation reduces residues by 50\% from raw skin on fish fillets used to determine Chlorpyrifos residue level.

\section{Maximum Allowable Daily Chlorpyrifos Ingestion Calculation}

3 micrograms per kilogram per day X 70 kilogram body weight $=210$ micrograms Chlorpyrifos allowed per day.

\section{Adult Advisory Assumptions - Chlorpyrifos Skin Off Fillet}

\section{Assumptions:}

1) Reference Dose is 3 micrograms Chlorpyrifos per kilogram per day

2) Average Meal Size is 227 grams or $1 / 2$ pound of uncooked fish.

3) Representative Consumer Body weight is 70 kilograms.

4) Five Advisory Groups: Unrestricted or 225 meals per year; One meal per week; One meal per month; Six meals per year; No Consumption.

5) Assume meal preparation reduces residues by $30 \%$ from raw skin on fish fillets used to determine Chlorpyrifos residue level.

\section{Maximum Allowable Daily Chlorpyrifos Ingestion Calculation}

3 micrograms per kilogram per day X 70 kilogram body weight $=210$ micrograms Chlorpyrifos allowed per day. 


\section{Chlorpyrifos Adult Advisory Groups - Skin On Fillets}

\section{GROUP 1}

Unrestricted Consumption or up to 225 meals per year (140 grams of sportfish per day)

210 micrograms per day Chlorpyrifos / 140 grams of fish per day/ .5 preparation reduction

Less than 3.0 ppm Chlorpyrifos in raw skin on fish fillet

\section{GROUP 2}

Up to 1 meal per week (32 grams of sportfish per day)

210 micrograms per day Chlorpyrifos / 32 grams of fish per day/ .5 preparation reduction

$3.0 \mathrm{ppm}$ to $13.13 \mathrm{ppm}$ Chlorpyrifos in raw skin on fish fillet

\section{GROUP 3}

Up to 1 meal per month

(7.4 grams of sportfish per day)

210 micrograms per day Chlorpyrifos / 7.4 grams of fish per day/.5 preparation reduction

$13.13 \mathrm{ppm}$ to $56.76 \mathrm{ppm}$ Chlorpyrifos in raw skin on fish fillet

\section{GROUP 4}

Up to 6 meals per year (3.7 grams of sportfish per day)

210 micrograms per day Chlorpyrifos / 3.7 grams of fish per day/.5 preparation reduction

$56.76 \mathrm{ppm}$ to $113.51 \mathrm{ppm}$ Chlorpyrifos in raw skin on fish fillet

\section{GROUP 5}

DO NOT EAT

Greater than 113.51 ppm Chlorpyrifos in raw skin on fish fillet 


\section{Chlorpyrifos Adult Advisory Groups - Skin Off Fillets}

\section{GROUP 1}

Unrestricted Consumption or up to 225 meals per year (140 grams of sportfish per day)

210 micrograms per day Chlorpyrifos / 140 grams of fish per day/.7 preparation reduction

Less than $2.14 \mathrm{ppm}$ Chlorpyrifos in raw skin off (catfish) fish fillet

\section{GROUP 2}

Up to 1 meal per week

(32 grams of sportfish per day)

210 micrograms per day Chlorpyrifos / 32 grams of fish per day/ .7 preparation reduction

$2.14 \mathrm{ppm}$ to $9.38 \mathrm{ppm}$ Chlorpyrifos in raw skin off (catfish) fish fillet

\section{GROUP 3}

Up to 1 meal per month

(7.4 grams of sportfish per day)

210 micrograms per day Chlorpyrifos / 7.4 grams of fish per day/.7 preparation reduction

$9.38 \mathrm{ppm}$ to $40.54 \mathrm{ppm}$ Chlorpyrifos in raw skin off (catfish) fish fillet

\section{GROUP 4}

Up to 6 meals per year

(3.7 grams of sportfish per day)

210 micrograms per day Chlorpyrifos / 3.7 grams of fish per day/ .7 preparation reduction

$40.54 \mathrm{ppm}$ to $81.08 \mathrm{ppm}$ Chlorpyrifos in raw skin off (catfish) fish fillet

\section{GROUP 5}

DO NOT EAT

Greater than 81.08 ppm Chlorpyrifos in raw skin off (catfish) fish fillet 


\section{Child Advisory Assumptions - Chlorpyrifos Skin On Fillet}

\section{Assumptions:}

1) Reference Dose is 3 micrograms Chlorpyrifos per kilogram per day

2) Average Meal Size is 52.5 grams or 3 ounces of uncooked fish.

3) Representative Consumer Body weight is 14.5 kilograms.

4) Five Advisory Groups: Unrestricted or 225 meals per year; One meal per week; One meal per month; Six meals per year; No Consumption.

5) Assume meal preparation reduces residues by 50\% from raw skin on fish fillets used to determine Chlorpyrifos residue level.

\section{Maximum Allowable Daily Chlorpyrifos Ingestion Calculation}

3 micrograms per kilogram per day X 14.5 kilogram body weight $=43.5$ micrograms

Chlorpyrifos allowed per day.

\section{Child Advisory Assumptions - Chlorpyrifos Skin Off Fillet}

\section{Assumptions:}

1) Reference Dose is 3 micrograms Chlorpyrifos per kilogram per day

2) Average Meal Size is 52.5 grams or 3 ounces of uncooked fish.

3) Representative Consumer Body weight is 14.5 kilograms.

4) Five Advisory Groups: Unrestricted or 225 meals per year; One meal per week; One meal per month; Six meals per year; No Consumption.

5) Assume meal preparation reduces residues by $30 \%$ from raw skin on fish fillets used to determine Chlorpyrifos residue level.

\section{Maximum Allowable Daily Chlorpyrifos Ingestion Calculation}

3 micrograms per kilogram per day X 14.5 kilogram body weight $=43.5$ micrograms

Chlorpyrifos allowed per day. 


\section{Chlorpyrifos Child Advisory Groups - Skin On Fillets}

\section{GROUP 1}

Unrestricted Consumption or up to 225 meals per year (52.5 grams of sportfish per day)

43.5 micrograms per day Chlorpyrifos / 52.5 grams of fish per day/ .5 preparation reduction Less than $1.66 \mathrm{ppm}$ Chlorpyrifos in raw skin on fish fillet

\section{GROUP 2}

Up to 1 meal per week (12.13 grams of sportfish per day)

43.5 micrograms per day Chlorpyrifos / 12.13 grams of fish per day/ .5 preparation reduction

$1.66 \mathrm{ppm}$ to $7.17 \mathrm{ppm}$ Chlorpyrifos in raw skin on fish fillet

\section{GROUP 3}

Up to 1 meal per month

(2.8 grams of sportfish per day)

43.5 micrograms per day Chlorpyrifos / 2.8 grams of fish per day/ .5 preparation reduction

$7.17 \mathrm{ppm}$ to $31.07 \mathrm{ppm}$ Chlorpyrifos in raw skin on fish fillet

\section{GROUP 4}

Up to 6 meals per year (1.4 grams of sportfish per day)

43.5 micrograms per day Chlorpyrifos / 1.4 grams of fish per day/ .5 preparation reduction

$31.07 \mathrm{ppm}$ to $62.14 \mathrm{ppm}$ Chlorpyrifos in raw skin on fish fillet

\section{GROUP 5}

DO NOT EAT

Greater than 62.14 ppm Chlorpyrifos in raw skin on fish fillet 


\section{Chlorpyrifos Child Advisory Groups - Skin Off Fillets}

\section{GROUP 1}

Unrestricted Consumption or up to 225 meals per year

(52.5 grams of sportfish per day)

43.5 micrograms per day Chlorpyrifos / 52.5 grams of fish per day/ .7 preparation reduction

Less than 1.18 ppm Chlorpyrifos in raw skin off (catfish) fish fillet

\section{GROUP 2}

Up to 1 meal per week

(12.13 grams of sportfish per day)

43.5 micrograms per day Chlorpyrifos / 12.13 grams of fish per day/ .7 preparation reduction

$1.18 \mathrm{ppm}$ to $5.12 \mathrm{ppm}$ Chlorpyrifos in raw skin off (catfish) fish fillet

\section{GROUP 3}

Up to 1 meal per month

(2.8 grams of sportfish per day)

43.5 micrograms per day Chlorpyrifos / 2.8 grams of fish per day/ .7 preparation reduction

$5.12 \mathrm{ppm}$ to $22.19 \mathrm{ppm}$ Chlorpyrifos in raw skin off (catfish) fish fillet

\section{GROUP 4}

Up to 6 meals per year

(1.4 grams of sportfish per day)

43.5 micrograms per day Chlorpyrifos / 1.4 grams of fish per day/ .7 preparation reduction

$22.19 \mathrm{ppm}$ to $44.39 \mathrm{ppm}$ Chlorpyrifos in raw skin off (catfish) fish fillet

\section{GROUP 5}

DO NOT EAT

Greater than 44.39 ppm Chlorpyrifos in raw skin off (catfish) fish fillet 


\section{DDT/DDD/DDE Summary}

Merck Number(s) 2298(DDT), 2297(DDD)

CAS Number(s) 50-29-3(DDT), 72-54-8(DDD), 72-55-9(DDE)

Oral RfD $0.0005 \mathrm{mg} / \mathrm{kg} / \mathrm{day}$

Oral Slope Factor $0.34 \mathrm{mg} / \mathrm{kg} /$ day

Preparation Dose Reduction .5 Skin On, .7 Skin Off

Dichlorodiphenyltrichloroethane(DDT) is an organochlorine broad use pesticide. It was first made in 1873 but the insecticidal effects were not discovered until 1939. DDT has a waxy solid technical grade with a sweet smell and a more pure odorless, white or clear crystal form. It was used to delouse U.S. troops during World War II and to control mosquitoes carrying malaria and other diseases. It was hailed as a miracle pesticide because it was thought to be safe, killed a wide range of insects and was inexpensive. It was widely used in agriculture in enormous quantities and many pests developed a resistance to its use. The U.S. registration was revoked in 1972, although it is still used in many other countries, especially in South America. DDT is very persistent in the environment. DDT bioconcentrates especially in aquatic ecosystems and is highly lipophilic. Fish have accumulated DDE residues $10^{5}$ times of that in the water. DDT was responsible for thinning egg shells of birds including the Bald Eagle(Haliaeetus leucocephalus) leading to their decline in numbers. Residues from DDT, DDD and DDE are still found worldwide in soils, fruits, vegetables, sediments, and animals including humans.

DDT is embryo and fetal toxic, leading to decreased brain, kidney and body weights in rabbits. Studies with dogs and mice have demonstrated DDT crosses the placenta. DDT is believed to cause premature delivery or spontaneous abortion in humans and bovines. Metabolites of DDT can mimic estrogen and may produce reproductive abnormalities. The U.S. Environmental Protection Agency lists DDT as a probable carcinogen. It has been demonstrated to increase production of liver and lung tumors and to increase occurrence of leukemia in mice, 
rats and hamsters. DDT was found in human milk in 1965 at levels 20 times greater than the mother's diet. Chronic exposure effects the liver, kidneys, the immune system and central nervous system in test animals, but these results have not been found in humans. Mutagenicity tests including a test on adult male humans indicate DDT causes chromosomal damage. Men with occupational exposure of DDT also showed significantly increased chromosome damage. 


\section{Cancer Effect Assumptions - DDT \DDD $\backslash$ DDE Skin On Fillet}

\section{Assumptions:}

1) Slope Factor is 0.34 milligrams $\mathbf{D D T} \backslash \mathbf{D D D} \backslash \mathbf{D D E}$ per kilogram per day

2) Average Meal Size is 227 grams or $1 / 2$ pound of uncooked fish.

3) Representative Consumer Body weight is 70 kilograms.

4) ARL is $10^{-4}$

5) Five Consumption Rates: Unrestricted 225 meals per year(140 g/day); One meal per week(32g/day); One meal per month(7.4 g/day); Six meals per year(3.7 g/day); No Consumption.

6) Assume meal preparation reduces residues by $50 \%$ from raw skin off (catfish) fish fillets used to determine DDT $\backslash$ DDD $\backslash$ DDE residue level.

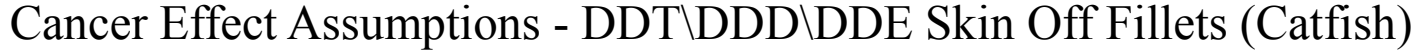

\section{Assumptions:}

1) Slope Factor is 0.35 milligrams $\mathbf{D D T} \backslash \mathbf{D D D} \backslash \mathbf{D D E}$ per kilogram per day

2) Average Meal Size is 227 grams or $1 / 2$ pound of uncooked fish.

3) Representative Consumer Body weight is 70 kilograms.

4) ARL is $10^{-4}$

5) Five Consumption Rates: Unrestricted 225 meals per year(140 g/day); One meal per week(32g/day); One meal per month(7.4 g/day); Six meals per year(3.7 g/day); No Consumption.

6) Assume meal preparation reduces residues by $30 \%$ from raw skin off (catfish) fish fillets used to determine DDT $\backslash \mathbf{D D D} \backslash \mathbf{D D E}$ residue level. 


\section{DDT/DDD/DDE Cancer Effect Advisory Groups - Skin On Fillet}

\section{GROUP 1}

Unrestricted Consumption or up to 225 meals per year

(140 grams of sportfish per day)

Less than 0.29 ppm DDT \DDD \DDE in raw skin on fish fillet

\section{GROUP 2}

Up to 1 meal per week

(32 grams of sportfish per day)

$0.29 \mathrm{ppm}$ to $1.29 \mathrm{ppm}$ DDT $\backslash \mathbf{D D D} \backslash \mathbf{D D E}$ in raw skin on fish fillet

\section{GROUP 3}

Up to 1 meal per month

(7.4 grams of sportfish per day)

$1.29 \mathrm{ppm}$ to $5.56 \mathrm{ppm}$ DDT $\backslash \mathbf{D D D} \backslash \mathbf{D D E}$ in raw skin on fish fillet

\section{GROUP 4}

Up to 6 meals per year

(3.7 grams of sportfish per day)

$5.56 \mathrm{ppm}$ to $11.13 \mathrm{ppm} \mathbf{D D T} \backslash \mathbf{D D D} \backslash \mathbf{D D E}$ in raw skin on fish fillet

\section{GROUP 5}

DO NOT EAT

Greater than 11.13 ppm DDT $\backslash \mathbf{D D D} \backslash \mathbf{D D E}$ in raw skin on fish fillet 
DDT/DDD/DDE Cancer Effect Advisory Groups Skin Off Fillet

\section{GROUP 1}

Unrestricted Consumption or up to 225 meals per year

(140 grams of sportfish per day)

Less than $0.21 \mathrm{ppm}$ DDT $\backslash \mathbf{D D D} \backslash \mathbf{D D E}$ in raw skin off (catfish) fish fillet

\section{GROUP 2}

Up to 1 meal per week

(32 grams of sportfish per day)

$0.21 \mathrm{ppm}$ to $0.92 \mathrm{ppm}$ DDT $\backslash \mathbf{D D D} \backslash \mathbf{D D E}$ in raw skin off (catfish) fish fillet

\section{GROUP 3}

Up to 1 meal per month

(7.4 grams of sportfish per day)

$0.92 \mathrm{ppm}$ to $3.97 \mathrm{ppm}$ DDT $\backslash$ DDD $\backslash$ DDE in raw skin off (catfish) fish fillet

\section{GROUP 4}

Up to 6 meals per year

(3.7 grams of sportfish per day)

$3.97 \mathrm{ppm}$ to $7.95 \mathrm{ppm}$ DDT $\backslash$ DDD $\backslash$ DDE in raw skin off (catfish) fish fillet

\section{GROUP 5}

DO NOT EAT

Greater than 7.95 ppm DDT 


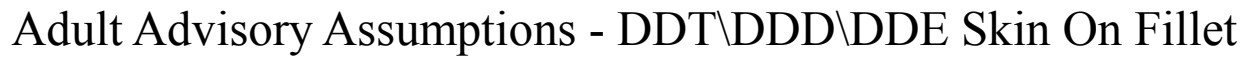

\section{Assumptions:}

1) Reference Dose is 0.5 micrograms DDT $\backslash \mathbf{D D D} \backslash \mathbf{D D E}$ per kilogram per day

2) Average Meal Size is 227 grams or $1 / 2$ pound of uncooked fish.

3) Representative Consumer Body weight is 70 kilograms.

4) Five Advisory Groups: Unrestricted or 225 meals per year; One meal per week; One meal per month; Six meals per year; No Consumption.

5) Assume meal preparation reduces residues by 50\% from raw skin on fish fillets used to determine DDT $\backslash$ DDD $\backslash$ DDE residue level.

\section{Maximum Allowable Daily DDT $\backslash D D D \backslash D D E$ Ingestion Calculation}

0.5 micrograms per kilogram per day X 70 kilogram body weight $=35$ micrograms

DDT $\backslash$ DDD $\backslash$ DDE allowed per day.

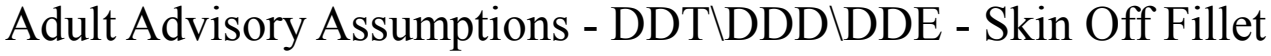

\section{Assumptions:}

1) Reference Dose is 0.5 micrograms DDT $\backslash \mathbf{D D D} \backslash \mathbf{D D E}$ per kilogram per day

2) Average Meal Size is 227 grams or $1 / 2$ pound of uncooked fish.

3) Representative Consumer Body weight is 70 kilograms.

4) Five Advisory Groups: Unrestricted or 225 meals per year; One meal per week; One meal per month; Six meals per year; No Consumption.

5) Assume meal preparation reduces residues by 30\% from raw skin off fish fillets used to determine DDT $\backslash$ DDD $\backslash$ DDE residue level.

\section{Maximum Allowable Daily DDT $\backslash D D D \backslash D D E$ Ingestion Calculation}

0.5 micrograms per kilogram per day $X 70$ kilogram body weight $=35$ micrograms

DDT $\backslash$ DDD $\backslash$ DDE allowed per day. 


\section{DDT/DDD/DDE Adult Advisory Groups - Skin On Fillet}

\section{GROUP 1}

Unrestricted Consumption or up to 225 meals per year

(140 grams of sportfish per day)

35 micrograms per day DDT \DDD\DDE / 140 grams of fish per day /.5 preparation reduction

Less than $0.5 \mathrm{ppm}$ DDT $\backslash$ DDD $\backslash$ DDE in raw skin on fish fillet

\section{GROUP 2}

Up to 1 meal per week

(32 grams of sportfish per day)

35 micrograms per day DDT $\backslash \mathbf{D D D} \backslash \mathbf{D D E}$ / 32 grams of fish per day / .5 preparation reduction

$0.5 \mathrm{ppm}$ to $2.19 \mathrm{ppm}$ DDT $\backslash \mathbf{D D D} \backslash \mathbf{D D E}$ in raw skin on fish fillet

\section{GROUP 3}

Up to 1 meal per month

(7.4 grams of sportfish per day)

35 micrograms per day DDT $\backslash$ DDD $\backslash \mathbf{D D E}$ / 7.4 grams of fish per day / .5 preparation reduction

$2.19 \mathrm{ppm}$ to $9.46 \mathrm{ppm}$ DDT $\backslash$ DDD $\backslash D D E$ in raw skin on fish fillet

\section{GROUP 4}

Up to 6 meals per year

(3.7 grams of sportfish per day)

35 micrograms per day DDT \DDD $\backslash \mathbf{D D E}$ / 3.7 grams of fish per day / .5 preparation reduction

$9.46 \mathrm{ppm}$ to $18.92 \mathrm{ppm}$ DDT $\backslash \mathbf{D D D} \backslash \mathbf{D D E}$ in raw skin on fish fillet

\section{GROUP 5}

DO NOT EAT

Greater than $18.92 \mathrm{ppm}$ DDT $\backslash \mathbf{D D D} \backslash \mathbf{D D E}$ in raw skin on fish fillet 


\section{DDT/DDD/DDE Adult Advisory Groups Skin Off Fillet}

\section{GROUP 1}

Unrestricted Consumption or up to 225 meals per year (140 grams of sportfish per day)

35 micrograms per day DDT\DDD \DDE / 140 grams of fish per day /.7 preparation reduction Less than $0.36 \mathrm{ppm}$ DDT $\backslash \mathbf{D D D} \backslash \mathbf{D D E}$ in raw skin off (catfish) fish fillet

\section{GROUP 2}

Up to 1 meal per week

(32 grams of sportfish per day)

35 micrograms per day DDT \DDD $\backslash \mathbf{D D E}$ / 32 grams of fish per day / .7 preparation reduction

$0.36 \mathrm{ppm}$ to $1.56 \mathrm{ppm}$ DDT $\backslash \mathbf{D D D} \backslash \mathbf{D D E}$ in raw skin off (catfish) fish fillet

\section{GROUP 3}

Up to 1 meal per month

(7.4 grams of sportfish per day)

35 micrograms per day DDT $\backslash \mathbf{D D D} \backslash \mathbf{D D E}$ / 7.4 grams of fish per day / .7 preparation reduction

$1.56 \mathrm{ppm}$ to $6.76 \mathrm{ppm} \mathbf{D D T} \backslash \mathbf{D D D} \backslash \mathbf{D D E}$ in raw skin off (catfish) fish fillet

\section{GROUP 4}

Up to 6 meals per year

(3.7 grams of sportfish per day)

35 micrograms per day DDT $\backslash \mathbf{D D D} \backslash \mathbf{D D E}$ / 3.7 grams of fish per day / .7 preparation reduction

$6.76 \mathrm{ppm}$ to $13.51 \mathrm{ppm} \mathbf{D D T} \backslash \mathbf{D D D} \backslash \mathbf{D D E}$ in raw skin off (catfish) fish fillet

\section{GROUP 5}

DO NOT EAT

Greater than $13.51 \mathrm{ppm}$ DDT $\backslash \mathbf{D D D} \backslash \mathbf{D D E}$ in raw skin off (catfish) fish fillet 


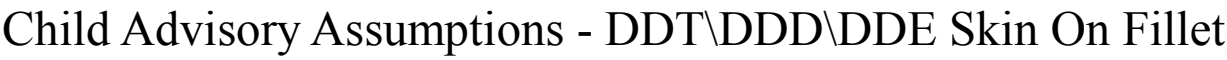

\section{Assumptions:}

1) Reference Dose is 0.5 micrograms DDT $\backslash \mathbf{D D D} \backslash \mathbf{D D E}$ per kilogram per day

2) Average Meal Size is 52.5 grams or 3 ounces of uncooked fish.

3) Representative Consumer Body weight is 14.5 kilograms.

4) Five Advisory Groups: Unrestricted or 225 meals per year; One meal per week; One meal per month; Six meals per year; No Consumption.

5) Assume meal preparation reduces residues by 50\% from raw skin on fish fillets used to determine DDT $\backslash \mathbf{D D D} \backslash \mathbf{D D E}$ residue level.

\section{Maximum Allowable Daily DDT $\backslash D D D \backslash D D E$ Ingestion Calculation}

0.5 micrograms per kilogram per day X 14.5 kilogram body weight $=7.25$ micrograms DDT $\backslash$ DDD $\backslash$ DDE allowed per day.

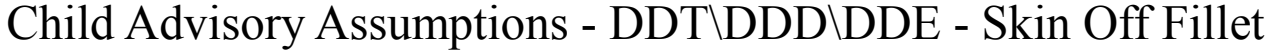

\section{Assumptions:}

1) Reference Dose is 0.5 micrograms DDT $\backslash \mathbf{D D D} \backslash \mathbf{D D E}$ per kilogram per day

2) Average Meal Size is 52.5 grams or 3 ounces of uncooked fish.

3) Representative Consumer Body weight is 14.5 kilograms.

4) Five Advisory Groups: Unrestricted or 225 meals per year; One meal per week; One meal per month; Six meals per year; No Consumption.

5) Assume meal preparation reduces residues by 30\% from raw skin off fish fillets used to determine DDT $\backslash$ DDD $\backslash$ DDE residue level.

\section{Maximum Allowable Daily DDT $\backslash$ DDD $\backslash$ DDE Ingestion Calculation}

0.5 micrograms per kilogram per day X 14.5 kilogram body weight $=7.25$ micrograms DDT $\backslash$ DDD $\backslash$ DDE allowed per day. 


\section{DDT/DDD/DDE Child Advisory Groups - Skin On Fillet}

\section{GROUP 1}

Unrestricted Consumption or up to 225 meals per year

(52.5 grams of sportfish per day)

7.25 micrograms per day DDT $\mathbf{D D D} \backslash \mathbf{D D E}$ / 52.5 grams of fish per day /.5 preparation reduction

Less than $0.28 \mathrm{ppm}$ DDT $\backslash \mathbf{D D D} \backslash \mathbf{D D E}$ in raw skin on fish fillet

\section{GROUP 2}

Up to 1 meal per week

(12.13 grams of sportfish per day)

7.25 micrograms per day DDT $\backslash$ DDD $\backslash$ DDE / 12.13 grams of fish per day / .5 preparation reduction

$0.28 \mathrm{ppm}$ to $1.20 \mathrm{ppm}$ DDT $\backslash \mathbf{D D D} \backslash \mathbf{D D E}$ in raw skin on fish fillet

\section{GROUP 3}

Up to 1 meal per month

(2.8 grams of sportfish per day)

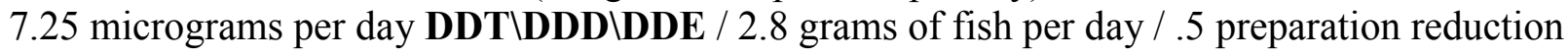

$1.20 \mathrm{ppm}$ to $5.18 \mathrm{ppm}$ DDT $\mathbf{D D D} \backslash \mathbf{D D E}$ in raw skin on fish fillet

\section{GROUP 4}

Up to 6 meals per year

(1.4 grams of sportfish per day)

7.25 micrograms per day DDT $\backslash \mathbf{D D D} \backslash \mathbf{D D E}$ / 1.4 grams of fish per day / .5 preparation reduction

$5.18 \mathrm{ppm}$ to $10.36 \mathrm{ppm}$ DDT $\backslash \mathbf{D D D} \backslash \mathbf{D D E}$ in raw skin on fish fillet

GROUP 5

DO NOT EAT

Greater than $10.36 \mathrm{ppm}$ DDT $\backslash \mathbf{D D D} \backslash \mathbf{D D E}$ in raw skin on fish fillet 


\section{DDT/DDD/DDE Child Advisory Groups Skin Off Fillet}

\section{GROUP 1}

Unrestricted Consumption or up to 225 meals per year

(52.5 grams of sportfish per day)

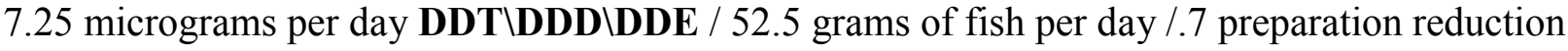

Less than $0.20 \mathrm{ppm}$ DDT $\backslash \mathbf{D D D} \backslash \mathbf{D D E}$ in raw skin off (catfish) fish fillet

\section{GROUP 2}

Up to 1 meal per week

(12.13 grams of sportfish per day) reduction

7.25 micrograms per day DDT $\backslash \mathbf{D D D} \backslash \mathbf{D D E}$ / 12.13 grams of fish per day /.7 preparation

$0.20 \mathrm{ppm}$ to $0.85 \mathrm{ppm}$ DDT $\backslash \mathbf{D D D} \backslash \mathbf{D D E}$ in raw skin off (catfish) fish fillet

\section{GROUP 3}

Up to 1 meal per month (2.8 grams of sportfish per day)

7.25 micrograms per day DDT $\backslash \mathbf{D D D} \backslash \mathbf{D D E}$ / 2.8 grams of fish per day /.7 preparation reduction

$0.85 \mathrm{ppm}$ to $3.70 \mathrm{ppm}$ DDT $\backslash$ DDD $\backslash$ DDE in raw skin off (catfish) fish fillet

\section{GROUP 4}

Up to 6 meals per year

(1.4 grams of sportfish per day)

7.25 micrograms per day DDT $\backslash \mathbf{D D D} \backslash \mathbf{D D E}$ / 1.4 grams of fish per day /.7 preparation reduction

$3.70 \mathrm{ppm}$ to $7.40 \mathrm{ppm}$ DDT $\backslash \mathbf{D D D} \backslash \mathbf{D D E}$ in raw skin off (catfish) fish fillet

\section{GROUP 5}

DO NOT EAT

Greater than $7.40 \mathrm{ppm}$ DDT $\backslash \mathbf{D D D} \backslash \mathbf{D D E}$ in raw skin off (catfish) fish fillet 


\section{Diazinon Summary}

Merck Number 3043

CAS Number 333-41-5

Oral RfD 0.00009 mg/kg/day

Preparation Dose Reduction 1

Diazinon is a clear to light brown liquid nonsystemic organophosphate pesticide introduced in 1952. It is used to treat for ants, cockroaches, fleas, and termites in residential and nonfood commercial buildings. Diazinon is a restricted use pesticide used to control sucking, leaf eating, and soil insects on ornamentals, lawns, fruits, nuts, forage crops and a variety of vegetables. It has been used to treat sheep for lice. It was widely used on turf farms and golf courses until 1988 when those applications were revoked. Diazinon usually degrades in less than two weeks in the environment, but factors such as low temperature, lack of moisture, and high alkalinity can keep it active for more than six months.

Chronic effects of Diazinon include enzyme inhibition in red blood cells, plasma, and brain cells and cholinesterase inhibition in red blood cells in many species. Teratogenic studies show mixed results; hamsters and rabbits exposed to low doses exhibited no effects, while chicks, dogs and swine showed deformities. Mutagenic effects are also not clear, most assays have been negative, but a study on human lymphocyte mitosis produced chromosomal abnormalities. The U.S. EPA has not classified the carcinogenicity of Diazinon due to insufficient information, although a two year study did not show tumor development in rats. Diazinon is highly toxic and accidental poisonings resulted in the deaths of several species of animals and humans. 


\section{Adult Advisory Assumptions - Diazinon}

\section{Assumptions:}

1) Reference Dose is 0.09 micrograms Diazinon per kilogram per day

2) Average Meal Size is 227 grams or $1 / 2$ pound of uncooked fish.

3) Representative Consumer Body weight is 70 kilograms.

4) Five Advisory Groups: Unrestricted or 225 meals per year; One meal per week; One meal per month; Six meals per year; No Consumption.

5) Assume meal preparation does not reduce residues by $50 \%$ from raw skin on fish fillets used to determine Diazinon residue level.

\section{Maximum Allowable Daily Diazinon Ingestion Calculation}

0.09 micrograms per kilogram per day X 70 kilogram body weight $=6.3$ micrograms Diazinon allowed per day. 


\section{Diazinon Adult Advisory Groups}

\section{GROUP 1}

Unrestricted Consumption or up to 225 meals per year (140 grams of sportfish per day)

6.3 micrograms per day Diazinon / 140 grams of fish per day

Less than 0.045 ppm Diazinon in raw skin on fish fillet

\section{GROUP 2}

Up to 1 meal per week

(32 grams of sportfish per day)

6.3 micrograms per day Diazinon / 32 grams of fish per day

$0.045 \mathrm{ppm}$ to $0.20 \mathrm{ppm}$ Diazinon in raw skin on fish fillet

\section{GROUP 3}

Up to 1 meal per month

(7.4 grams of sportfish per day)

6.3 micrograms per day Diazinon / 7.4 grams of fish per day

$0.20 \mathrm{ppm}$ to $0.85 \mathrm{ppm}$ Diazinon in raw skin on fish fillet

\section{GROUP 4}

Up to 6 meals per year (3.7 grams of sportfish per day)

6.3 micrograms per day Diazinon / 3.7 grams of fish per day

$0.85 \mathrm{ppm}$ to $1.70 \mathrm{ppm}$ Diazinon in raw skin on fish fillet

\section{GROUP 5}

DO NOT EAT

Greater than 1.70 ppm Diazinon in raw skin on fish fillet 


\section{Children Advisory Assumptions - Diazinon}

\section{Assumptions:}

1) Reference Dose is 0.09 micrograms Diazinon per kilogram per day

2) Average Meal Size is 52.5 grams or 3 ounces of uncooked fish.

3) Representative Consumer Body weight is 14.5 kilograms.

4) Five Advisory Groups: Unrestricted or 225 meals per year; One meal per week; One meal per month; Six meals per year; No Consumption.

5) Assume meal preparation does not reduce residues by $50 \%$ from raw skin on fish fillets used to determine Diazinon residue level.

\section{Maximum Allowable Daily Diazinon Ingestion Calculation}

0.09 micrograms per kilogram per day X 14.5 kilogram body weight $=1.305$ micrograms Diazinon allowed per day. 


\section{Diazinon Child Advisory Groups}

\section{GROUP 1}

Unrestricted Consumption or up to 225 meals per year (52.5 grams of sportfish per day)

1.305 micrograms per day Diazinon / 52.5 grams of fish per day

Less than 0.025 ppm Diazinon in raw skin on fish fillet

\section{GROUP 2}

Up to 1 meal per week

(12.13 grams of sportfish per day)

1.305 micrograms per day Diazinon / 12.13 grams of fish per day

$0.025 \mathrm{ppm}$ to $0.108 \mathrm{ppm}$ Diazinon in raw skin on fish fillet

\section{GROUP 3}

Up to 1 meal per month

(2.8 grams of sportfish per day)

1.305 micrograms per day Diazinon / 2.8 grams of fish per day

$0.108 \mathrm{ppm}$ to $0.47 \mathrm{ppm}$ Diazinon in raw skin on fish fillet

\section{GROUP 4}

Up to 6 meals per year (1.4 grams of sportfish per day)

1.305 micrograms per day Diazinon / 1.4 grams of fish per day

$0.47 \mathrm{ppm}$ to $0.93 \mathrm{ppm}$ Diazinon in raw skin on fish fillet

\section{GROUP 5}

DO NOT EAT

Greater than $0.93 \mathrm{ppm}$ Diazinon in raw skin on fish fillet 


\section{Dicofol Summary}

Merck Number 3136

CAS Number 115-32-2

Oral RfD $0.0005 \mathrm{mg} / \mathrm{kg} / \mathrm{day}$

Preparation Dose Reduction 1

Dicofol is an organochlorine miticide registered for use in 1957 in the United States. Its pure form is a white crystal, and technical grade dicofol is a red to brown or amber colored thick liquid with the scent of freshly mowed hay. There are thirty-two registered dicofol products used on a variety of fruits, vegetables, lawns and ornamentals. It is available in concentrates and wettable powders. Dicofol is structurally similar to DDT. Dicofol was commonly contaminated with up 15\% DDT and its registration was temporarily revoked in 1986. In 1989 the U.S. Environmental Protection Agency ordered the DDT contamination to account for less than $0.1 \%$ of the product.

Data is limited for this chemical. In limited studies, Dicofol has shown no teratogenic effects. Human lymph cell studies were positive at a rate 13 times higher than controls. The U.S. Environmental Protection Agency has listed dicofol as a B2 and C carcinogen but is reviewing the dicofol carcinogenic data. Chronic exposure in dogs, mice and rats produced decreased weights and damage to the liver kidney and heart. 


\section{Adult Advisory Assumptions - Dicofol}

\section{Assumptions:}

1) Reference Dose is 4 micrograms Dicofol per kilogram per day

2) Average Meal Size is 227 grams or $1 / 2$ pound of uncooked fish.

3) Representative Consumer Body weight is 70 kilograms.

4) Five Advisory Groups: Unrestricted or 225 meals per year; One meal per week; One meal per month; Six meals per year; No Consumption.

5) Assume meal preparation does not reduce residues by $50 \%$ from raw skin on fish fillets used to determine Dicofol residue level.

\section{Maximum Allowable Daily Dicofol Ingestion Calculation}

4 micrograms per kilogram per day X 70 kilogram body weight $=280$ micrograms Dicofol allowed per day. 


\section{Dicofol Adult Advisory Groups}

\section{GROUP 1}

Unrestricted Consumption or up to 225 meals per year (140 grams of sportfish per day)

280 micrograms per day Dicofol / 140 grams of fish per day

Less than $2.0 \mathrm{ppm}$ Dicofol in raw skin on fish fillet

\section{GROUP 2}

Up to 1 meal per week

(32 grams of sportfish per day)

280 micrograms per day Dicofol / 32 grams of fish per day

$2.0 \mathrm{ppm}$ to $8.75 \mathrm{ppm}$ Dicofol in raw skin on fish fillet

\section{GROUP 3}

Up to 1 meal per month

(7.4 grams of sportfish per day)

280 micrograms per day Dicofol / 7.4 grams of fish per day

$8.75 \mathrm{ppm}$ to $37.84 \mathrm{ppm}$ Dicofol in raw skin on fish fillet

\section{GROUP 4}

Up to 6 meals per year (3.7 grams of sportfish per day)

280 micrograms per day Dicofol / 3.7 grams of fish per day

$37.84 \mathrm{ppm}$ to $75.68 \mathrm{ppm}$ Dicofol in raw skin on fish fillet

\section{GROUP 5}

DO NOT EAT

Greater than $75.68 \mathrm{ppm}$ Dicofol in raw skin on fish fillet 


\section{Child Advisory Assumptions - Dicofol}

\section{Assumptions:}

1) Reference Dose is 4 micrograms Dicofol per kilogram per day

2) Average Meal Size is 52.5 grams or 3 ounces of uncooked fish.

3) Representative Consumer Body weight is 14.5 kilograms.

4) Five Advisory Groups: Unrestricted or 225 meals per year; One meal per week; One meal per month; Six meals per year; No Consumption.

5) Assume meal preparation does not reduce residues by $50 \%$ from raw skin on fish fillets used to determine Dicofol residue level.

\section{Maximum Allowable Daily Dicofol Ingestion Calculation}

4 micrograms per kilogram per day X 14.5 kilogram body weight $=58$ micrograms Dicofol allowed per day. 


\section{Dicofol Child Advisory Groups}

\section{GROUP 1}

Unrestricted Consumption or up to 225 meals per year (52.5grams of sportfish per day)

58 micrograms per day Dicofol / 52.5 grams of fish per day

Less than $1.10 \mathrm{ppm}$ Dicofol in raw skin on fish fillet

\section{GROUP 2}

Up to 1 meal per week

(12.13 grams of sportfish per day)

58 micrograms per day Dicofol / 12.13 grams of fish per day

1.10ppm to $4.78 \mathrm{ppm}$ Dicofol in raw skin on fish fillet

\section{GROUP 3}

Up to 1 meal per month

(2.8 grams of sportfish per day)

58 micrograms per day Dicofol / 2.8 grams of fish per day

$4.78 \mathrm{ppm}$ to $20.71 \mathrm{ppm}$ Dicofol in raw skin on fish fillet

\section{GROUP 4}

Up to 6 meals per year (1.4 grams of sportfish per day)

58 micrograms per day Dicofol / 1.4 grams of fish per day

$20.71 \mathrm{ppm}$ to $41.43 \mathrm{ppm}$ Dicofol in raw skin on fish fillet

\section{GROUP 5}

DO NOT EAT

Greater than 41.43 ppm Dicofol in raw skin on fish fillet 


\section{Dieldrin Summary}

Merck Number 3152

CAS Number 60-57-1

Oral RfD $0.00005 \mathrm{mg} / \mathrm{kg} / \mathrm{day}$

Oral Slope Factor $16 \mathrm{mg} / \mathrm{kg} /$ day

Preparation Dose Reduction .5 Skin On, .7 Skin Off

Dieldrin is an organochlorine insecticide that was extensively used in agriculture and termite treatment. Technical grade dieldrin is a tan and flaky substance and in its purer form is a white crystal. The registration was canceled in 1987, but residues are still detected in vegetables across the country. Dieldrin is also a product of degraded aldrin a closely related pesticide.

Dieldrin is extremely persistent in the environment and bioconcentrates in organisms. Dieldrin is fat soluble and stored in fatty tissues in animals.

Mutagenic data on dieldrin is restricted and mixed. Studies of human lung cells and mouse bone marrow show increased chromosome irregularities. Other mammalian mutagenicity investigations were not conclusive. Dieldrin may depress transfer RNA interfering with metabolic processes. A human investigation of organochlorines connected with premature labor were positive for aldrin. Dieldrin has been shown to alter levels of luteinizing hormone in female animals and gonadotropin in male animals. Dieldrin was fetotoxic in mice, producing extra ribs and reduced caudal ossification. Other animal developmental studies showed skeletal abnormalities, cleft palates, and webbed feet. The U.S. Environmental Protection Agency lists dieldrin as a probable human carcinogen. Adrenal, lymphoid, hepatic, pulmonary, and thyroid tumors have been found in animal experiments. Dieldrin imitates estrogen, and may contribute to human breast cancer and disrupt the endocrine system. Chronic exposure cause skin irritation, weight loss, liver damage, central nervous system damage, learning and behavioral disorders. Very young children, people with lessened liver or immune function are more susceptible to 
dieldrin toxicity. 


\section{Cancer Effect Assumptions - Dieldrin Skin On Fillets}

\section{Assumptions:}

1) Slope Factor is 16 milligrams Dieldrin per kilogram per day

2) Average Meal Size is 227 grams or $1 / 2$ pound of uncooked fish.

3) Representative Consumer Body weight is 70 kilograms.

4) ARL is $10^{-4}$

5) Five Consumption Rates: Unrestricted 225 meals per year(140 g/day); One meal per week(32g/day); One meal per month(7.4 g/day); Six meals per year(3.7 g/day); No Consumption.

6) Assume meal preparation reduces residues by 50\% from raw skin off (catfish) fish fillets used to determine Dieldrin residue level.

\section{Cancer Effect Assumptions - Dieldrin Skin Off Fillets (Catfish)}

\section{Assumptions:}

1) Slope Factor is 16 milligrams Dieldrin per kilogram per day

2) Average Meal Size is 227 grams or $1 / 2$ pound of uncooked fish.

3) Representative Consumer Body weight is 70 kilograms.

4) ARL is $10^{-4}$

5) Five Consumption Rates: Unrestricted 225 meals per year(140 g/day); One meal per week(32g/day); One meal per month(7.4 g/day); Six meals per year(3.7 g/day); No Consumption.

6) Assume meal preparation reduces residues by $30 \%$ from raw skin off (catfish) fish fillets used to determine Dieldrin residue level. 


\section{Dieldrin Cancer Effect Advisory Groups - Skin On Fillet}

\section{GROUP 1}

Unrestricted Consumption or up to 225 meals per year (140 grams of sportfish per day)

Less than $0.0063 \mathrm{ppm}$ Dieldrin in raw skin on fish fillet

\section{GROUP 2}

Up to 1 meal per week

(32 grams of sportfish per day)

$0.0063 \mathrm{ppm}$ to $0.027 \mathrm{ppm}$ Dieldrin in raw skin on fish fillet

\section{GROUP 3}

Up to 1 meal per month

(7.4 grams of sportfish per day)

$0.027 \mathrm{ppm}$ to $0.12 \mathrm{ppm}$ Dieldrin in raw skin on fish fillet

\section{GROUP 4}

Up to 6 meals per year

(3.7 grams of sportfish per day)

$0.12 \mathrm{ppm}$ to $0.24 \mathrm{ppm}$ Dieldrin in raw skin on fish fillet

\section{GROUP 5 \\ DO NOT EAT}

Greater than $0.24 \mathrm{ppm}$ Dieldrin in raw skin on fish fillet 


\section{Dieldrin Cancer Effect Advisory Groups - Skin Off Fillets}

\section{GROUP 1}

Unrestricted Consumption or up to 225 meals per year

(140 grams of sportfish per day)

Less than 0.0045 ppm Dieldrin in raw skin off (catfish) fish fillet

\section{GROUP 2}

Up to 1 meal per week

(32 grams of sportfish per day)

$0.0045 \mathrm{ppm}$ to $0.020 \mathrm{ppm}$ Dieldrin in raw skin off (catfish) fish fillet

\section{GROUP 3}

Up to 1 meal per month

(7.4 grams of sportfish per day)

$0.020 \mathrm{ppm}$ to $0.084 \mathrm{ppm}$ Dieldrin in raw skin off (catfish) fish fillet

\section{GROUP 4}

Up to 6 meals per year

(3.7 grams of sportfish per day)

$0.084 \mathrm{ppm}$ to $0.17 \mathrm{ppm}$ Dieldrin in raw skin off (catfish) fish fillet

\section{GROUP 5}

DO NOT EAT

Greater than 0.17 ppm Dieldrin in raw skin off (catfish) fish fillet 


\section{Adult Advisory Assumptions - Dieldrin Skin On Fillets}

\section{Assumptions:}

1) Reference Dose is 0.05 micrograms Dieldrin per kilogram per day

2) Average Meal Size is 227 grams or $1 / 2$ pound of uncooked fish.

3) Representative Consumer Body weight is 70 kilograms.

4) Five Advisory Groups: Unrestricted or 225 meals per year; One meal per week; One meal per month; Six meals per year; No Consumption.

5) Assume meal preparation reduces residues by 50\% from raw skin on fish fillets used to determine Dieldrin residue level.

\section{Maximum Allowable Daily Dieldrin Ingestion Calculation}

0.05 micrograms per kilogram per day X 70 kilogram body weight $=3.5$ micrograms Dieldrin allowed per day.

\section{Adult Advisory Assumptions - Dieldrin Skin Off Fillets}

\section{Assumptions:}

1) Reference Dose is 0.05 micrograms Dieldrin per kilogram per day

2) Average Meal Size is 227 grams or $1 / 2$ pound of uncooked fish.

3) Representative Consumer Body weight is 70 kilograms.

4) Five Advisory Groups: Unrestricted or 225 meals per year; One meal per week; One meal per month; Six meals per year; No Consumption.

5) Assume meal preparation reduces residues by 30\% from raw skin off (catfish) fish fillets used to determine Dieldrin residue level.

\section{Maximum Allowable Daily Dieldrin Ingestion Calculation}

0.05 micrograms per kilogram per day X 70 kilogram body weight $=3.5$ micrograms Dieldrin allowed per day 


\section{Dieldrin Adult Advisory Groups - Skin On Fillet}

\section{GROUP 1}

Unrestricted Consumption or up to 225 meals per year (140 grams of sportfish per day)

3.5 micrograms per day Dieldrin / 140 grams of fish per day / .5 preparation reduction

Less than $0.05 \mathrm{ppm}$ Dieldrin in raw skin on fish fillet

\section{GROUP 2}

Up to 1 meal per week

(32 grams of sportfish per day)

3.5 micrograms per day Dieldrin / 32 grams of fish per day / .5 preparation reduction

$0.05 \mathrm{ppm}$ to $0.22 \mathrm{ppm}$ Dieldrin in raw skin on fish fillet

\section{GROUP 3}

Up to 1 meal per month

(7.4 grams of sportfish per day)

3.5 micrograms per day Dieldrin / 7.4 grams of fish per day /.5 preparation reduction

$0.22 \mathrm{ppm}$ to $0.95 \mathrm{ppm}$ Dieldrin in raw skin on fish fillet

\section{GROUP 4}

Up to 6 meals per year

(3.7 grams of sportfish per day)

3.5 micrograms per day Dieldrin / 3.7 grams of fish per day /.5 preparation reduction

$0.95 \mathrm{ppm}$ to $1.89 \mathrm{ppm}$ Dieldrin in raw skin on fish fillet

\section{GROUP 5}

DO NOT EAT

Greater than 1.89 ppm Dieldrin in raw skin on fish fillet 


\section{Dieldrin Adult Advisory Groups - Skin Off Fillets}

\section{GROUP 1}

Unrestricted Consumption or up to 225 meals per year (140 grams of sportfish per day)

3.5 micrograms per day Dieldrin / 140 grams of fish per day / .7 preparation reduction

Less than $0.036 \mathrm{ppm}$ Dieldrin in raw skin off (catfish) fish fillet

\section{GROUP 2}

Up to 1 meal per week (32 grams of sportfish per day)

3.5 micrograms per day Dieldrin / 32 grams of fish per day / .7 preparation reduction $0.036 \mathrm{ppm}$ to $0.16 \mathrm{ppm}$ Dieldrin in raw skin off (catfish) fish fillet

\section{GROUP 3}

Up to 1 meal per month

(7.4 grams of sportfish per day)

3.5 micrograms per day Dieldrin / 7.4 grams of fish per day /.7 preparation reduction

$0.16 \mathrm{ppm}$ to $0.68 \mathrm{ppm}$ Dieldrin in raw skin off (catfish) fish fillet

\section{GROUP 4}

Up to 6 meals per year (3.7 grams of sportfish per day)

3.5 micrograms per day Dieldrin / 3.7 grams of fish per day /.7 preparation reduction

$0.68 \mathrm{ppm}$ to $1.35 \mathrm{ppm}$ Dieldrin in raw skin off (catfish) fish fillet

\section{GROUP 5}

DO NOT EAT

Greater than 1.89 ppm Dieldrin in raw skin off (catfish) fish fillet 


\section{Children Advisory Assumptions - Dieldrin Skin On Fillets}

\section{Assumptions:}

1) Reference Dose is 0.05 micrograms Dieldrin per kilogram per day

2) Average Meal Size is 52.5 grams or 3 ounces of uncooked fish.

3) Representative Consumer Body weight is 14.5 kilograms.

4) Five Advisory Groups: Unrestricted or 225 meals per year; One meal per week; One meal per month; Six meals per year; No Consumption.

5) Assume meal preparation reduces residues by 50\% from raw skin on fish fillets used to determine Dieldrin residue level.

\section{Maximum Allowable Daily Dieldrin Ingestion Calculation}

0.05 micrograms per kilogram per day X 14.5 kilogram body weight $=0.725$ micrograms Dieldrin allowed per day.

\section{Children Advisory Assumptions - Dieldrin Skin Off Fillets}

\section{Assumptions:}

1) Reference Dose is 0.05 micrograms Dieldrin per kilogram per day

2) Average Meal Size is 52.5 grams or 3 ounces of uncooked fish.

3) Representative Consumer Body weight is 14.5 kilograms.

4) Five Advisory Groups: Unrestricted or 225 meals per year; One meal per week; One meal per month; Six meals per year; No Consumption.

5) Assume meal preparation reduces residues by 30\% from raw skin off (catfish) fish fillets used to determine Dieldrin residue level.

\section{Maximum Allowable Daily Dieldrin Ingestion Calculation}

0.05 micrograms per kilogram per day X 14.5 kilogram body weight $=0.725$ micrograms

Dieldrin allowed per day. 


\section{Dieldrin Child Advisory Groups - Skin On Fillet}

\section{GROUP 1}

Unrestricted Consumption or up to 225 meals per year (52.5 grams of sportfish per day)

0.725 micrograms per day Dieldrin / 52.5 grams of fish per day / .5 preparation reduction

Less than $0.028 \mathrm{ppm}$ Dieldrin in raw skin on fish fillet

\section{GROUP 2}

Up to 1 meal per week

(12.13 grams of sportfish per day)

0.725 micrograms per day Dieldrin / 12.13 grams of fish per day / .5 preparation reduction

$0.028 \mathrm{ppm}$ to $0.120 \mathrm{ppm}$ Dieldrin in raw skin on fish fillet

\section{GROUP 3}

Up to 1 meal per month

(2.8 grams of sportfish per day)

0.725 micrograms per day Dieldrin / 2.8 grams of fish per day /.5 preparation reduction

$0.120 \mathrm{ppm}$ to $0.52 \mathrm{ppm}$ Dieldrin in raw skin on fish fillet

\section{GROUP 4}

Up to 6 meals per year

(1.4 grams of sportfish per day)

0.725 micrograms per day Dieldrin / 1.4 grams of fish per day /.5 preparation reduction

$0.52 \mathrm{ppm}$ to $1.036 \mathrm{ppm}$ Dieldrin in raw skin on fish fillet

\section{GROUP 5}

DO NOT EAT

Greater than $1.036 \mathrm{ppm}$ Dieldrin in raw skin on fish fillet 


\section{Dieldrin Child Advisory Groups - Skin Off Fillets}

\section{GROUP 1}

Unrestricted Consumption or up to 225 meals per year

(52.5 grams of sportfish per day)

0.725 micrograms per day Dieldrin / 52.5 grams of fish per day / .7 preparation reduction

Less than $0.020 \mathrm{ppm}$ Dieldrin in raw skin off (catfish) fish fillet

\section{GROUP 2}

Up to 1 meal per week

(12.13 grams of sportfish per day)

0.725 micrograms per day Dieldrin / 12.13 grams of fish per day / .7 preparation reduction

$0.020 \mathrm{ppm}$ to $0.085 \mathrm{ppm}$ Dieldrin in raw skin off (catfish) fish fillet

\section{GROUP 3}

Up to 1 meal per month

(2.8 grams of sportfish per day)

0.725 micrograms per day Dieldrin / 2.8 grams of fish per day /.7 preparation reduction

$0.085 \mathrm{ppm}$ to $0.37 \mathrm{ppm}$ Dieldrin in raw skin off (catfish) fish fillet

\section{GROUP 4}

Up to 6 meals per year (1.4 grams of sportfish per day)

0.725 micrograms per day Dieldrin / 1.4 grams of fish per day /.7 preparation reduction

$0.37 \mathrm{ppm}$ to $0.74 \mathrm{ppm}$ Dieldrin in raw skin off (catfish) fish fillet

\section{GROUP 5}

DO NOT EAT

Greater than $0.74 \mathrm{ppm}$ Dieldrin in raw skin off (catfish) fish fillet 


\section{Dioxin Summary}

Merck Number 9252

CAS Number 1746-01-6

MRL .000000001 mg/kg/day *

Dose Reduction Factor .5 Skin On, .7 Skin Off

Dioxin is a white crystalline solid. It is one of the most toxic manmade compounds

produced. It is persistent in the environment and bioconcentrates in the aquatic environment.

Dioxin is not commercially used or produced in the United States. It is a byproduct of

chlorinated herbicide production, paper bleaching, fossil fuel combustion and reactions in flyash

and products of combustion. Atmospheric transport can be a major source in the environment.

The Viet Nam War raised concerns about the toxicity of dioxin. Agent Orange, a herbicide

contaminated with up to 60,000 ppb dioxin, was extensively used to defoliate Viet Nam's

jungles. Soldiers and civilians exposed to Agent Orange became sick. Other environmental

releases causing illness have been documented such as Seveso, Italy and Times Beach, Missouri.

Dioxin is still under review by the U.S. EPA. Acute doses of dioxin can cause chloracne, liver damage, weight loss, degeneration of the thymus, suppression of the immune system, head aches, dizziness, digestive problems and generalized pain. Chronic exposure to dioxin can lead to reduced fertility, increase in stillbirth and birth defects including cleft palate, cystic kidney, and spinal deformities in animal studies. Dioxin is considered a carcinogen causing sarcomas in humans, and various cancers in animals.

Due to the analytical capabilities and extremely low screening values, where there is credible evidence of dioxin contamination, levels will be assumed at one half of minimum detection limits.

* Chronic MRL from Toxicological Profile for Chlorinated Dibenzo-p-Dioxins - Draft for Public Comment. 


\section{Cancer Effect Assumptions - Dioxin Skin On Fillets}

\section{Assumptions:}

1) Slope Factor is 157000 milligrams Dioxin per kilogram per day

2) Average Meal Size is 227 grams or $1 / 2$ pound of uncooked fish.

3) Representative Consumer Body weight is 70 kilograms.

4) ARL is $10^{-4}$

5) Five Consumption Rates: Unrestricted 225 meals per year(140 g/day); One meal per week(32g/day); One meal per month(7.4 g/day); Six meals per year(3.7 g/day); No Consumption.

6) Assume meal preparation reduces residues by 50\% from raw skin off (catfish) fish fillets used to determine Dioxin residue level.

\section{Cancer Effect Assumptions - Dioxin Skin Off Fillets (Catfish)}

\section{Assumptions:}

1) Slope Factor is 157000 milligrams Dioxin per kilogram per day

2) Average Meal Size is 227 grams or $1 / 2$ pound of uncooked fish.

3) Representative Consumer Body weight is 70 kilograms.

4) ARL is $10^{-4}$

5) Five Consumption Rates: Unrestricted 225 meals per year(140 g/day); One meal per week(32g/day); One meal per month(7.4 g/day); Six meals per year(3.7 g/day); No Consumption.

6) Assume meal preparation reduces residues by $30 \%$ from raw skin off (catfish) fish fillets used to determine Dioxin residue level. 


\section{Dioxin Cancer Effect Advisory Groups - Skin On Fillet}

\section{GROUP 1}

Unrestricted Consumption or up to 225 meals per year

(140 grams of sportfish per day)

Less than $0.00000064 \mathrm{ppm}$ Dioxin in raw skin on fish fillet

\section{GROUP 2}

Up to 1 meal per week

(32 grams of sportfish per day)

$0.00000064 \mathrm{ppm}$ to $0.0000028 \mathrm{ppm}$ Dioxin in raw skin on fish fillet

\section{GROUP 3}

Up to 1 meal per month

(7.4 grams of sportfish per day)

$0.0000028 \mathrm{ppm}$ to $0.000012 \mathrm{ppm}$ Dioxin in raw skin on fish fillet

\section{GROUP 4}

Up to 6 meals per year

(3.7 grams of sportfish per day)

$0.000012 \mathrm{ppm}$ to $0.000024 \mathrm{ppm}$ Dioxin in raw skin on fish fillet

\section{GROUP 5}

DO NOT EAT

Greater than 0.000024 ppm Dioxin in raw skin on fish fillet 


\section{Dioxin Cancer Effect Advisory Groups - Skin Off Fillets}

\section{GROUP 1}

Unrestricted Consumption or up to 225 meals per year

(140 grams of sportfish per day)

Less than 0.00000045 ppm Dioxin in raw skin off (catfish) fish fillet

\section{GROUP 2}

Up to 1 meal per week

(32 grams of sportfish per day)

$0.00000045 \mathrm{ppm}$ to $0.000002 \mathrm{ppm}$ Dioxin in raw skin off (catfish) fish fillet

\section{GROUP 3}

Up to 1 meal per month

(7.4 grams of sportfish per day)

$0.000002 \mathrm{ppm}$ to $0.0000086 \mathrm{ppm}$ Dioxin in raw skin off (catfish) fish fillet

\section{GROUP 4}

Up to 6 meals per year

(3.7 grams of sportfish per day)

$0.0000086 \mathrm{ppm}$ to $0.000017 \mathrm{ppm}$ Dioxin in raw skin off (catfish) fish fillet

\section{GROUP 5}

DO NOT EAT

Greater than $0.000017 \mathrm{ppm}$ Dioxin in raw skin off (catfish) fish fillet 


\section{Adult Advisory Assumptions - Dioxin Skin On Fillets}

\section{Assumptions:}

1)Minimal Risk Level is 0.000001 micrograms Dioxin per kilogram per day

2) Average Meal Size is 227 grams or $1 / 2$ pound of uncooked fish.

3) Representative Consumer Body weight is 70 kilograms.

4) Five Advisory Groups: Unrestricted or 225 meals per year; One meal per week; One meal per month; Six meals per year; No Consumption.

5) Assume meal preparation reduces residues by 50\% from raw skin on fish fillets used to determine Dioxin residue level.

\section{Maximum Allowable Daily Dioxin Ingestion Calculation}

0.000001 micrograms per kilogram per day X 70 kilogram body weight $=0.00007$ micrograms Dioxin allowed per day.

\section{Adult Advisory Assumptions - Dioxin Skin Off Fillets}

\section{Assumptions:}

1)Minimal Risk Level is 0.000001 micrograms Dioxin per kilogram per day

2) Average Meal Size is 227 grams or $1 / 2$ pound of uncooked fish.

3) Representative Consumer Body weight is 70 kilograms.

4) Five Advisory Groups: Unrestricted or 225 meals per year; One meal per week; One meal per month; Six meals per year; No Consumption.

5) Assume meal preparation reduces residues by $30 \%$ from raw skin on fish fillets used to determine Dioxin residue level.

\section{Maximum Allowable Daily Dioxin Ingestion Calculation}

0.000001 micrograms per kilogram per day X 70 kilogram body weight $=0.00007$ micrograms

Dioxin allowed per day. 


\section{Dioxin Adult Advisory Groups - Skin On Fillet}

\section{GROUP 1}

Unrestricted Consumption or up to 225 meals per year (140 grams of sportfish per day)

0.00007 micrograms per day Dioxin / 140 grams of fish per day / .5 preparation reduction

Less than $0.000001 \mathrm{ppm}$ Dioxin in raw skin on fish fillet

\section{GROUP 2}

Up to 1 meal per week

(32 grams of sportfish per day)

0.00007 micrograms per day Dioxin / 32 grams of fish per day / .5 preparation reduction

$0.000001 \mathrm{ppm}$ to $.00000438 \mathrm{ppm}$ Dioxin in raw skin on fish fillet

\section{GROUP 3}

Up to 1 meal per month

(7.4 grams of sportfish per day)

0.00007 micrograms per day Dioxin / 7.4 grams of fish per day / .5 preparation reduction $.00000438 \mathrm{ppm}$ to $0.0000189 \mathrm{ppm}$ Dioxin in raw skin on fish fillet

\section{GROUP 4}

Up to 6 meals per year (3.7 grams of sportfish per day)

0.00007 micrograms per day Dioxin / 3.7 grams of fish per day / .5 preparation reduction $0.0000189 \mathrm{ppm}$ to $0.0000378 \mathrm{ppm}$ Dioxin in raw skin on fish fillet

\section{GROUP 5}

DO NOT EAT

Greater than 0.0000378 ppm Dioxin in raw skin on fish fillet 


\section{Dioxin Adult Advisory Groups - Skin Off Fillet}

\section{GROUP 1}

Unrestricted Consumption or up to 225 meals per year (140 grams of sportfish per day)

0.00007 micrograms per day Dioxin / 140 grams of fish per day / .7 preparation reduction Less than $0.000000714 \mathrm{ppm}$ Dioxin in raw skin on fish fillet

\section{GROUP 2}

Up to 1 meal per week

(32 grams of sportfish per day)

0.00007 micrograms per day Dioxin / 32 grams of fish per day / .7 preparation reduction

$0.000000714 \mathrm{ppm}$ to $0.00000313 \mathrm{ppm}$ Dioxin in raw skin on fish fillet

\section{GROUP 3}

Up to 1 meal per month

(7.4 grams of sportfish per day)

0.00007 micrograms per day Dioxin / 7.4 grams of fish per day / .7 preparation reduction $0.00000313 \mathrm{ppm}$ to $0.0000135 \mathrm{ppm}$ Dioxin in raw skin on fish fillet

\section{GROUP 4}

Up to 6 meals per year (3.7 grams of sportfish per day)

0.00007 micrograms per day Dioxin / 3.7 grams of fish per day / .7 preparation reduction $0.0000135 \mathrm{ppm}$ to $0.000027 \mathrm{ppm}$ Dioxin in raw skin on fish fillet

\section{GROUP 5}

DO NOT EAT

Greater than $0.000027 \mathrm{ppm}$ Dioxin in raw skin on fish fillet 


\section{Children Advisory Assumptions - Dioxin Skin On Fillets}

\section{Assumptions:}

1)Minimal Risk Level is 0.000001 micrograms Dioxin per kilogram per day

2) Average Meal Size is 52.5 grams or 3 ounces of uncooked fish.

3) Representative Consumer Body weight is 14.5 kilograms.

4) Five Advisory Groups: Unrestricted or 225 meals per year; One meal per week; One meal per month; Six meals per year; No Consumption.

5) Assume meal preparation reduces residues by 50\% from raw skin on fish fillets used to determine Dioxin residue level.

\section{Maximum Allowable Daily Dioxin Ingestion Calculation}

0.000001 micrograms per kilogram per day X 14.5 kilogram body weight $=0.0000145$ micrograms Dioxin allowed per day.

\section{Children Advisory Assumptions - Dioxin Skin Off Fillets}

\section{Assumptions:}

1)Minimal Risk Level is 0.000001 micrograms Dioxin per kilogram per day

2) Average Meal Size is 52.5 grams or 3 ounces of uncooked fish.

3) Representative Consumer Body weight is 14.5 kilograms.

4) Five Advisory Groups: Unrestricted or 225 meals per year; One meal per week; One meal per month; Six meals per year; No Consumption.

5) Assume meal preparation reduces residues by $30 \%$ from raw skin on fish fillets used to determine Dioxin residue level.

\section{Maximum Allowable Daily Dioxin Ingestion Calculation}

0.000001 micrograms per kilogram per day X 14.5 kilogram body weight $=0.0000145$ micrograms Dioxin allowed per day. 


\section{Dioxin Child Advisory Groups - Skin On Fillet}

\section{GROUP 1}

Unrestricted Consumption or up to 225 meals per year

(52.5 grams of sportfish per day)

0.0000145 micrograms per day Dioxin / 52.5 grams of fish per day / .5 preparation reduction

Less than $0.000000552 \mathrm{ppm}$ Dioxin in raw skin on fish fillet

\section{GROUP 2}

Up to 1 meal per week

(12.13 grams of sportfish per day)

0.0000145 micrograms per day Dioxin / 12.13 grams of fish per day / .5 preparation reduction

$0.000000552 \mathrm{ppm}$ to $0.00000239 \mathrm{ppm}$ Dioxin in raw skin on fish fillet

\section{GROUP 3}

Up to 1 meal per month

(2.8 grams of sportfish per day)

0.0000145 micrograms per day Dioxin / 2.8 grams of fish per day / .5 preparation reduction

$0.00000239 \mathrm{ppm}$ to $0.0000104 \mathrm{ppm}$ Dioxin in raw skin on fish fillet

\section{GROUP 4}

Up to 6 meals per year

(1.4 grams of sportfish per day)

0.0000145 micrograms per day Dioxin / 1.4 grams of fish per day / .5 preparation reduction

$0.0000104 \mathrm{ppm}$ to $0.0000207 \mathrm{ppm}$ Dioxin in raw skin on fish fillet

\section{GROUP 5}

DO NOT EAT

Greater than $0.0000207 \mathrm{ppm}$ Dioxin in raw skin on fish fillet 


\section{Dioxin Child Advisory Groups - Skin Off Fillet}

\section{GROUP 1}

Unrestricted Consumption or up to 225 meals per year

(52.5 grams of sportfish per day)

0.0000145 micrograms per day Dioxin / 52.5 grams of fish per day / .7preparation reduction

Less than $0.000000395 \mathrm{ppm}$ Dioxin in raw skin on fish fillet

\section{GROUP 2}

Up to 1 meal per week

(12.13 grams of sportfish per day)

0.0000145 micrograms per day Dioxin / 12.13 grams of fish per day / .7preparation reduction

$0.000000395 \mathrm{ppm}$ to $0.00000171 \mathrm{ppm}$ Dioxin in raw skin on fish fillet

\section{GROUP 3}

Up to 1 meal per month

(2.8 grams of sportfish per day)

0.0000145 micrograms per day Dioxin / 2.8 grams of fish per day / .7preparation reduction

$0.00000171 \mathrm{ppm}$ to $0.0000074 \mathrm{ppm}$ Dioxin in raw skin on fish fillet

\section{GROUP 4}

Up to 6 meals per year

(1.4 grams of sportfish per day)

0.0000145 micrograms per day Dioxin / 1.4 grams of fish per day / .7preparation reduction

$0.0000074 \mathrm{ppm}$ to $0.0000148 \mathrm{ppm}$ Dioxin in raw skin on fish fillet

\section{GROUP 5}

DO NOT EAT

Greater than $0.0000148 \mathrm{ppm}$ Dioxin in raw skin on fish fillet 


\section{Disulfoton Summary}

Merck Number 3429

CAS Number 289-04-4

Oral RfD $0.00004 \mathrm{mg} / \mathrm{kg} / \mathrm{day}$

Preparation Dose Reduction 1

Disulfoton is an organophosphate systemic insecticide and acaracide. It is very effective on sucking insects, leafhoppers, thrips, spider mites, and leaf miners. It is approved for use on cotton, tobacco, corn, grains and root crops. Products with more than $2 \%$ disulfoton are restricted use pesticides, and may be purchased and used only by certified pesticide applicators.

Incomplete skull and sternum ossification were found in a rat teratogenic experiment. Developmental studies showed underdeveloped testes, kidney disease and damaged liver. Reduced litter size, survival, and birth weights were found in another rat study. Disulfoton is readily absorbed through the digestive tract, respiratory system and skin in mammals. Chronic exposure of rats to disulfoton was linked with cholinesterase inhibition and optic nerve deterioration. Brain, kidney, liver, pituitary, seminal vesicle, and spleen damage due to long term exposure has also been reported. Human occupational exposures have caused flu-like symptoms, memory loss, delayed reaction times, irritability, anxiety, and sluggish thinking. No evidence of carcinogenic effects has been found. Rat and mice studies of disulfoton did not produce significant tumor growth. The U.S. Environmental Protection Agency has not determined carcinogenicity of disulfoton due to lack of data. 


\section{Adult Advisory Assumptions - Disulfoton}

\section{Assumptions:}

1) Reference Dose is 0.04 micrograms Disulfoton per kilogram per day

2) Average Meal Size is 227 grams or $1 / 2$ pound of uncooked fish.

3) Representative Consumer Body weight is 70 kilograms.

4) Five Advisory Groups: Unrestricted or 225 meals per year; One meal per week; One meal per month; Six meals per year; No Consumption.

5) Assume meal preparation does not reduce residues from raw fish fillets used to determine

Disulfoton residue level.

\section{Maximum Allowable Daily Disulfoton Ingestion Calculation}

0.04 micrograms per kilogram per day X 70 kilogram body weight $=2.8$ micrograms Disulfoton allowed per day. 


\section{Disulfoton Adult Advisory Groups}

\section{GROUP 1}

Unrestricted Consumption or up to 225 meals per year (140 grams of sportfish per day)

2.8 micrograms per day Disulfoton / 140 grams of fish per day

Less than $0.02 \mathrm{ppm}$ Disulfoton in raw skin on fish fillet

\section{GROUP 2}

Up to 1 meal per week

(32 grams of sportfish per day)

2.8 micrograms per day Disulfoton / 32 grams of fish per day

$0.02 \mathrm{ppm}$ to $0.09 \mathrm{ppm}$ Disulfoton in raw skin on fish fillet

\section{GROUP 3}

Up to 1 meal per month

(7.4 grams of sportfish per day)

2.8 micrograms per day Disulfoton / 7.4 grams of fish per day

$0.09 \mathrm{ppm}$ to $0.38 \mathrm{ppm}$ Disulfoton in raw skin on fish fillet

\section{GROUP 4}

Up to 6 meals per year (3.7 grams of sportfish per day)

2.8 micrograms per day Disulfoton / 3.7 grams of fish per day

$0.38 \mathrm{ppm}$ to $0.76 \mathrm{ppm}$ Disulfoton in raw skin on fish fillet

\section{GROUP 5}

DO NOT EAT

Greater than 0.76 ppm Disulfoton in raw skin on fish fillet 


\section{Children Advisory Assumptions - Disulfoton}

\section{Assumptions:}

1) Reference Dose is 0.04 micrograms Disulfoton per kilogram per day

2) Average Meal Size is 52.5 grams or 3 ounces of uncooked fish.

3) Representative Consumer Body weight is 14.5 kilograms.

4) Five Advisory Groups: Unrestricted or 225 meals per year; One meal per week; One meal per month; Six meals per year; No Consumption.

5) Assume meal preparation does not reduce residues from raw fish fillets used to determine

Disulfoton residue level.

Maximum Allowable Daily Disulfoton Ingestion Calculation

0.04 micrograms per kilogram per day X 14.5 kilogram body weight $=0.58$ micrograms

Disulfoton allowed per day. 


\section{Disulfoton Child Advisory Groups}

\section{GROUP 1}

Unrestricted Consumption or up to 225 meals per year (52.5 grams of sportfish per day)

0.58 micrograms per day Disulfoton / 52.5 grams of fish per day

Less than $0.011 \mathrm{ppm}$ Disulfoton in raw skin on fish fillet

\section{GROUP 2}

Up to 1 meal per week

(12.13 grams of sportfish per day)

0.58 micrograms per day Disulfoton / 12.13 grams of fish per day

0.011 to $0.048 \mathrm{ppm}$ Disulfoton in raw skin on fish fillet

\section{GROUP 3}

Up to 1 meal per month

(2.8 grams of sportfish per day)

0.58 micrograms per day Disulfoton / 2.8 grams of fish per day

$0.048 \mathrm{ppm}$ to $0.21 \mathrm{ppm}$ Disulfoton in raw skin on fish fillet

\section{GROUP 4}

Up to 6 meals per year (1.4 grams of sportfish per day)

0.58 micrograms per day Disulfoton / 1.4 grams of fish per day

$0.21 \mathrm{ppm}$ to $0.41 \mathrm{ppm}$ Disulfoton in raw skin on fish fillet

\section{GROUP 5}

DO NOT EAT

Greater than $0.41 \mathrm{ppm}$ Disulfoton in raw skin on fish fillet 


\section{Endosulfan Summary}

Merck Number 3614

CAS Number 115-29-7

Oral RfD $0.006 \mathrm{mg} / \mathrm{kg} / \mathrm{day}$

Preparation Dose Reduction 1

Endosulfan is an organochlorine contact insecticide used on a assortment of mites and insects. It has also been used as a wood preservative. Endosulfan is used to treat grains, fruits, tea and vegetables. It is a mixture of alpha and beta isomers, and comes in a brown crystal form with a sulfur odor. Endosulfan has been found in surface waters and air nationwide. Residues have been found in several foods including fruits, milk, seafood and vegetables.

Mutagenic evaluations have had conflicting results with many positive and negative results. Endosulfan is mutagenic to bacteria and yeast. Some mammalian experiments including mice have shown chromosome abnormalities and mutated genes. Rat teratogenicity studies produced numerous effects such as webbed limbs, clubbed limbs, hypoplastic aorta, edema, curvature of the spine, decreased weight size. The U.S. Environmental Protection Agency has not classified the carcinogenicity of endosulfan because inadequate evidence. Carcinogenicity research has resulted in varied findings with some studies showing increased tumor rates. Endosulfan imitates estrogen and has shown to have effects on human breast cancer cells. Endosulfan is also thought to interfere with the endocrine system because of its estrogen like actions. Chronic exposure can effect the kidney, liver, testes, parathyroid gland, lungs and cause blood vessel aneurysm and behavioral changes. 


\section{Adult Advisory Assumptions - Endosulfan}

\section{Assumptions:}

1) Reference Dose is 6 micrograms Endosulfan per kilogram per day

2) Average Meal Size is 227 grams or $1 / 2$ pound of uncooked fish.

3) Representative Consumer Body weight is 70 kilograms.

4) Five Advisory Groups: Unrestricted or 225 meals per year; One meal per week; One meal per month; Six meals per year; No Consumption.

5) Assume meal preparation does not reduce residues by $50 \%$ from raw skin on fish fillets used to determine Endosulfan residue level.

\section{Maximum Allowable Daily Endosulfan Ingestion Calculation}

6 micrograms per kilogram per day X 70 kilogram body weight $=420$ micrograms Endosulfan allowed per day. 


\section{Endosulfan Adult Advisory Groups}

\section{GROUP 1}

Unrestricted Consumption or up to 225 meals per year (140 grams of sportfish per day)

420 micrograms per day Endosulfan / 140 grams of fish per day

Less than $3.0 \mathrm{ppm}$ Endosulfan in raw skin on fish fillet

\section{GROUP 2}

Up to 1 meal per week

(32 grams of sportfish per day)

420 micrograms per day Endosulfan / 32 grams of fish per day

$3.0 \mathrm{ppm}$ to $13.13 \mathrm{ppm}$ Endosulfan in raw skin on fish fillet

\section{GROUP 3}

Up to 1 meal per month

(7.4 grams of sportfish per day)

420 micrograms per day Endosulfan / 7.4 grams of fish per day

$13.13 \mathrm{ppm}$ to $56.76 \mathrm{ppm}$ Endosulfan in raw skin on fish fillet

\section{GROUP 4}

Up to 6 meals per year (3.7 grams of sportfish per day)

420 micrograms per day Endosulfan / 3.7 grams of fish per day

$56.76 \mathrm{ppm}$ to $113.51 \mathrm{ppm}$ Endosulfan in raw skin on fish fillet

\section{GROUP 5}

DO NOT EAT

Greater than $113.51 \mathrm{ppm}$ Endosulfan in raw skin on fish fillet 


\section{Child Advisory Assumptions - Endosulfan}

\section{Assumptions:}

1) Reference Dose is 6 micrograms Endosulfan per kilogram per day

2) Average Meal Size is 52.5 grams or 3 ounces of uncooked fish.

3) Representative Consumer Body weight is 14.5 kilograms.

4) Five Advisory Groups: Unrestricted or 225 meals per year; One meal per week; One meal per month; Six meals per year; No Consumption.

5) Assume meal preparation does not reduce residues by $50 \%$ from raw skin on fish fillets used to determine Endosulfan residue level.

\section{Maximum Allowable Daily Endosulfan Ingestion Calculation}

6 micrograms per kilogram per day X 14.5 kilogram body weight $=87$ micrograms Endosulfan allowed per day. 


\section{Endosulfan Child Advisory Groups}

\section{GROUP 1}

Unrestricted Consumption or up to 225 meals per year (52.5 grams of sportfish per day)

87 micrograms per day Endosulfan / 52.5 grams of fish per day

Less than 1.66 ppm Endosulfan in raw skin on fish fillet

\section{GROUP 2}

Up to 1 meal per week

(12.13 grams of sportfish per day)

87 micrograms per day Endosulfan / 12.13 grams of fish per day

$1.66 \mathrm{ppm}$ to $7.17 \mathrm{ppm}$ Endosulfan in raw skin on fish fillet

\section{GROUP 3}

Up to 1 meal per month

(2.8 grams of sportfish per day)

87 micrograms per day Endosulfan / 2.8 grams of fish per day

$7.17 \mathrm{ppm}$ to $31.07 \mathrm{ppm}$ Endosulfan in raw skin on fish fillet

\section{GROUP 4}

Up to 6 meals per year (1.4 grams of sportfish per day)

87 micrograms per day Endosulfan / 1.4 grams of fish per day

$31.07 \mathrm{ppm}$ to $62.14 \mathrm{ppm}$ Endosulfan in raw skin on fish fillet

\section{GROUP 5}

DO NOT EAT

Greater than 62.14 ppm Endosulfan in raw skin on fish fillet 


\section{Endrin Summary}

Merck Number 3618

CAS Number 72-20-8

Oral RfD $0.0003 \mathrm{mg} / \mathrm{kg} / \mathrm{day}$

Preparation Dose Reduction .5 Skin on, .7 Skin Off

Endrin is an organochlorine pesticide used on various agricultural crops and orchards. The registration was canceled in 1986 except for a bird perch toxicant that was canceled in 1991. There is currently no approved use in the United States. Endrin is highly persistent and bioaccumulates in fat and fatty tissues.

There is no evidence of endrin mutagenicity. Prenatal exposure caused structural deformities including fused ribs, webbed feet, cleft palate, behavioral changes, altered learning ability and decrease survival in mice and hamsters. The U.S. Environmental Protection Agency has listed endrin as having inadequate results to classify its carcinogenicity, although trials have shown tumor production in adrenal glands, liver, mammary glands, pituitary gland, and the uterus in different species. Chronic exposure produced liver lesions and convulsions in dogs. 


\section{Adult Advisory Assumptions - Endrin Skin On Fillet}

\section{Assumptions:}

1) Reference Dose is 0.3 micrograms Endrin per kilogram per day

2) Average Meal Size is 227 grams or $1 / 2$ pound of uncooked fish.

3) Representative Consumer Body weight is 70 kilograms.

4) Five Advisory Groups: Unrestricted or 225 meals per year; One meal per week; One meal per month; Six meals per year; No Consumption.

5) Assume meal preparation reduces residues by 50\% from raw skin on fish fillets used to determine Endrin residue level.

\section{Maximum Allowable Daily Endrin Ingestion Calculation}

0.3 micrograms per kilogram per day X 70 kilogram body weight $=21$ micrograms Endrin allowed per day.

\section{Adult Advisory Assumptions - Endrin Skin Off Fillet}

\section{Assumptions:}

1) Reference Dose is 0.3 micrograms Endrin per kilogram per day

2) Average Meal Size is 227 grams or $1 / 2$ pound of uncooked fish.

3) Representative Consumer Body weight is 70 kilograms.

4) Five Advisory Groups: Unrestricted or 225 meals per year; One meal per week; One meal per month; Six meals per year; No Consumption.

5) Assume meal preparation reduces residues by 30\% from raw skin off (catfish) fish fillets used to determine Endrin residue level.

\section{Maximum Allowable Daily Endrin Ingestion Calculation}

0.3 micrograms per kilogram per day X 70 kilogram body weight $=21$ micrograms Endrin allowed per day. 


\section{Endrin Adult Advisory Groups Skin On Fillet}

\section{GROUP 1}

Unrestricted Consumption or up to 225 meals per year (140 grams of sportfish per day)

21 micrograms per day Endrin / 140 grams of fish per day /.5 preparation reduction

Less than $0.3 \mathrm{ppm}$ Endrin in raw skin on fish fillet

\section{GROUP 2}

Up to 1 meal per week (32 grams of sportfish per day)

21 micrograms per day Endrin / 32 grams of fish per day / .5 preparation reduction

$0.3 \mathrm{ppm}$ to $1.31 \mathrm{ppm}$ Endrin in raw skin on fish fillet

\section{GROUP 3}

Up to 1 meal per month

(7.4 grams of sportfish per day)

21 micrograms per day Endrin / 7.4 grams of fish per day / .5 preparation reduction

$1.31 \mathrm{ppm}$ to $5.68 \mathrm{ppm}$ Endrin in raw skin on fish fillet

\section{GROUP 4}

Up to 6 meals per year (3.7 grams of sportfish per day)

21 micrograms per day Endrin / 3.7 grams of fish per day / .5 preparation reduction

$5.68 \mathrm{ppm}$ to $11.35 \mathrm{ppm}$ Endrin in raw skin on fish fillet

\section{GROUP 5}

DO NOT EAT

Greater than 11.35 ppm Endrin in raw skin on fish fillet 


\section{Endrin Adult Advisory Groups Skin Off Fillet}

\section{GROUP 1}

Unrestricted Consumption or up to 225 meals per year (140 grams of sportfish per day)

21 micrograms per day Endrin / 140 grams of fish per day /.7 preparation reduction

Less than $0.21 \mathrm{ppm}$ Endrin in raw skin off (catfish) fish fillet

\section{GROUP 2}

Up to 1 meal per week

(32 grams of sportfish per day)

21 micrograms per day Endrin / 32 grams of fish per day / .7 preparation reduction

$0.21 \mathrm{ppm}$ to $0.94 \mathrm{ppm}$ Endrin in raw skin off (catfish) fish fillet

\section{GROUP 3}

Up to 1 meal per month

(7.4 grams of sportfish per day)

21 micrograms per day Endrin / 7.4 grams of fish per day / .7 preparation reduction

$0.94 \mathrm{ppm}$ to $4.054 \mathrm{ppm}$ Endrin in raw skin off (catfish) fish fillet

\section{GROUP 4}

Up to 6 meals per year (3.7 grams of sportfish per day)

21 micrograms per day Endrin / 3.7 grams of fish per day / .7 preparation reduction

$4.054 \mathrm{ppm}$ to $8.11 \mathrm{ppm}$ Endrin in raw skin off (catfish) fish fillet

\section{GROUP 5}

DO NOT EAT

Greater than 8.11 ppm Endrin in raw skin off (catfish) fish fillet 


\section{Children Advisory Assumptions - Endrin Skin On Fillet}

\section{Assumptions:}

1) Reference Dose is 0.3 micrograms Endrin per kilogram per day

2) Average Meal Size is 52.5 grams or 3 ounces of uncooked fish.

3) Representative Consumer Body weight is 14.5 kilograms.

4) Five Advisory Groups: Unrestricted or 225 meals per year; One meal per week; One meal per month; Six meals per year; No Consumption.

5) Assume meal preparation reduces residues by 50\% from raw skin on fish fillets used to determine Endrin residue level.

\section{Maximum Allowable Daily Endrin Ingestion Calculation}

0.3 micrograms per kilogram per day X 14.5 kilogram body weight $=4.35$ micrograms Endrin allowed per day.

\section{Children Advisory Assumptions - Endrin Skin Off Fillet}

\section{Assumptions:}

1) Reference Dose is 0.3 micrograms Endrin per kilogram per day

2) Average Meal Size is 52.5 grams or 3 ounces of uncooked fish.

3) Representative Consumer Body weight is 14.5 kilograms.

4) Five Advisory Groups: Unrestricted or 225 meals per year; One meal per week; One meal per month; Six meals per year; No Consumption.

5) Assume meal preparation reduces residues by $30 \%$ from raw skin off (catfish) fish fillets used to determine Endrin residue level.

\section{Maximum Allowable Daily Endrin Ingestion Calculation}

0.3 micrograms per kilogram per day X 14.5 kilogram body weight $=4.35$ micrograms Endrin allowed per day. 


\section{Endrin Child Advisory Groups Skin On Fillet}

\section{GROUP 1}

Unrestricted Consumption or up to 225 meals per year (52.5 grams of sportfish per day)

4.35 micrograms per day Endrin / 52.5 grams of fish per day /.5 preparation reduction

Less than $0.17 \mathrm{ppm}$ Endrin in raw skin on fish fillet

\section{GROUP 2}

Up to 1 meal per week

(12.13 grams of sportfish per day)

4.35 micrograms per day Endrin / 12.13 grams of fish per day / .5 preparation reduction

$0.17 \mathrm{ppm}$ to $0.72 \mathrm{ppm}$ Endrin in raw skin on fish fillet

\section{GROUP 3}

Up to 1 meal per month

(2.8 grams of sportfish per day)

4.35 micrograms per day Endrin / 2.8 grams of fish per day / .5 preparation reduction

$0.72 \mathrm{ppm}$ to $3.11 \mathrm{ppm}$ Endrin in raw skin on fish fillet

\section{GROUP 4}

Up to 6 meals per year (1.4 grams of sportfish per day)

4.35 micrograms per day Endrin / 1.4 grams of fish per day / .5 preparation reduction

$3.11 \mathrm{ppm}$ to $6.21 \mathrm{ppm}$ Endrin in raw skin on fish fillet

\section{GROUP 5}

DO NOT EAT

Greater than $6.21 \mathrm{ppm}$ Endrin in raw skin on fish fillet 


\section{Endrin Child Advisory Groups Skin Off Fillet}

\section{GROUP 1}

Unrestricted Consumption or up to 225 meals per year

(52.5 grams of sportfish per day)

4.35 micrograms per day Endrin / 52.5 grams of fish per day /.7 preparation reduction

Less than 0.12 ppm Endrin in raw skin off (catfish) fish fillet

\section{GROUP 2}

Up to 1 meal per week

(12.13 grams of sportfish per day)

4.35 micrograms per day Endrin / 12.13 grams of fish per day / .7 preparation reduction

$0.12 \mathrm{ppm}$ to $0.51 \mathrm{ppm}$ Endrin in raw skin off (catfish) fish fillet

\section{GROUP 3}

Up to 1 meal per month

(2.8 grams of sportfish per day)

4.35 micrograms per day Endrin / 2.8 grams of fish per day / .7 preparation reduction

$0.51 \mathrm{ppm}$ to $2.22 \mathrm{ppm}$ Endrin in raw skin off (catfish) fish fillet

\section{GROUP 4}

Up to 6 meals per year

(1.4 grams of sportfish per day)

4.35 micrograms per day Endrin / 1.4 grams of fish per day / .7 preparation reduction

$2.22 \mathrm{ppm}$ to $4.44 \mathrm{ppm}$ Endrin in raw skin off (catfish) fish fillet

\section{GROUP 5}

DO NOT EAT

Greater than $4.44 \mathrm{ppm}$ Endrin in raw skin off (catfish) fish fillet 


\section{Ethion Summary}

Merck Number 3782

CAS Number 563-12-2

Oral RfD $0.0005 \mathrm{mg} / \mathrm{kg} / \mathrm{day}$

Preparation Dose Reduction 1

Ethion is an organophosphate pesticide used to control aphids, leaf feeding larvae, leafhoppers, maggots, mites, scales and thrips. It is used primarily on citrus crops but has minor uses on cattle, lawns, ornamental crops, and turf. It is available in concentrates, dusts, granular, solutions, and wettable powders. Ethion is a light brown to amber colored liquid.

Several studies show no evidence indicating ethion is mutagenic. Teratogenic studies of ethion in rats found elevated frequency of slowed ossification of pubic bones. In a similar study with rabbits there was increased occurrence of fused sternal bones. Studies with mice and rats produced no evidence ethion is carcinogenic. The U.S. Environmental Protection Agency has not determined its carcinogenic status due to inadequate information. Chronic exposure studies of dogs, human males, rats showed inhibition of cholinesterase. Occupational exposures have

produced concentration and memory damage, depression, disorientation, flu-like symptoms, and irritability. 


\section{Adult Advisory Assumptions - Ethion}

\section{Assumptions:}

1) Reference Dose is 0.5 micrograms Ethion per kilogram per day

2) Average Meal Size is 227 grams or $1 / 2$ pound of uncooked fish.

3) Representative Consumer Body weight is 70 kilograms.

4) Five Advisory Groups: Unrestricted or 225 meals per year; One meal per week; One meal per month; Six meals per year; No Consumption.

5) Assume meal preparation does not reduce residues by $50 \%$ from raw skin on fish fillets used to determine Ethion residue level.

\section{Maximum Allowable Daily Ethion Ingestion Calculation}

0.5 micrograms per kilogram per day X 70 kilogram body weight $=35$ micrograms Ethion allowed per day. 


\section{Ethion Adult Advisory Groups}

\section{GROUP 1}

Unrestricted Consumption or up to 225 meals per year (140 grams of sportfish per day)

35 micrograms per day Ethion / 140 grams of fish per day

Less than 0.25 ppm Ethion in raw skin on fish fillet

\section{GROUP 2}

Up to 1 meal per week

(32 grams of sportfish per day)

35 micrograms per day Ethion / 32 grams of fish per day

$0.25 \mathrm{ppm}$ to $1.09 \mathrm{ppm}$ Ethion in raw skin on fish fillet

\section{GROUP 3}

Up to 1 meal per month

(7.4 grams of sportfish per day)

35 micrograms per day Ethion / 7.4 grams of fish per day

$1.09 \mathrm{ppm}$ to $4.73 \mathrm{ppm}$ Ethion in raw skin on fish fillet

\section{GROUP 4}

Up to 6 meals per year (3.7 grams of sportfish per day)

35 micrograms per day Ethion / 3.7 grams of fish per day

$4.73 \mathrm{ppm}$ to $9.46 \mathrm{ppm}$ Ethion in raw skin on fish fillet

\section{GROUP 5}

DO NOT EAT

Greater than 9.46 ppm Ethion in raw skin on fish fillet 


\section{Children Advisory Assumptions - Ethion}

\section{Assumptions:}

1) Reference Dose is 0.5 micrograms Ethion per kilogram per day

2) Average Meal Size is 52.5 grams or 3 ounces of uncooked fish.

3) Representative Consumer Body weight is 14.5 kilograms.

4) Five Advisory Groups: Unrestricted or 225 meals per year; One meal per week; One meal per month; Six meals per year; No Consumption.

5) Assume meal preparation does not reduce residues by $50 \%$ from raw skin on fish fillets used to determine Ethion residue level.

\section{Maximum Allowable Daily Ethion Ingestion Calculation}

0.5 micrograms per kilogram per day X 14.5 kilogram body weight $=7.25$ micrograms Ethion allowed per day. 


\section{Ethion Child Advisory Groups}

\section{GROUP 1}

Unrestricted Consumption or up to 225 meals per year (52.5 grams of sportfish per day)

7.25 micrograms per day Ethion / 52.5 grams of fish per day

Less than $0.14 \mathrm{ppm}$ Ethion in raw skin on fish fillet

\section{GROUP 2}

Up to 1 meal per week

(12.13 grams of sportfish per day)

7.25 micrograms per day Ethion / 12.13 grams of fish per day

$0.14 \mathrm{ppm}$ to $0.60 \mathrm{ppm}$ Ethion in raw skin on fish fillet

\section{GROUP 3}

Up to 1 meal per month

(2.8 grams of sportfish per day)

7.25 micrograms per day Ethion / 2.8 grams of fish per day

$0.60 \mathrm{ppm}$ to $2.59 \mathrm{ppm}$ Ethion in raw skin on fish fillet

\section{GROUP 4}

Up to 6 meals per year (1.4 grams of sportfish per day)

7.25 micrograms per day Ethion / 1.4 grams of fish per day

$2.59 \mathrm{ppm}$ to $5.18 \mathrm{ppm}$ Ethion in raw skin on fish fillet

\section{GROUP 5}

DO NOT EAT

Greater than 5.18 ppm Ethion in raw skin on fish fillet 


\section{Heptachlor Epoxide Summary}

Merck Number 4690 (Heptachlor)

CAS Number 1024-57-3

Oral RfD $0.000013 \mathrm{mg} / \mathrm{kg} /$ day

Oral Slope Factor $9.1 \mathrm{mg} / \mathrm{kg} / \mathrm{day}$

Preparation Dose Reduction .5 Skin on, .7 Skin off

Heptachlor epoxide is a product of the degradation of organochlorine pesticides heptachlor and chlordane. Heptachlor is no longer registered for use in the United States and chlordane has only a minor use for treating fire ants in power transformers. Heptachlor epoxide was also a contaminant found in both formulations. Chlordane is persistent in soil, water and sediment and is readily bioconcentrated in aquatic ecosystems. Heptachlor is very persistent in soils and readily hydrolyzed into heptachlor epoxide in water. Both heptachlor and heptachlor epoxide bioconcentrate in aquatic ecosystems. Heptachlor has been found in fish at levels 37,000 times of that in surrounding waters. Heptachlor epoxide is a very persistent and toxic metabolite in the environment.

Mutagenicity testing has produced conflicting information although some experiments reported changes in chromosomes. A dog reproductive study noted liver lesions in pups after two generations. Rat studies have reported significantly lowered pup survival and cataracts. The U.S. Environmental Protection Agency lists heptachlor epoxide as a probable human carcinogen. Rat studies show increased liver and thyroid tumors. Prenatal exposures have been connected with brain tumors in children. Chronic exposure has produced liver damage, increased bilirubin, white blood cell counts, and serum creatine phosphokinase levels. Heptachlor epoxide is stored mainly in fat, but is found in the bone marrow, kidney and liver. Heptachlor epoxide has been found in human milk and in fetal blood at levels four times higher than the mother has. 


\section{Cancer Effect Assumptions - Heptachlor Epoxide Skin On Fillets}

\section{Assumptions:}

1) Slope Factor is 9.1 milligrams Heptachlor Epoxide per kilogram per day

2) Average Meal Size is 227 grams or $1 / 2$ pound of uncooked fish.

3) Representative Consumer Body weight is 70 kilograms.

4) ARL is $10^{-4}$

5) Five Consumption Rates: Unrestricted 225 meals per year(140 g/day); One meal per week(32g/day); One meal per month(7.4 g/day); Six meals per year(3.7 g/day); No Consumption.

6) Assume meal preparation reduces residues by $50 \%$ from raw skin off (catfish) fish fillets used to determine Heptachlor Epoxide residue level.

\section{Cancer Effect Assumptions - Heptachlor Epoxide Skin Off Fillets (Catfish)}

\section{Assumptions:}

1) Slope Factor is 9.1 milligrams Heptachlor Epoxide per kilogram per day

2) Average Meal Size is 227 grams or $1 / 2$ pound of uncooked fish.

3) Representative Consumer Body weight is 70 kilograms.

4) ARL is $10^{-4}$

5) Five Consumption Rates: Unrestricted 225 meals per year(140 g/day); One meal per week(32g/day); One meal per month(7.4 g/day); Six meals per year(3.7 g/day); No Consumption.

6) Assume meal preparation reduces residues by $30 \%$ from raw skin off (catfish) fish fillets used to determine Heptachlor Epoxide residue level. 


\section{Heptachlor Epoxide Cancer Effect Advisory Groups - Skin On Fillets}

\section{GROUP 1}

Unrestricted Consumption or up to 225 meals per year

(140 grams of sportfish per day)

Less than 0.011 ppm Heptachlor Epoxide in raw skin on fish fillet

\section{GROUP 2}

Up to 1 meal per week

(32 grams of sportfish per day)

$0.011 \mathrm{ppm}$ to $0.048 \mathrm{ppm}$ Heptachlor Epoxide in raw skin on fish fillet

\section{GROUP 3}

Up to 1 meal per month

(7.4 grams of sportfish per day)

$0.048 \mathrm{ppm}$ to $0.21 \mathrm{ppm}$ Heptachlor Epoxide in raw skin on fish fillet

GROUP 4

Up to 6 meals per year

(3.7 grams of sportfish per day)

$0.21 \mathrm{ppm}$ to $0.42 \mathrm{ppm}$ Heptachlor Epoxide in raw skin on fish fillet

\section{GROUP 5}

DO NOT EAT

Greater than 0.42 ppm Heptachlor Epoxide in raw skin on fish fillet 
Heptachlor Epoxide Cancer Effect Advisory Groups - Skin Off Fillets

\section{GROUP 1}

Unrestricted Consumption or up to 225 meals per year

(140 grams of sportfish per day)

Less than 0.0078 ppm Heptachlor Epoxide in raw skin off (catfish) fish fillet

\section{GROUP 2}

Up to 1 meal per week

(32 grams of sportfish per day)

$0.0078 \mathrm{ppm}$ to $0.034 \mathrm{ppm}$ Heptachlor Epoxide in raw skin off (catfish) fish fillet

\section{GROUP 3}

Up to 1 meal per month

(7.4 grams of sportfish per day)

$0.034 \mathrm{ppm}$ to $0.15 \mathrm{ppm}$ Heptachlor Epoxide in raw skin off (catfish) fish fillet

\section{GROUP 4}

Up to 6 meals per year

(3.7 grams of sportfish per day)

$0.15 \mathrm{ppm}$ to $0.30 \mathrm{ppm}$ Heptachlor Epoxide in raw skin off (catfish) fish fillet

\section{GROUP 5}

DO NOT EAT

Greater than $0.30 \mathrm{ppm}$ Heptachlor Epoxide in raw skin off (catfish) fish fillet 


\section{Adult Advisory Assumptions - Heptachlor Epoxide Skin On Fillets}

\section{Assumptions:}

1) Reference Dose is 0.013 micrograms Heptachlor Epoxide per kilogram per day

2) Average Meal Size is 227 grams or $1 / 2$ pound of uncooked fish.

3) Representative Consumer Body weight is 70 kilograms.

4) Five Advisory Groups: Unrestricted or 225 meals per year; One meal per week; One meal per month; Six meals per year; No Consumption.

5) Assume meal preparation reduces residues by 50\% from raw skin on fish fillets used to determine Heptachlor Epoxide residue level.

\section{Maximum Allowable Daily Heptachlor Epoxide Ingestion Calculation}

0.013 micrograms per kilogram per day X 70 kilogram body weight $=0.91$ micrograms Heptachlor Epoxide allowed per day.

\section{Adult Advisory Assumptions - Heptachlor Epoxide Skin Off Fillets}

\section{Assumptions:}

1) Reference Dose is 0.013 micrograms Heptachlor Epoxide per kilogram per day

2) Average Meal Size is 227 grams or $1 / 2$ pound of uncooked fish.

3) Representative Consumer Body weight is 70 kilograms.

4) Five Advisory Groups: Unrestricted or 225 meals per year; One meal per week; One meal per month; Six meals per year; No Consumption.

5) Assume meal preparation reduces residues by 30\% from raw skin off (catfish) fish fillets used to determine Heptachlor Epoxide residue level.

\section{Maximum Allowable Daily Heptachlor Epoxide Ingestion Calculation}

0.013 micrograms per kilogram per day X 70 kilogram body weight $=0.91$ micrograms Heptachlor Epoxide allowed per day. 
Heptachlor Epoxide Adult Advisory Groups - Skin On Fillets

\section{GROUP 1}

Unrestricted Consumption or up to 225 meals per year

(140 grams of sportfish per day)

0.91 micrograms per day Heptachlor Epoxide / 140 grams of fish per day / .5 preparation reduction

Less than 0.013 ppm Heptachlor Epoxide in raw skin on fish fillet

\section{GROUP 2}

Up to 1 meal per week

(32 grams of sportfish per day)

0.91 micrograms per day Heptachlor Epoxide / 32 grams of fish per day /.5 preparation reduction

$0.013 \mathrm{ppm}$ to $0.057 \mathrm{ppm}$ Heptachlor Epoxide in raw skin on fish fillet

\section{GROUP 3}

Up to 1 meal per month

(7.4 grams of sportfish per day)

0.91 micrograms per day Heptachlor Epoxide / 7.4 grams of fish per day /.5 preparation reduction

$0.057 \mathrm{ppm}$ to $0.24 \mathrm{ppm}$ Heptachlor Epoxide in raw skin on fish fillet

\section{GROUP 4}

Up to 6 meals per year (3.7 grams of sportfish per day)

0.91 micrograms per day Heptachlor Epoxide / 3.7 grams of fish per day /.5 preparation reduction

$0.24 \mathrm{ppm}$ to $0.49 \mathrm{ppm}$ Heptachlor Epoxide in raw skin on fish fillet

GROUP 5

DO NOT EAT

Greater than 0.49 ppm Heptachlor Epoxide in raw skin on fish fillet 
Heptachlor Epoxide Adult Advisory Groups - Skin Off Fillets

\section{GROUP 1}

Unrestricted Consumption or up to 225 meals per year

(140 grams of sportfish per day)

0.91 micrograms per day Heptachlor Epoxide / 140 grams of fish per day / .7 preparation reduction

Less than 0.0093 ppm Heptachlor Epoxide in raw skin off (catfish) fish fillet

\section{GROUP 2}

Up to 1 meal per week

(32 grams of sportfish per day)

0.91 micrograms per day Heptachlor Epoxide / 32 grams of fish per day /.7 preparation reduction

$0.0093 \mathrm{ppm}$ to $0.041 \mathrm{ppm}$ Heptachlor Epoxide in raw skin off (catfish) fish fillet

\section{GROUP 3}

Up to 1 meal per month

(7.4 grams of sportfish per day)

0.91 micrograms per day Heptachlor Epoxide / 7.4 grams of fish per day /.7 preparation reduction

$0.041 \mathrm{ppm}$ to $0.18 \mathrm{ppm}$ Heptachlor Epoxide in raw skin off (catfish) fish fillet

\section{GROUP 4}

Up to 6 meals per year (3.7 grams of sportfish per day)

0.91 micrograms per day Heptachlor Epoxide / 3.7 grams of fish per day /.7 preparation reduction

$0.18 \mathrm{ppm}$ to $0.35 \mathrm{ppm}$ Heptachlor Epoxide in raw skin off (catfish) fish fillet

GROUP 5

DO NOT EAT

Greater than $0.35 \mathrm{ppm}$ Heptachlor Epoxide in raw skin off (catfish) fish fillet 


\section{Child Advisory Assumptions - Heptachlor Epoxide Skin On Fillets}

\section{Assumptions:}

1) Reference Dose is 0.013 micrograms Heptachlor Epoxide per kilogram per day

2) Average Meal Size is 52.5 grams or 3 ounces of uncooked fish.

3) Representative Consumer Body weight is 14.5 kilograms.

4) Five Advisory Groups: Unrestricted or 225 meals per year; One meal per week; One meal per month; Six meals per year; No Consumption.

5) Assume meal preparation reduces residues by 50\% from raw skin on fish fillets used to determine Heptachlor Epoxide residue level.

\section{Maximum Allowable Daily Heptachlor Epoxide Ingestion Calculation}

0.013 micrograms per kilogram per day X 14.5 kilogram body weight $=0.1885$ micrograms Heptachlor Epoxide allowed per day.

\section{Child Advisory Assumptions - Heptachlor Epoxide Skin Off Fillets}

\section{Assumptions:}

1) Reference Dose is 0.013 micrograms Heptachlor Epoxide per kilogram per day

2) Average Meal Size is 52.5 grams or 3 ounces of uncooked fish.

3) Representative Consumer Body weight is 14.5 kilograms.

4) Five Advisory Groups: Unrestricted or 225 meals per year; One meal per week; One meal per month; Six meals per year; No Consumption.

5) Assume meal preparation reduces residues by 30\% from raw skin off (catfish) fish fillets used to determine Heptachlor Epoxide residue level.

Maximum Allowable Daily Heptachlor Epoxide Ingestion Calculation

0.013 micrograms per kilogram per day X 14.5 kilogram body weight $=0.1885$ micrograms Heptachlor Epoxide allowed per day. 


\section{Heptachlor Epoxide Child Advisory Groups - Skin On Fillets}

\section{GROUP 1}

Unrestricted Consumption or up to 225 meals per year (52.5 grams of sportfish per day)

0.1885 micrograms per day Heptachlor Epoxide / 52.5 grams of fish per day / .5 preparation reduction

Less than 0.0072 ppm Heptachlor Epoxide in raw skin on fish fillet

\section{GROUP 2}

Up to 1 meal per week

(12.13 grams of sportfish per day)

0.1885 micrograms per day Heptachlor Epoxide / 12.13 grams of fish per day /.5 preparation reduction

$0.0072 \mathrm{ppm}$ to $0.031 \mathrm{ppm}$ Heptachlor Epoxide in raw skin on fish fillet

\section{GROUP 3}

Up to 1 meal per month

(2.8 grams of sportfish per day)

0.1885 micrograms per day Heptachlor Epoxide / 2.8 grams of fish per day /.5 preparation reduction

$0.031 \mathrm{ppm}$ to $0.13 \mathrm{ppm}$ Heptachlor Epoxide in raw skin on fish fillet

\section{GROUP 4}

Up to 6 meals per year (1.4 grams of sportfish per day)

0.1885 micrograms per day Heptachlor Epoxide / 1.4 grams of fish per day /.5 preparation reduction

$0.13 \mathrm{ppm}$ to $0.27 \mathrm{ppm}$ Heptachlor Epoxide in raw skin on fish fillet

\section{GROUP 5}

DO NOT EAT

Greater than 0.27 ppm Heptachlor Epoxide in raw skin on fish fillet 


\section{Heptachlor Epoxide Child Advisory Groups - Skin Off Fillets}

\section{GROUP 1}

Unrestricted Consumption or up to 225 meals per year

(52.5 grams of sportfish per day)

0.1885 micrograms per day Heptachlor Epoxide / 52.5 grams of fish per day / .7 preparation reduction

Less than 0.0051 ppm Heptachlor Epoxide in raw skin off (catfish) fish fillet

\section{GROUP 2}

Up to 1 meal per week

(12.13 grams of sportfish per day)

0.1885 micrograms per day Heptachlor Epoxide / 12.13 grams of fish per day /.7 preparation reduction

$0.0051 \mathrm{ppm}$ to $0.022 \mathrm{ppm}$ Heptachlor Epoxide in raw skin off (catfish) fish fillet

\section{GROUP 3}

Up to 1 meal per month

(2.8 grams of sportfish per day)

0.1885 micrograms per day Heptachlor Epoxide / 2.8 grams of fish per day /.7 preparation reduction

$0.022 \mathrm{ppm}$ to $0.096 \mathrm{ppm}$ Heptachlor Epoxide in raw skin off (catfish) fish fillet

\section{GROUP 4}

Up to 6 meals per year (1.4 grams of sportfish per day)

0.1885 micrograms per day Heptachlor Epoxide / 1.4 grams of fish per day /.7 preparation reduction

$0.096 \mathrm{ppm}$ to $0.19 \mathrm{ppm}$ Heptachlor Epoxide in raw skin off (catfish) fish fillet

\section{GROUP 5}

DO NOT EAT

Greater than 0.19 ppm Heptachlor Epoxide in raw skin off (catfish) fish fillet 


\section{Hexachlorobenzene Summary}

Merck Number 4714

CAS Number 118-74-1

Oral RfD $0.0008 \mathrm{mg} / \mathrm{kg} / \mathrm{day}$

Oral Slope Factor $1.6 \mathrm{mg} / \mathrm{kg} / \mathrm{day}$

Preparation Dose Reduction .5 skin on, .7 skin off

Hexachlorobenzene is a chlorinated hydrocarbon manufacturing byproduct and seed fungicide and fumigant, and is no longer registered for use in the United States. It was used mainly to treat wheat seeds for common and dwarf bunt. It was a dry or slurry treatment and a clear crystal in pure form. Hexachlorobenzene is extremely persistent in soils and bioaccumulates in aquatic systems. Rainbow trout were found to accumulate residue levels up to 8900 times that in water. Hexachlorobenzene is very lipophilic and accumulates in the body fat. It has been found in human milk. Hexachlorobenzene produced teratogenic results in animal studies. Rats were born with reduced weights and extra ribs. Mouse pups had cleft palates, kidney malformations, and higher mortality with prenatal exposure. Mutagenic tests have had conflicting results. Hexachlorobenzene produced mutations in bacteria and yeast but rat testing was negative. The U.S. EPA classifies hexachlorobenzene as a probable human carcinogen. Animal studies showed increased liver, lung, spleen and thyroid tumors. Rats and mice had increased liver tumors. Residents of Turkey were exposed for a four year period from 1955 to 1959 because of contaminated grain. The people effected have developed osteoporosis, arthritis, muscle weakness, rigidity, enlarged thyroids, liver damage, and decrease uroporphyrin synthase levels. Chronic exposure in animals resulted in the same outcomes and also caused porphyria. 


\section{Cancer Effect Assumptions - Hexachlorobenzene Skin On Fillets}

\section{Assumptions:}

1) Slope Factor is 1.6 milligrams Hexachlorobenzene per kilogram per day

2) Average Meal Size is 227 grams or $1 / 2$ pound of uncooked fish.

3) Representative Consumer Body weight is 70 kilograms.

4) ARL is $10^{-4}$

5) Five Consumption Rates: Unrestricted 225 meals per year(140 g/day); One meal per week(32g/day); One meal per month(7.4 g/day); Six meals per year(3.7 g/day); No Consumption.

6) Assume meal preparation reduces residues by 50\% from raw skin off (catfish) fish fillets used to determine Hexachlorobenzene residue level.

\section{Cancer Effect Assumptions - Hexachlorobenzene Skin Off Fillets (Catfish)}

\section{Assumptions:}

1) Slope Factor is 1.6 milligrams Hexachlorobenzene per kilogram per day

2) Average Meal Size is 227 grams or $1 / 2$ pound of uncooked fish.

3) Representative Consumer Body weight is 70 kilograms.

4) ARL is $10^{-4}$

5) Five Consumption Rates: Unrestricted 225 meals per year(140 g/day); One meal per week(32g/day); One meal per month(7.4 g/day); Six meals per year(3.7 g/day); No Consumption.

6) Assume meal preparation reduces residues by 30\% from raw skin off (catfish) fish fillets used to determine Hexachlorobenzene residue level. 


\section{Hexachlorobenzene Cancer Effect Advisory Groups - Skin On Fillets}

\section{GROUP 1}

Unrestricted Consumption or up to 225 meals per year

(140 grams of sportfish per day)

Less than $0.063 \mathrm{ppm}$ Hexachlorobenzene in raw skin on fish fillet

\section{GROUP 2}

Up to 1 meal per week

(32 grams of sportfish per day)

$0.063 \mathrm{ppm}$ to $0.27 \mathrm{ppm}$ Hexachlorobenzene in raw skin on fish fillet

\section{GROUP 3}

Up to 1 meal per month

(7.4 grams of sportfish per day)

$0.27 \mathrm{ppm}$ to $1.18 \mathrm{ppm}$ Hexachlorobenzene in raw skin on fish fillet

\section{GROUP 4}

Up to 0.8 meals per year

(3.7 grams of sportfish per day)

$1.18 \mathrm{ppm}$ to $2.36 \mathrm{ppm}$ Hexachlorobenzene in raw skin on fish fillet

\section{GROUP 5}

DO NOT EAT

Greater than $2.36 \mathrm{ppm}$ Hexachlorobenzene in raw skin on fish fillet 
Hexachlorobenzene Cancer Effect Advisory Groups - Skin Off Fillets

\section{GROUP 1}

Unrestricted Consumption or up to 225 meals per year

(140 grams of sportfish per day)

Less than $0.045 \mathrm{ppm}$ Hexachlorobenzene in raw skin off (catfish) fish fillet

\section{GROUP 2}

Up to 1 meal per week

(32 grams of sportfish per day)

56 micrograms per day Hexachlorobenzene / 32 grams of fish per day /.7 preparation reduction

$0.045 \mathrm{ppm}$ to $0.20 \mathrm{ppm}$ Hexachlorobenzene in raw skin off (catfish) fish fillet

\section{GROUP 3}

Up to 1 meal per month

(7.4 grams of sportfish per day)

$0.20 \mathrm{ppm}$ to $0.84 \mathrm{ppm}$ Hexachlorobenzene in raw skin off (catfish) fish fillet

\section{GROUP 4}

Up to 0.8 meals per year

(3.7 grams of sportfish per day)

$0.84 \mathrm{ppm}$ to $1.69 \mathrm{ppm}$ Hexachlorobenzene in raw skin off (catfish) fish fillet

\section{GROUP 5}

DO NOT EAT

Greater than 1.69 ppm Hexachlorobenzene in raw skin off (catfish) fish fillet 
Adult Advisory Assumptions - Hexachlorobenzene Skin On Fillet

\section{Assumptions:}

1) Reference Dose is 0.8 micrograms Hexachlorobenzene per kilogram per day

2) Average Meal Size is 227 grams or $1 / 2$ pound of uncooked fish.

3) Representative Consumer Body weight is 70 kilograms.

4) Five Advisory Groups: Unrestricted or 225 meals per year; One meal per week; One meal per month; Six meals per year; No Consumption.

5) Assume meal preparation reduces residues by 50\% from raw skin on fish fillets used to determine Hexachlorobenzene residue level.

\section{Maximum Allowable Daily Hexachlorobenzene Ingestion Calculation}

0.8 micrograms per kilogram per day $X 70$ kilogram body weight $=56$ micrograms Hexachlorobenzene allowed per day.

\section{Adult Advisory Assumptions - Hexachlorobenzene Skin Off Fillet}

\section{Assumptions:}

1) Reference Dose is 0.8 micrograms Hexachlorobenzene per kilogram per day

2) Average Meal Size is 227 grams or $1 / 2$ pound of uncooked fish.

3) Representative Consumer Body weight is 70 kilograms.

4) Five Advisory Groups: Unrestricted or 225 meals per year; One meal per week; One meal per month; Six meals per year; No Consumption.

5) Assume meal preparation reduces residues by 30\% from raw skin off (catfish) fish fillets used to determine Hexachlorobenzene residue level.

\section{Maximum Allowable Daily Hexachlorobenzene Ingestion Calculation}

0.8 micrograms per kilogram per day X 70 kilogram body weight $=56$ micrograms Hexachlorobenzene allowed per day. 


\section{Hexachlorobenzene Adult Advisory Groups - Skin On Fillets}

\section{GROUP 1}

Unrestricted Consumption or up to 225 meals per year (140 grams of sportfish per day)

56 micrograms per day Hexachlorobenzene / 140 grams of fish per day /.5 preparation reduction

Less than $0.80 \mathrm{ppm}$ Hexachlorobenzene in raw skin on fish fillet

\section{GROUP 2}

Up to 1 meal per week (32 grams of sportfish per day)

56 micrograms per day Hexachlorobenzene / 32 grams of fish per day /.5 preparation reduction

$0.80 \mathrm{ppm}$ to $3.50 \mathrm{ppm}$ Hexachlorobenzene in raw skin on fish fillet

\section{GROUP 3}

Up to 1 meal per month

(7.4 grams of sportfish per day)

56 micrograms per day Hexachlorobenzene / 7.4 grams of fish per day /.5 preparation reduction

$3.50 \mathrm{ppm}$ to $15.14 \mathrm{ppm}$ Hexachlorobenzene in raw skin on fish fillet

\section{GROUP 4}

Up to 0.8 meals per year

(3.7 grams of sportfish per day)

56 micrograms per day Hexachlorobenzene / 3.7 grams of fish per day / .5 preparation reduction

$15.14 \mathrm{ppm}$ to $30.27 \mathrm{ppm}$ Hexachlorobenzene in raw skin on fish fillet

\section{GROUP 5}

DO NOT EAT

Greater than 30.27 ppm Hexachlorobenzene in raw skin on fish fillet 


\section{Hexachlorobenzene Adult Advisory Groups - Skin Off Fillets}

\section{GROUP 1}

Unrestricted Consumption or up to 225 meals per year (140 grams of sportfish per day)

56 micrograms per day Hexachlorobenzene / 140 grams of fish per day /.7 preparation reduction

Less than $0.57 \mathrm{ppm}$ Hexachlorobenzene in raw skin off (catfish) fish fillet

\section{GROUP 2}

Up to 1 meal per week (32 grams of sportfish per day)

56 micrograms per day Hexachlorobenzene / 32 grams of fish per day /.7 preparation reduction

$0.57 \mathrm{ppm}$ to $2.50 \mathrm{ppm}$ Hexachlorobenzene in raw skin off (catfish) fish fillet

\section{GROUP 3}

Up to 1 meal per month (7.4 grams of sportfish per day)

56 micrograms per day Hexachlorobenzene / 7.4 grams of fish per day /.7 preparation reduction

$2.50 \mathrm{ppm}$ to $10.81 \mathrm{ppm}$ Hexachlorobenzene in raw skin off (catfish) fish fillet

\section{GROUP 4}

Up to 0.8 meals per year

(3.7 grams of sportfish per day)

56 micrograms per day Hexachlorobenzene / 3.7 grams of fish per day / .7 preparation reduction

$10.81 \mathrm{ppm}$ to $21.62 \mathrm{ppm}$ Hexachlorobenzene in raw skin off (catfish) fish fillet

GROUP 5

DO NOT EAT

Greater than 21.62 ppm Hexachlorobenzene in raw skin off (catfish) fish fillet 


\section{Children Advisory Assumptions - Hexachlorobenzene Skin On Fillet}

\section{Assumptions:}

1) Reference Dose is 0.8 micrograms Hexachlorobenzene per kilogram per day

2) Average Meal Size is 52.5 grams or 3 ounces of uncooked fish.

3) Representative Consumer Body weight is 14.5 kilograms.

4) Five Advisory Groups: Unrestricted or 225 meals per year; One meal per week; One meal per month; Six meals per year; No Consumption.

5) Assume meal preparation reduces residues by 50\% from raw skin on fish fillets used to determine Hexachlorobenzene residue level.

\section{Maximum Allowable Daily Hexachlorobenzene Ingestion Calculation}

0.8 micrograms per kilogram per day X 14.5 kilogram body weight $=11.6$ micrograms Hexachlorobenzene allowed per day.

\section{Children Advisory Assumptions - Hexachlorobenzene Skin Off Fillet}

\section{Assumptions:}

1) Reference Dose is 0.8 micrograms Hexachlorobenzene per kilogram per day

2) Average Meal Size is 52.5 grams or 3 ounces of uncooked fish.

3) Representative Consumer Body weight is 14.5 kilograms.

4) Five Advisory Groups: Unrestricted or 225 meals per year; One meal per week; One meal per month; Six meals per year; No Consumption.

5) Assume meal preparation reduces residues by 30\% from raw skin off (catfish) fish fillets used to determine Hexachlorobenzene residue level.

\section{Maximum Allowable Daily Hexachlorobenzene Ingestion Calculation}

0.8 micrograms per kilogram per day X 14.5 kilogram body weight $=11.6$ micrograms

Hexachlorobenzene allowed per day. 


\section{Hexachlorobenzene Child Advisory Groups - Skin On Fillets}

\section{GROUP 1}

Unrestricted Consumption or up to 225 meals per year

(52.5 grams of sportfish per day)

11.6 micrograms per day Hexachlorobenzene / 52.5 grams of fish per day /.5 preparation reduction

Less than 0.44 ppm Hexachlorobenzene in raw skin on fish fillet

\section{GROUP 2}

Up to 1 meal per week

(12.13 grams of sportfish per day)

11.6 micrograms per day Hexachlorobenzene / 12.13 grams of fish per day /.5 preparation reduction

$0.44 \mathrm{ppm}$ to $1.91 \mathrm{ppm}$ Hexachlorobenzene in raw skin on fish fillet

\section{GROUP 3}

Up to 1 meal per month

(2.8 grams of sportfish per day)

11.6 micrograms per day Hexachlorobenzene / 2.8 grams of fish per day /.5 preparation reduction

$1.91 \mathrm{ppm}$ to $8.29 \mathrm{ppm}$ Hexachlorobenzene in raw skin on fish fillet

\section{GROUP 4}

Up to 6 meals per year

(1.4 grams of sportfish per day)

11.6 micrograms per day Hexachlorobenzene / 1.4 grams of fish per day / .5 preparation reduction

$8.29 \mathrm{ppm}$ to $16.57 \mathrm{ppm}$ Hexachlorobenzene in raw skin on fish fillet

GROUP 5

DO NOT EAT

Greater than 16.57 ppm Hexachlorobenzene in raw skin on fish fillet 


\section{Hexachlorobenzene Child Advisory Groups - Skin Off Fillets}

\section{GROUP 1}

Unrestricted Consumption or up to 225 meals per year

(52.5 grams of sportfish per day)

11.6 micrograms per day Hexachlorobenzene / 52.5 grams of fish per day /.7 preparation reduction

Less than $0.32 \mathrm{ppm}$ Hexachlorobenzene in raw skin off (catfish) fish fillet

\section{GROUP 2}

Up to 1 meal per week

(12.13 grams of sportfish per day)

11.6 micrograms per day Hexachlorobenzene / 12.13 grams of fish per day /.7 preparation reduction

$0.32 \mathrm{ppm}$ to $1.37 \mathrm{ppm}$ Hexachlorobenzene in raw skin off (catfish) fish fillet

\section{GROUP 3}

Up to 1 meal per month

(2.8 grams of sportfish per day)

11.6 micrograms per day Hexachlorobenzene / 2.8 grams of fish per day /.7 preparation reduction

$1.37 \mathrm{ppm}$ to $5.92 \mathrm{ppm}$ Hexachlorobenzene in raw skin off (catfish) fish fillet

\section{GROUP 4}

Up to 6 meals per year

(1.4 grams of sportfish per day)

11.6 micrograms per day Hexachlorobenzene / 1.4 grams of fish per day / .7 preparation reduction

$5.92 \mathrm{ppm}$ to $11.84 \mathrm{ppm}$ Hexachlorobenzene in raw skin off (catfish) fish fillet

\section{GROUP 5}

DO NOT EAT

Greater than $11.84 \mathrm{ppm}$ Hexachlorobenzene in raw skin off (catfish) fish fillet 


\section{Lead Summary}

Merck Number 5410

CAS Number 7439-92-1

Oral RfD None

Preparation Dose Reduction 1

Lead is a blue-white to silver-gray metal, which shines when cut. Humans have used it for nearly 7,000 years. There is no evidence that lead is biologically essential or useful. Lead causes problems with behavior, development, growth, learning, metabolism and survival. Lead poisoning was first recognized 2,500 years ago. Lead has many uses and is the fifth most used metal in the United States. Although able to be recycled only $40-50 \%$ of lead is reused in the U.S. Lead is used in primarily in manufacturing lead acid storage batteries, as well as ammunition, pigments, and solder. Sources of lead in the environment include mining, smelting, lead shot and sinkers, lead based paint, and until recently leaded gasoline. Lead does bioaccumulate in some shellfish and mussels, but does not accumulate significantly in fish. "Lead intake in fish is confined to the mucous on the epidermis and scales so that availability in edible portions does not pose a human health danger."(EPA 1999)

"By comparison to most other environmental toxicants, the degree of uncertainty about the health effects of lead is quite low. It appears that some of these effects, particularly changes in the levels of certain blood enzymes and in aspects of children's neurobehavioral development, may occur at level so low as to be without a threshold."(U.S. EPA 1988) because of this the EPA decided it was "inappropriate" to set a reference dose for inorganic lead. 
Acute lead poisoning can occur at low doses and effects include anemia, central nervous system damage, delayed mental and physical development, attention deficits, hearing loss, learning disabilities, and increased blood pressure. Chronic exposure can cause inflammation of the brain and kidney disease. The U.S. EPA list lead as a probable human carcinogen. Studies have been shown to cause kidney and lung cancer in rats and mice. Lead accumulates in bone, acting as calcium. 


\section{Lindane Summary}

Merck Number 5526

CAS Number 58-89-9

Oral RfD $0.0003 \mathrm{mg} / \mathrm{kg} / \mathrm{day}$

Preparation Dose Reduction .5 skin on, .7 Skin off

Lindane or hexachlorocyclohexane is a clear crystal solid organochlorine pesticide, having a slight musty odor. It was manufactured in the United States from 1945 until 1976, and now is imported. It was widely used for grain and household fumigation, fruit, nuts, vegetables, cotton, hardwoods, in shampoo to treat head lice, and to control insect vectors of disease, until its use was restricted. Lindane is registered as a restricted use pesticide for treating wood boring beetles, seeds, warehouse fumigant, nut and fruit trees, vegetables, timber, ornamentals, soil treatment and as a dip for livestock and pets. It is available as a concentrate, fumigant, seed treatment, wettable and dustable powders, and a liquid. Lindane bioconcentrates in the aquatic ecosystem and accumulates in fatty tissue of fish.

Lindane's acute effects include convulsions, headaches, dizziness, nervous system damage, fever, seizures, and pulmonary edema. Chronic exposure caused immunosuppression, liver and kidney damage in animal studies. Accidental human exposures confirm immune system effects. Studies with rats produced reduced sperm counts in males and changes in the uterus and cervix in females due to hormonal effects. Mutagenic studies have been mixed. Many test on mice and microbes were negative, but changes in human lymphocytes and chromosomal damage. The U.S. EPA considers lindane a probable/possible human carcinogen. Rats and mice exposed to lindane developed liver tumors. The EPA is reviewing evidence lindane may cause aplastic anemia in humans. 


\section{Adult Advisory Assumptions - Lindane Skin On Fillet}

\section{Assumptions:}

1) Reference Dose is 0.3 micrograms Lindane per kilogram per day

2) Average Meal Size is 227 grams or $1 / 2$ pound of uncooked fish.

3) Representative Consumer Body weight is 70 kilograms.

4) Five Advisory Groups: Unrestricted or 225 meals per year; One meal per week; One meal per month; Six meals per year; No Consumption.

5) Assume meal preparation reduces residues by 50\% from raw skin on fish fillets used to determine Lindane residue level.

\section{Maximum Allowable Daily Lindane Ingestion Calculation}

0.3 micrograms per kilogram per day X 70 kilogram body weight $=21$ micrograms Lindane allowed per day.

\section{Adult Advisory Assumptions - Lindane Skin Off Fillet}

\section{Assumptions:}

1) Reference Dose is 0.3 micrograms Lindane per kilogram per day

2) Average Meal Size is 227 grams or $1 / 2$ pound of uncooked fish.

3) Representative Consumer Body weight is 70 kilograms.

4) Five Advisory Groups: Unrestricted or 225 meals per year; One meal per week; One meal per month; Six meals per year; No Consumption.

5) Assume meal preparation reduces residues by 30\% from raw skin off (catfish) fish fillets used to determine Lindane residue level.

\section{Maximum Allowable Daily Lindane Ingestion Calculation}

0.3 micrograms per kilogram per day X 70 kilogram body weight $=21$ micrograms Lindane allowed per day. 


\section{Lindane Adult Advisory Groups - Skin On Fillet}

\section{GROUP 1}

Unrestricted Consumption or up to 225 meals per year (140 grams of sportfish per day)

21 micrograms per day Lindane / 140 grams of fish per day /.5 preparation reduction

Less than $0.30 \mathrm{ppm}$ Lindane in raw skin on fish fillet

\section{GROUP 2}

Up to 1 meal per week

(32 grams of sportfish per day)

21 micrograms per day Lindane / 32 grams of fish per day /.5 preparation reduction

$0.30 \mathrm{ppm}$ to $1.31 \mathrm{ppm}$ Lindane in raw skin on fish fillet

\section{GROUP 3}

Up to 1 meal per month

(7.4 grams of sportfish per day)

21 micrograms per day Lindane / 7.4 grams of fish per day /.5 preparation reduction

$1.31 \mathrm{ppm}$ to $5.68 \mathrm{ppm}$ Lindane in raw skin on fish fillet

\section{GROUP 4}

Up to 6 meals per year (3.7 grams of sportfish per day)

21 micrograms per day Lindane / 3.7 grams of fish per day / .5 preparation reduction

$5.68 \mathrm{ppm}$ to $11.35 \mathrm{ppm}$ Lindane in raw skin on fish fillet

\section{GROUP 5}

DO NOT EAT

Greater than $11.35 \mathrm{ppm}$ Lindane in raw skin on fish fillet 


\section{Lindane Adult Advisory Groups - Skin Off Fillet}

\section{GROUP 1}

Unrestricted Consumption or up to 225 meals per year (140 grams of sportfish per day)

21 micrograms per day Lindane / 140 grams of fish per day /.7 preparation reduction

Less than $0.21 \mathrm{ppm}$ Lindane in raw skin off (catfish) fish fillet

\section{GROUP 2}

Up to 1 meal per week (32 grams of sportfish per day)

21 micrograms per day Lindane / 32 grams of fish per day /.7 preparation reduction

$0.21 \mathrm{ppm}$ to $0.94 \mathrm{ppm}$ Lindane in raw skin off (catfish) fish fillet

\section{GROUP 3}

Up to 1 meal per month

(7.4 grams of sportfish per day)

21 micrograms per day Lindane / 7.4 grams of fish per day /.7 preparation reduction

$0.94 \mathrm{ppm}$ to $4.05 \mathrm{ppm}$ Lindane in raw skin off (catfish) fish fillet

\section{GROUP 4}

Up to 6 meals per year (3.7 grams of sportfish per day)

21 micrograms per day Lindane / 3.7 grams of fish per day / .7 preparation reduction

$4.05 \mathrm{ppm}$ to $8.11 \mathrm{ppm}$ Lindane in raw skin off (catfish) fish fillet

\section{GROUP 5}

DO NOT EAT

Greater than $8.11 \mathrm{ppm}$ Lindane in raw skin off (catfish) fish fillet 


\section{Children Advisory Assumptions - Lindane Skin On Fillet}

\section{Assumptions:}

1) Reference Dose is 0.3 micrograms Lindane per kilogram per day

2) Average Meal Size is 52.5 grams or 3 ounces of uncooked fish.

3) Representative Consumer Body weight is 14.5 kilograms.

4) Five Advisory Groups: Unrestricted or 225 meals per year; One meal per week; One meal per month; Six meals per year; No Consumption.

5) Assume meal preparation reduces residues by 50\% from raw skin on fish fillets used to determine Lindane residue level.

\section{Maximum Allowable Daily Lindane Ingestion Calculation}

0.3 micrograms per kilogram per day X 14.5 kilogram body weight $=4.35$ micrograms Lindane allowed per day.

\section{Children Advisory Assumptions - Lindane Skin Off Fillet}

\section{Assumptions:}

1) Reference Dose is 0.3 micrograms Lindane per kilogram per day

2) Average Meal Size is 52.5 grams or 3 ounces of uncooked fish.

3) Representative Consumer Body weight is 14.5 kilograms.

4) Five Advisory Groups: Unrestricted or 225 meals per year; One meal per week; One meal per month; Six meals per year; No Consumption.

5) Assume meal preparation reduces residues by 30\% from raw skin off (catfish) fish fillets used to determine Lindane residue level.

\section{Maximum Allowable Daily Lindane Ingestion Calculation}

0.3 micrograms per kilogram per day X 14.5 kilogram body weight $=4.35$ micrograms Lindane allowed per day. 


\section{Lindane Child Advisory Groups - Skin On Fillet}

\section{GROUP 1}

Unrestricted Consumption or up to 225 meals per year (52.5 grams of sportfish per day)

4.35 micrograms per day Lindane / 52.5 grams of fish per day /.5 preparation reduction

Less than $0.17 \mathrm{ppm}$ Lindane in raw skin on fish fillet

\section{GROUP 2}

Up to 1 meal per week

(12.13 grams of sportfish per day)

4.35 micrograms per day Lindane / 12.13 grams of fish per day /.5 preparation reduction

$0.17 \mathrm{ppm}$ to $0.72 \mathrm{ppm}$ Lindane in raw skin on fish fillet

\section{GROUP 3}

Up to 1 meal per month

(2.8 grams of sportfish per day)

4.35 micrograms per day Lindane / 2.8 grams of fish per day /.5 preparation reduction

$0.72 \mathrm{ppm}$ to $3.11 \mathrm{ppm}$ Lindane in raw skin on fish fillet

\section{GROUP 4}

Up to 6 meals per year (1.4 grams of sportfish per day)

4.35 micrograms per day Lindane / 1.4 grams of fish per day / .5 preparation reduction

$3.11 \mathrm{ppm}$ to $6.21 \mathrm{ppm}$ Lindane in raw skin on fish fillet

\section{GROUP 5}

DO NOT EAT

Greater than $6.21 \mathrm{ppm}$ Lindane in raw skin on fish fillet 


\section{Lindane Child Advisory Groups - Skin Off Fillet}

\section{GROUP 1}

Unrestricted Consumption or up to 225 meals per year (52.5 grams of sportfish per day)

4.35 micrograms per day Lindane / 52.5 grams of fish per day /.7 preparation reduction

Less than $0.12 \mathrm{ppm}$ Lindane in raw skin off (catfish) fish fillet

\section{GROUP 2}

Up to 1 meal per week

(12.13 grams of sportfish per day)

4.35 micrograms per day Lindane / 12.13 grams of fish per day /.7 preparation reduction

$0.12 \mathrm{ppm}$ to $0.51 \mathrm{ppm}$ Lindane in raw skin off (catfish) fish fillet

\section{GROUP 3}

Up to 1 meal per month

(2.8 grams of sportfish per day)

4.35 micrograms per day Lindane / 2.8 grams of fish per day /.7 preparation reduction

$0.51 \mathrm{ppm}$ to $2.22 \mathrm{ppm}$ Lindane in raw skin off (catfish) fish fillet

\section{GROUP 4}

Up to 6 meals per year (1.4 grams of sportfish per day)

4.35 micrograms per day Lindane / 1.4 grams of fish per day / .7 preparation reduction

$2.22 \mathrm{ppm}$ to $4.44 \mathrm{ppm}$ Lindane in raw skin off (catfish) fish fillet

\section{GROUP 5}

DO NOT EAT

Greater than 4.44 ppm Lindane in raw skin off (catfish) fish fillet 


\section{Methylmercury Summary}

Merck Number 5957 (Mercury)

CAS Number 22967-92-6

Oral RfD 0.0001

Preparation Dose Reduction 1

Humans have mined mercury since $415 \mathrm{BC}$. It has been used in gold extraction, in mirrors, to make felt hats, for electrodes to produce chlorine, in electrical components, as an antiseptic, in plastic manufacturing, as a slimicide in the pulp and paper industry, and as an agricultural fungicide. Mercury is widespread in the environment from both natural and human sources. Combustion of fossil fuels, especially coal, is the currently largest contributor of mercury into the environment. Combustion of coal is estimated to contribute $50 \%$ of the anthropogenic mercury to the atmosphere.(Pinkney et al 1997) Mercury has no known metabolic function. Biological and other processes transform low toxicity forms of mercury into forms with high toxicity. Mercury, like many compounds can be bioconcentrated through the food chain. Methylmercury is lipophilic, but also binds to protein and is found in considerable amounts in fish fillets.

Humans rapidly and almost completely absorb methylmercury. It is mutagenic causing chromosome damage in animal studies. Methylmercury is of great concern for women in their child bearing years and pregnant women. Pregnant women exposed to methylmercury in their diets bore children with nervous system damage at levels producing only minor effects in the mothers. The U.S. EPA lists methylmercury as a possible human carcinogen. Male mice had higher levels of kidney tumors after being dosed with methylmercury. Chronic effects from the human exposures in Japan and Iraq include impaired vision, numbness, lost coordination, slurred speech, damaged hearing, inability to walk and mental problems. 
It has been reported that more than eighty percent of the total mercury found in fish is in the form of methylmercury ( Kannan et al 1998, Eisler 1987). Due to cost and difficulty of analytical methods, analysis for total mercury will be used to determine fish consumption advisories. This approach will also provide additional health protection for those following the advisory. 


\section{Adult Advisory Assumptions - Methylmercury}

\section{Assumptions:}

1) Reference Dose is 0.1 micrograms Methylmercury per kilogram per day

2) Average Meal Size is 227 grams or $1 / 2$ pound of uncooked fish.

3) Representative Consumer Body weight is 70 kilograms.

4) Five Advisory Groups: Unrestricted or 225 meals per year; One meal per week; One meal per month; Six meals per year; No Consumption.

5) Assume meal preparation does not reduce residues by $50 \%$ from raw skin on fish fillets used to determine Methylmercury residue level.

\section{Maximum Allowable Daily Methylmercury Ingestion Calculation}

0.1 micrograms per kilogram per day X 70 kilogram body weight $=7$ micrograms

Methylmercury allowed per day. 


\section{Methylmercury Adult Advisory Groups}

\section{GROUP 1}

Unrestricted Consumption or up to 225 meals per year (140 grams of sportfish per day)

7 micrograms per day Methylmercury / 140 grams of fish per day

Less than $0.05 \mathrm{ppm}$ Methylmercury in raw skin on fish fillet

\section{GROUP 2}

Up to 1 meal per week

(32 grams of sportfish per day)

7 micrograms per day Methylmercury / 32 grams of fish per day

$0.05 \mathrm{ppm}$ to $0.22 \mathrm{ppm}$ Methylmercury in raw skin on fish fillet

\section{GROUP 3}

Up to 1 meal per month

(7.4 grams of sportfish per day)

7 micrograms per day Methylmercury / 7.4 grams of fish per day

$0.22 \mathrm{ppm}$ to $0.95 \mathrm{ppm}$ Methylmercury in raw skin on fish fillet

\section{GROUP 4}

Up to 6 meals per year

(3.7 grams of sportfish per day)

7 micrograms per day Methylmercury / 3.7 grams of fish per day

$0.95 \mathrm{ppm}$ to $1.89 \mathrm{ppm}$ Methylmercury in raw skin on fish fillet

\section{GROUP 5}

DO NOT EAT

Greater than 1.89 ppm Methylmercury in raw skin on fish fillet 


\section{Children Advisory Assumptions - Methylmercury}

\section{Assumptions:}

1) Reference Dose is 0.1 micrograms Methylmercury per kilogram per day

2) Average Meal Size is 52.5 grams or 3 ounces of uncooked fish.

3) Representative Consumer Body weight is 14.5 kilograms.

4) Five Advisory Groups: Unrestricted or 225 meals per year; One meal per week; One meal per month; Six meals per year; No Consumption.

5) Assume meal preparation does not reduce residues by $50 \%$ from raw skin on fish fillets used to determine Methylmercury residue level.

\section{Maximum Allowable Daily Methylmercury Ingestion Calculation}

0.1 micrograms per kilogram per day X 14.5 kilogram body weight $=1.45$ micrograms Methylmercury allowed per day. 


\section{Methylmercury Child Advisory Groups}

\section{GROUP 1}

Unrestricted Consumption or up to 225 meals per year

(52.5 grams of sportfish per day)

1.45 micrograms per day Methylmercury / 52.5 grams of fish per day

Less than $0.028 \mathrm{ppm}$ Methylmercury in raw skin on fish fillet

\section{GROUP 2}

Up to 1 meal per week

(12.13 grams of sportfish per day)

1.45 micrograms per day Methylmercury / 12.13 grams of fish per day

$0.028 \mathrm{ppm}$ to $0.12 \mathrm{ppm}$ Methylmercury in raw skin on fish fillet

\section{GROUP 3}

Up to 1 meal per month

(2.8 grams of sportfish per day)

1.45 micrograms per day Methylmercury / 2.8 grams of fish per day

$0.12 \mathrm{ppm}$ to $0.52 \mathrm{ppm}$ Methylmercury in raw skin on fish fillet

\section{GROUP 4}

Up to 6 meals per year

(1.4 grams of sportfish per day)

1.45 micrograms per day Methylmercury / 1.4 grams of fish per day

$0.52 \mathrm{ppm}$ to $1.036 \mathrm{ppm}$ Methylmercury in raw skin on fish fillet

\section{GROUP 5}

DO NOT EAT

Greater than 1.036 ppm Methylmercury in raw skin on fish fillet 


\section{Mirex Summary}

Merck Number 6294

CAS Number 2385-85-5

Oral RfD $0.0002 \mathrm{mg} / \mathrm{kg}$

Preparation Dose Reduction .5 Skin on, .7 Skin off

Mirex is a polymerizing agent that was used as an organochlorine pesticide and fire retardant. Its registration as a pesticide and use as a fire retardant was revoked in 1975. Mirex is an odorless white crystal. Mirex was used as an insecticide, rodenticide and in antifouling paints. Mirex was used as a fire retardant in electrical components, rubber, paint, and plastic. Mirex is highly lipophilic and bioconcentrates in the ecosystem. Mirex has been found in human milk.

Mutagenicity testing is limited and most bacterial testing was negative. Animal studies have shown prenatal exposure causing smaller liters, cataracts and skeletal deformities. The U.S. EPA has listed Mirex as a probable human carcinogen. Animal studies have shown increased rates of adrenal gland and liver tumors. Chronic exposure in rats caused kidney, liver, spleen and thyroid damage. A study found $90 \%$ of the experimental dose in the fat of monkeys 106 days after intake. 


\section{Adult Advisory Assumptions - Mirex Skin On Fillet}

\section{Assumptions:}

1) Reference Dose is 0.2 micrograms Mirex per kilogram per day

2) Average Meal Size is 227 grams or $1 / 2$ pound of uncooked fish.

3) Representative Consumer Body weight is 70 kilograms.

4) Five Advisory Groups: Unrestricted or 225 meals per year; One meal per week; One meal per month; Six meals per year; No Consumption.

5) Assume meal preparation reduces residues by 50\% from raw skin on fish fillets used to determine Mirex residue level.

\section{Maximum Allowable Daily Mirex Ingestion Calculation}

0.2 micrograms per kilogram per day X 70 kilogram body weight $=14$ micrograms Mirex allowed per day.

\section{Adult Advisory Assumptions - Mirex Skin Off Fillet}

\section{Assumptions:}

1) Reference Dose is 0.2 micrograms Mirex per kilogram per day

2) Average Meal Size is 227 grams or $1 / 2$ pound of uncooked fish.

3) Representative Consumer Body weight is 70 kilograms.

4) Five Advisory Groups: Unrestricted or 225 meals per year; One meal per week; One meal per month; Six meals per year; No Consumption.

5) Assume meal preparation reduces residues by 30\% from raw skin off (catfish) fish fillets used to determine Mirex residue level.

\section{Maximum Allowable Daily Mirex Ingestion Calculation}

0.2 micrograms per kilogram per day X 70 kilogram body weight $=14$ micrograms Mirex allowed per day. 
Mirex Adult Advisory Groups Skin On Fillet

\section{GROUP 1}

Unrestricted Consumption or up to 225 meals per year (140 grams of sportfish per day)

14 micrograms per day Mirex / 140 grams of fish per day / .5 preparation reduction

Less than $0.20 \mathrm{ppm}$ Mirex in raw skin on fish fillet

\section{GROUP 2}

Up to 1 meal per week

(32 grams of sportfish per day)

14 micrograms per day Mirex / 32 grams of fish per day / .5 preparation reduction

$0.20 \mathrm{ppm}$ to $0.88 \mathrm{ppm}$ Mirex in raw skin on fish fillet

\section{GROUP 3}

Up to 1 meal per month

(7.4 grams of sportfish per day)

14 micrograms per day Mirex / 7.4 grams of fish per day / .5 preparation reduction

$0.88 \mathrm{ppm}$ to $3.78 \mathrm{ppm}$ Mirex in raw skin on fish fillet

\section{GROUP 4}

Up to 6 meals per year (3.7 grams of sportfish per day)

14 micrograms per day Mirex / 3.7 grams of fish per day / .5 preparation reduction

$3.78 \mathrm{ppm}$ to $7.56 \mathrm{ppm}$ Mirex in raw skin on fish fillet

\section{GROUP 5}

DO NOT EAT

Greater than $7.56 \mathrm{ppm}$ Mirex in raw skin on fish fillet 


\section{Mirex Adult Advisory Groups Skin Off Fillet}

\section{GROUP 1}

Unrestricted Consumption or up to 225 meals per year (140 grams of sportfish per day)

14 micrograms per day Mirex / 140 grams of fish per day / .7 preparation reduction

Less than $0.14 \mathrm{ppm}$ Mirex in raw skin off (catfish) fish fillet

\section{GROUP 2}

Up to 1 meal per week

(32 grams of sportfish per day)

14 micrograms per day Mirex / 32 grams of fish per day / .7 preparation reduction

$0.14 \mathrm{ppm}$ to $0.63 \mathrm{ppm}$ Mirex in raw skin off (catfish) fish fillet

\section{GROUP 3}

Up to 1 meal per month

(7.4 grams of sportfish per day)

14 micrograms per day Mirex / 7.4 grams of fish per day / .7 preparation reduction

$0.63 \mathrm{ppm}$ to $2.70 \mathrm{ppm}$ Mirex in raw skin off (catfish) fish fillet

\section{GROUP 4}

Up to 6 meals per year (3.7 grams of sportfish per day)

14 micrograms per day Mirex / 3.7 grams of fish per day / .7 preparation reduction

$2.70 \mathrm{ppm}$ to $5.41 \mathrm{ppm}$ Mirex in raw skin off (catfish) fish fillet

\section{GROUP 5}

DO NOT EAT

Greater than $5.41 \mathrm{ppm}$ Mirex in raw skin off (catfish) fish fillet 


\section{Children Advisory Assumptions - Mirex Skin On Fillet}

\section{Assumptions:}

1) Reference Dose is 0.2 micrograms Mirex per kilogram per day

2) Average Meal Size is 52.5 grams or 3ounces of uncooked fish.

3) Representative Consumer Body weight is 14.5 kilograms.

4) Five Advisory Groups: Unrestricted or 225 meals per year; One meal per week; One meal per month; Six meals per year; No Consumption.

5) Assume meal preparation reduces residues by 50\% from raw skin on fish fillets used to determine Mirex residue level.

\section{Maximum Allowable Daily Mirex Ingestion Calculation}

0.2 micrograms per kilogram per day X 14.5 kilogram body weight $=2.9$ micrograms Mirex allowed per day.

\section{Children Advisory Assumptions - Mirex Skin Off Fillet}

\section{Assumptions:}

1) Reference Dose is 0.2 micrograms Mirex per kilogram per day

2) Average Meal Size is 52.5 grams or 3 ounces of uncooked fish.

3) Representative Consumer Body weight is 14.5 kilograms.

4) Five Advisory Groups: Unrestricted or 225 meals per year; One meal per week; One meal per month; Six meals per year; No Consumption.

5) Assume meal preparation reduces residues by 30\% from raw skin off (catfish) fish fillets used to determine Mirex residue level.

\section{Maximum Allowable Daily Mirex Ingestion Calculation}

0.2 micrograms per kilogram per day X 14.5 kilogram body weight $=2.9$ micrograms Mirex allowed per day. 


\section{Mirex Child Advisory Groups Skin On Fillet}

\section{GROUP 1}

Unrestricted Consumption or up to 225 meals per year (52.5 grams of sportfish per day)

2.9 micrograms per day Mirex / 52.5 grams of fish per day / .5 preparation reduction

Less than $0.11 \mathrm{ppm}$ Mirex in raw skin on fish fillet

\section{GROUP 2}

Up to 1 meal per week

(12.13 grams of sportfish per day)

2.9 micrograms per day Mirex / 12.13 grams of fish per day / .5 preparation reduction

$0.11 \mathrm{ppm}$ to $0.49 \mathrm{ppm}$ Mirex in raw skin on fish fillet

\section{GROUP 3}

Up to 1 meal per month

(2.8 grams of sportfish per day)

2.9 micrograms per day Mirex / 2.8 grams of fish per day / .5 preparation reduction

$0.49 \mathrm{ppm}$ to $2.071 \mathrm{ppm}$ Mirex in raw skin on fish fillet

\section{GROUP 4}

Up to 6 meals per year (1.4 grams of sportfish per day)

2.9 micrograms per day Mirex / 1.4 grams of fish per day / .5 preparation reduction

$2.071 \mathrm{ppm}$ to $4.14 \mathrm{ppm}$ Mirex in raw skin on fish fillet

\section{GROUP 5}

DO NOT EAT

Greater than $4.14 \mathrm{ppm}$ Mirex in raw skin on fish fillet 


\section{Mirex Child Advisory Groups Skin Off Fillet}

\section{GROUP 1}

Unrestricted Consumption or up to 225 meals per year

(52.5 grams of sportfish per day)

2.9 micrograms per day Mirex / 52.5 grams of fish per day / .7 preparation reduction

Less than $0.079 \mathrm{ppm}$ Mirex in raw skin off (catfish) fish fillet

\section{GROUP 2}

Up to 1 meal per week

(12.13 grams of sportfish per day)

2.9 micrograms per day Mirex / 12.13 grams of fish per day / .7 preparation reduction

$0.079 \mathrm{ppm}$ to $0.34 \mathrm{ppm}$ Mirex in raw skin off (catfish) fish fillet

\section{GROUP 3}

Up to 1 meal per month

(2.8 grams of sportfish per day)

2.9 micrograms per day Mirex / 2.8 grams of fish per day / .7 preparation reduction

$0.34 \mathrm{ppm}$ to $1.48 \mathrm{ppm}$ Mirex in raw skin off (catfish) fish fillet

\section{GROUP 4}

Up to 6 meals per year (1.4 grams of sportfish per day)

2.9 micrograms per day Mirex / 1.4 grams of fish per day / .7 preparation reduction

$1.48 \mathrm{ppm}$ to $2.96 \mathrm{ppm}$ Mirex in raw skin off (catfish) fish fillet

\section{GROUP 5}

DO NOT EAT

Greater than $2.96 \mathrm{ppm}$ Mirex in raw skin off (catfish) fish fillet 


\section{Polychlorinated Biphenyl Summary}

Merck Number

CAS Number 1336-36-3

Human Protection Value $0.00005 \mathrm{mg} / \mathrm{kg} / \mathrm{day}$

Preparation Dose Reduction .5 Skin on, .7 Skin off

Polychlorinated biphenyls (PCBs) are a group of 209 isomers of synthetic halogenated hydrocarbons invented in 1881. They were used for heat transfer agents, lubricant, dielectric agents, flame retardants, plasticizers, and waterproofing materials. Since 1971, PCBs have been used only for insulation or cooling in closed electrical components. Due to indiscriminate disposal and atmospheric transport, PCB residues are found worldwide. They are extremely persistent in the environment, fat soluble, and bioaccumulate in the environment. The Toxic Substances Control Act which went into effect in 1979, banned the manufacture processing, distribution, and use of PCBs except in totally enclosed systems.

PCBs are very readily absorbed through the gastrointestinal tract and stored fatty tissue including the liver, skin, and in milk. PCBs are commonly found in human milk and can be transferred through the placenta. Acute doses have caused death in animal studies, although no human deaths have been documented due to PCB exposure. Chronic exposures in animal studies include hepatic, gastrointestinal, hematological, dermal, endocrine, immunological, reproductive, and developmental effects. One human study showed lower birth weight, smaller head circumference, and shorter gestational age. The children at age 4 displayed decreased short-term memory. At age 11 the children with prenatal exposure had lower full scale and verbal IQ scores. Most mutagenicity tests produced negative results. Workers with occupational exposures of 10 -25 years have increased chromosomal abnormalities and increased sister chromatid exchange. The U.S. EPA lists PCBs as a probable human carcinogen. They have 
produced liver cancers in rats. Further studies indicate increased cancer risk with increased chlorination. 


\section{Advisory Assumptions - PCB Skin On Fillet}

\section{Assumptions:}

1) Human Protection Value is 0.05 micrograms PCB per kilogram per day

2) Average Meal Size is 227 grams or $1 / 2$ pound of uncooked fish.

3) Representative Consumer Body weight is 70 kilograms.

4) Five Advisory Groups: Unrestricted or 225 meals per year; One meal per week; One meal per month; Six meals per year; No Consumption.

5) Assume meal preparation reduces residues by 50\% from raw skin on fish fillets used to determine PCB residue level.

\section{Maximum Allowable Daily PCB Ingestion Calculation}

0.05 micrograms per kilogram per day X 70 kilogram body weight $=3.5$ micrograms $\mathbf{P C B}$ allowed per day.

\section{Advisory Assumptions - PCB Skin Off Fillet}

\section{Assumptions:}

1) Human Protection Value is 0.05 micrograms PCB per kilogram per day

2) Average Meal Size is 227 grams or $1 / 2$ pound of uncooked fish.

3) Representative Consumer Body weight is 70 kilograms.

4) Five Advisory Groups: Unrestricted or 225 meals per year; One meal per week; One meal per month; Six meals per year; No Consumption.

5) Assume meal preparation reduces residues by 30\% from raw skin off (catfish) fish fillets used to determine PCB residue level.

\section{Maximum Allowable Daily PCB Ingestion Calculation}

0.05 micrograms per kilogram per day X 70 kilogram body weight $=3.5$ micrograms $\mathbf{P C B}$ allowed per day. 


\section{PCB Advisory Groups - Skin On Fillet}

\section{GROUP 1}

Unrestricted Consumption or up to 225 meals per year (140 grams of sportfish per day)

3.5 micrograms per day $\mathbf{P C B} / 140$ grams of fish per day /.5 preparation reduction

Less than $0.05 \mathrm{ppm}$ PCB in raw skin on fish fillet

\section{GROUP 2}

Up to 1 meal per week

(32 grams of sportfish per day)

3.5 micrograms per day PCB / 32 grams of fish per day / .5 preparation reduction

$0.05 \mathrm{ppm}$ to $0.22 \mathrm{ppm} \mathbf{P C B}$ in raw skin on fish fillet

\section{GROUP 3}

Up to 1 meal per month

(7.4 grams of sportfish per day)

3.5 micrograms per day $\mathbf{P C B}$ / 7.4 grams of fish per day / .5 preparation reduction

$0.22 \mathrm{ppm}$ to $0.95 \mathrm{ppm} \mathbf{P C B}$ in raw skin on fish fillet

\section{GROUP 4}

Up to 6 meals per year (3.7 grams of sportfish per day)

3.5 micrograms per day PCB / 3.7 grams of fish per day / .5 preparation reduction

$0.95 \mathrm{ppm}$ to $1.89 \mathrm{ppm} \mathbf{P C B}$ in raw skin on fish fillet

\section{GROUP 5}

DO NOT EAT

Greater than $1.89 \mathrm{ppm}$ PCB in raw skin on fish fillet 


\section{PCB Advisory Groups - Skin Off Fillet}

\section{GROUP 1}

Unrestricted Consumption or up to 225 meals per year (140 grams of sportfish per day)

3.5 micrograms per day PCB / 140 grams of fish per day /.7 preparation reduction

Less than $0.036 \mathrm{ppm}$ PCB in raw skin off (catfish) fish fillet

\section{GROUP 2}

Up to 1 meal per week

(32 grams of sportfish per day)

3.5 micrograms per day PCB / 32 grams of fish per day / .7 preparation reduction

$0.036 \mathrm{ppm}$ to $0.16 \mathrm{ppm} \mathbf{P C B}$ in raw skin off (catfish) fish fillet

\section{GROUP 3}

Up to 1 meal per month

(7.4 grams of sportfish per day)

3.5 micrograms per day $\mathbf{P C B}$ / 7.4 grams of fish per day / .7 preparation reduction

$0.16 \mathrm{ppm}$ to $0.68 \mathrm{ppm} \mathbf{P C B}$ in raw skin off (catfish) fish fillet

\section{GROUP 4}

Up to 6 meals per year (3.7 grams of sportfish per day)

3.5 micrograms per day PCB / 3.7 grams of fish per day / .7 preparation reduction

$0.68 \mathrm{ppm}$ to $1.35 \mathrm{ppm}$ PCB in raw skin off (catfish) fish fillet

\section{GROUP 5}

DO NOT EAT

Greater than 1.35 ppm PCB in raw skin off (catfish) fish fillet 


\section{Polycyclic Aromatic Hydrocarbons}

Merck Number

CAS Number 130498-29-2

Oral RfD None

Oral Slope Factor $7.3 \mathrm{mg} / \mathrm{kg} / \mathrm{day}$

Preparation Dose Reduction

Polycyclic aromatic hydrocarbons (PAHs) are a group of more than 100 different compounds.

PAHs occur naturally and can be made. They are formed from incomplete combustion of coal, oil, gas and organic materials. PAHs in pure form are colorless, white or yellow-green solids. Most PAHs are not water soluble and are persistent in the environment for periods of months to years. Some PAHs are used in dyes, plastics, medicines and pesticides. PAHs are stored in the kidneys, liver, fat and to a lesser extent in the spleen, adrenal glands and ovaries. Most PAHs exit the body within a few days through the feces and urine.

PAHs are listed as $\mathrm{B}_{2}$ a probable human carcinogen by the EPA. They caused tumors in animals when taken orally. Mice fed PAHs had difficulty reproducing as did their offspring. PAHs also cause birth defects and decreased birth weight in mice. PAHs also cause skin and immune system problems in animal studies. The EPA has set limits on PAHs in drinking water based on levels of benzo(a)pyrene and similar compounds.

\# based on Benzo(a)pyrene 
Cancer Effect Assumptions - Polycyclic Aromatic Hydrocarbons Skin On Fillets

\section{Assumptions:}

1) Slope Factor is 7.3 milligrams Polycyclic Aromatic Hydrocarbons per kilogram per day

2) Average Meal Size is 227 grams or $1 / 2$ pound of uncooked fish.

3) Representative Consumer Body weight is 70 kilograms.

4) ARL is $10^{-4}$

5) Five Consumption Rates: Unrestricted 225 meals per year(140 g/day); One meal per week(32g/day); One meal per month(7.4 g/day); Six meals per year(3.7 g/day); No Consumption.

6) Assume meal preparation reduces residues by 50\% from raw skin off (catfish) fish fillets used to determine Polycyclic Aromatic Hydrocarbons residue level.

\section{Cancer Effect Assumptions - Polycyclic Aromatic Hydrocarbons Skin Off Fillets (Catfish)}

\section{Assumptions:}

1) Slope Factor is 7.3 milligrams Polycyclic Aromatic Hydrocarbons per kilogram per day

2) Average Meal Size is 227 grams or $1 / 2$ pound of uncooked fish.

3) Representative Consumer Body weight is 70 kilograms.

4) ARL is $10^{-4}$

5) Five Consumption Rates: Unrestricted 225 meals per year(140 g/day); One meal per week(32g/day); One meal per month(7.4 g/day); Six meals per year(3.7 g/day); No Consumption.

6) Assume meal preparation reduces residues by 30\% from raw skin off (catfish) fish fillets used to determine Polycyclic Aromatic Hydrocarbons residue level. 
Polycyclic Aromatic Hydrocarbons Cancer Effect Advisory Groups - Skin On Fillets

\section{GROUP 1}

Unrestricted Consumption or up to 225 meals per year

(140 grams of sportfish per day)

Less than 0.014 ppm Polycyclic Aromatic Hydrocarbons in raw skin on fish fillet

\section{GROUP 2}

Up to 1 meal per week

(32 grams of sportfish per day)

$0.014 \mathrm{ppm}$ to $0.060 \mathrm{ppm}$ Polycyclic Aromatic Hydrocarbons in raw skin on fish fillet

\section{GROUP 3}

Up to 1 meal per month

(7.4 grams of sportfish per day)

$0.060 \mathrm{ppm}$ to $0.26 \mathrm{ppm}$ Polycyclic Aromatic Hydrocarbons in raw skin on fish fillet

\section{GROUP 4}

Up to 0.8 meals per year

(3.7 grams of sportfish per day)

$0.26 \mathrm{ppm}$ to $0.52 \mathrm{ppm}$ Polycyclic Aromatic Hydrocarbons in raw skin on fish fillet

\section{GROUP 5 \\ DO NOT EAT}

Greater than $0.52 \mathrm{ppm}$ Polycyclic Aromatic Hydrocarbons in raw skin on fish fillet 
Polycyclic Aromatic Hydrocarbons Cancer Effect Advisory Groups -

Skin Off Fillets

\section{GROUP 1}

Unrestricted Consumption or up to 225 meals per year

(140 grams of sportfish per day)

Less than 0.010 ppm Polycyclic Aromatic Hydrocarbons in raw skin off (catfish) fish fillet

\section{GROUP 2}

Up to 1 meal per week

(32 grams of sportfish per day)

0.010 ppm to 0.043 ppm Polycyclic Aromatic Hydrocarbons in raw skin off (catfish) fish fillet

\section{GROUP 3}

Up to 1 meal per month

(7.4 grams of sportfish per day)

$0.043 \mathrm{ppm}$ to $0.19 \mathrm{ppm}$ Polycyclic Aromatic Hydrocarbons in raw skin off (catfish) fish fillet

\section{GROUP 4}

Up to 0.8 meals per year

(3.7 grams of sportfish per day)

$0.19 \mathrm{ppm}$ to $0.37 \mathrm{ppm}$ Polycyclic Aromatic Hydrocarbons in raw skin off (catfish) fish fillet

\section{GROUP 5}

DO NOT EAT

Greater than 0.37 ppm Polycyclic Aromatic Hydrocarbons in raw skin off (catfish) fish fillet 


\section{Selenium Summary}

Merck Number 8572

CAS Number 7782-49-2

Oral RfD $0.005 \mathrm{mg} / \mathrm{kg}$

Preparation Dose Reduction 1

Berzelius identified selenium as an element in 1817. Selenium is one of the essential trace metals, required at low levels for metabolism and growth, but can be toxic at higher concentrations. Selenium is naturally occurring in the environment, but human releases are significant. Anthropogenic sources of selenium come from burning coal and other fossil fuels, manufacturing processes, municipal waste and copper and nickel mining. Selenium has been used in electronic components, ceramics, glass, paints, rubber, steel, and varnishes. Selenium was used as a fungicide, pesticide and in medicines.

Selenium is easily absorbed and bound to proteins. It accumulates mainly in the kidney and liver. Selenium has produced teratogenic, fetotoxic, and embryotoxic effects. Several studies of livestock exposure have documented fetal deformities and reduced birth weights. Mutagenicity testing has found chromosome damage in human lymphocytes and rat bone marrow and unscheduled DNA synthesis. There have been some studies illustrating lower doses of selenium may prevent mutation by chemical compounds. The U.S. EPA list selenium as a probable human carcinogen. Rodent and livestock studies have show increases in liver tumors after exposure from selenium. Chronic exposure to selenium can cause brittle and thickened nails, CNS abnormalities, hair and nail loss, reduced hemoglobin levels, mottled teeth, skin lesions, lowered blood clotting, liver malfunction and muscle spasms. Neurological problems have been documented in humans and animals ranging from lethargy to spinal cord lesions. 


\section{Adult Advisory Assumptions - Selenium}

\section{Assumptions:}

1) Reference Dose is 5 micrograms Selenium per kilogram per day

2) Average Meal Size is 227 grams or $1 / 2$ pound of uncooked fish.

3) Representative Consumer Body weight is 70 kilograms.

4) Five Advisory Groups: Unrestricted or 225 meals per year; One meal per week; One meal per month; Six meals per year; No Consumption.

5) Assume meal preparation does not reduce residues by $50 \%$ from raw skin on fish fillets used to determine Selenium residue level.

\section{Maximum Allowable Daily Selenium Ingestion Calculation}

5 micrograms per kilogram per day X 70 kilogram body weight $=350$ micrograms Selenium allowed per day. 


\section{Selenium Adult Advisory Groups}

\section{GROUP 1}

Unrestricted Consumption or up to 225 meals per year (140 grams of sportfish per day)

350 micrograms per day Selenium / 140 grams of fish per day

Less than $2.5 \mathrm{ppm}$ Selenium in raw skin on fish fillet

\section{GROUP 2}

Up to 1 meal per week

(32 grams of sportfish per day)

350 micrograms per day Selenium / 32 grams of fish per day

$2.5 \mathrm{ppm}$ to $10.94 \mathrm{ppm}$ Selenium in raw skin on fish fillet

\section{GROUP 3}

Up to 1 meal per month

(7.4 grams of sportfish per day)

350 micrograms per day Selenium / 7.4 grams of fish per day

$10.94 \mathrm{ppm}$ to $47.30 \mathrm{ppm}$ Selenium in raw skin on fish fillet

\section{GROUP 4}

Up to 5 meals per year (3.7 grams of sportfish per day)

350 micrograms per day Selenium / 3.7 grams of fish per day

$47.30 \mathrm{ppm}$ to $94.59 \mathrm{ppm}$ Selenium in raw skin on fish fillet

\section{GROUP 5}

DO NOT EAT

Greater than 94.59 ppm Selenium in raw skin on fish fillet 


\section{Child Advisory Assumptions - Selenium}

\section{Assumptions:}

1) Reference Dose is 5 micrograms Selenium per kilogram per day

2) Average Meal Size is 52.5 grams or 3 ounces of uncooked fish.

3) Representative Consumer Body weight is 14.5 kilograms.

4) Five Advisory Groups: Unrestricted or 225 meals per year; One meal per week; One meal per month; Six meals per year; No Consumption.

5) Assume meal preparation does not reduce residues from raw fish fillets used to determine Selenium residue level.

\section{Maximum Allowable Daily Selenium Ingestion Calculation}

5 micrograms per kilogram per day X 14.5 kilogram body weight $=72.5$ micrograms Selenium allowed per day. 


\section{Selenium Child Advisory Groups}

\section{GROUP 1}

Unrestricted Consumption or up to 225 meals per year (52.5 grams of sportfish per day)

72.5 micrograms per day Selenium / 52.5 grams of fish per day

Less than $1.38 \mathrm{ppm}$ Selenium in raw skin on fish fillet

\section{GROUP 2}

Up to 1 meal per week

(12.13 grams of sportfish per day)

72.5 micrograms per day Selenium / 12.13 grams of fish per day

$1.38 \mathrm{ppm}$ to $5.98 \mathrm{ppm}$ Selenium in raw skin on fish fillet

\section{GROUP 3}

Up to 1 meal per month

(2.8 grams of sportfish per day)

72.5 micrograms per day Selenium / 2.8 grams of fish per day

$5.98 \mathrm{ppm}$ to $25.89 \mathrm{ppm}$ Selenium in raw skin on fish fillet

\section{GROUP 4}

Up to 5 meals per year (2.8 grams of sportfish per day)

72.5 micrograms per day Selenium / 2.8 grams of fish per day

$25.89 \mathrm{ppm}$ to $51.79 \mathrm{ppm}$ Selenium in raw skin on fish fillet

\section{GROUP 5}

DO NOT EAT

Greater than 51.79 ppm Selenium in raw skin on fish fillet 


\section{Terbufos Summary}

Merck Number 9301

CAS Number 13071-79-9

Oral RfD $0.00005 \mathrm{mg} / \mathrm{kg}$

Preparation Dose Reduction 1

Terbufos is an organophosphate insecticide and nematicide. It is used on corn, sorghum, and sugar beets to treat corn root worm larvae, seedcorn maggots, white grubs and wireworms. Terbufos is a clear amber liquid manufactured in granules spread directly in or on the seed furrow. Non lethal doses of terbufos are quickly eliminated from all animals tested including rats, chickens, cows, and fish.

Experiments have produced no evidence that terbufos is mutagenic or teratogenic or carcinogenic. The U.S. EPA has not been unable to classify the carcinogenicity of terbufos because of lack of data. Several animal studies have resulted in cholinesterase inhibition with chronic exposure. Other chronic effects noted include clouded cornea, loss of balance, hair loss, and protrusion and rupture of the eyes. 


\section{Adult Advisory Assumptions - Terbufos}

\section{Assumptions:}

1) Reference Dose is 0.05 micrograms Terbufos per kilogram per day

2) Average Meal Size is 227 grams or $1 / 2$ pound of uncooked fish.

3) Representative Consumer Body weight is 70 kilograms.

4) Five Advisory Groups: Unrestricted or 225 meals per year; One meal per week; One meal per month; Six meals per year; No Consumption.

5) Assume meal preparation does not reduce residues by $50 \%$ from raw skin on fish fillets used to determine Terbufos residue level.

\section{Maximum Allowable Daily Terbufos Ingestion Calculation}

0.05 micrograms per kilogram per day X 70 kilogram body weight $=3.5$ micrograms Terbufos allowed per day. 


\section{Terbufos Adult Advisory Groups}

\section{GROUP 1}

Unrestricted Consumption or up to 225 meals per year (140 grams of sportfish per day)

3.5 micrograms per day Terbufos / 140 grams of fish per day

Less than 0.025 ppm Terbufos in raw skin on fish fillet

\section{GROUP 2}

Up to 1 meal per week

(32 grams of sportfish per day)

3.5 micrograms per day Terbufos / 32 grams of fish per day

$0.025 \mathrm{ppm}$ to $0.11 \mathrm{ppm}$ Terbufos in raw skin on fish fillet

\section{GROUP 3}

Up to 1 meal per month

(7.4 grams of sportfish per day)

3.5 micrograms per day Terbufos / 7.4 grams of fish per day

$0.11 \mathrm{ppm}$ to $0.47 \mathrm{ppm}$ Terbufos in raw skin on fish fillet

\section{GROUP 4}

Up to 5 meals per year (3.7 grams of sportfish per day)

3.5 micrograms per day Terbufos / 3.7 grams of fish per day

$0.47 \mathrm{ppm}$ to $0.95 \mathrm{ppm}$ Terbufos in raw skin on fish fillet

\section{GROUP 5}

DO NOT EAT

Greater than $0.95 \mathrm{ppm}$ Terbufos in raw skin on fish fillet 


\section{Children Advisory Assumptions - Terbufos}

\section{Assumptions:}

1) Reference Dose is 0.05 micrograms Terbufos per kilogram per day

2) Average Meal Size is 52.5 grams or 3 ounces of uncooked fish.

3) Representative Consumer Body weight is 14.5 kilograms.

4) Five Advisory Groups: Unrestricted or 225 meals per year; One meal per week; One meal per month; Six meals per year; No Consumption.

5) Assume meal preparation does not reduce residues from raw fish fillets used to determine Terbufos residue level.

Maximum Allowable Daily Terbufos Ingestion Calculation

0.05 micrograms per kilogram per day X 14.5 kilogram body weight $=0.725$ micrograms Terbufos allowed per day. 


\section{Terbufos Child Advisory Groups}

\section{GROUP 1}

Unrestricted Consumption or up to 225 meals per year (52.5 grams of sportfish per day)

0.725 micrograms per day Terbufos / 52.5 grams of fish per day

Less than 0.014 ppm Terbufos in raw skin on fish fillet

\section{GROUP 2}

Up to 1 meal per week

(12.13 grams of sportfish per day)

0.725 micrograms per day Terbufos / 12.13 grams of fish per day

$0.014 \mathrm{ppm}$ to $0.060 \mathrm{ppm}$ Terbufos in raw skin on fish fillet

\section{GROUP 3}

Up to 1 meal per month

(2.8 grams of sportfish per day)

0.725 micrograms per day Terbufos / 2.8 grams of fish per day

$0.060 \mathrm{ppm}$ to $0.26 \mathrm{ppm}$ Terbufos in raw skin on fish fillet

\section{GROUP 4}

Up to 5 meals per year (1.4 grams of sportfish per day)

0.725 micrograms per day Terbufos / 1.4 grams of fish per day

$0.26 \mathrm{ppm}$ to $0.52 \mathrm{ppm}$ Terbufos in raw skin on fish fillet

\section{GROUP 5}

DO NOT EAT

Greater than $0.52 \mathrm{ppm}$ Terbufos in raw skin on fish fillet 


\section{Toxaphene Summary}

Merck Number 9693

CAS Number 8001-35-2

Oral RfD $0.00036 \mathrm{mg} / \mathrm{kg} / \mathrm{day}$

Oral Slope Factor $1.1 \mathrm{mg} / \mathrm{kg} / \mathrm{day}$

Preparation Dose Reduction .5 Skin on, .7 Skin Off

Toxaphene is a very persistent amber to yellow waxy solid organochlorine insecticide with a turpentine odor. It was one of the most used pesticides in the United States until its uses were restricted in 1982, and eventually banned for all use in 1990. Toxaphene was used for insect control on cotton, corn, fruit, vegetables, grain, soybeans, parasite control on livestock. It was used as a piscicide to eliminate unwanted fish populations, until biologists encountered difficulties establishing sport fisheries in water bodies treated with toxaphene. It is very lipophilic, accumulating in the fatty tissue of predatory fish and mammals. Toxaphene has been found worldwide including many places where it has never been used.

Toxaphene's acute effects include central nervous system, liver, lungs, and kidney damage. Three fatal human poisonings have been documented. Chronic exposure can cause damage to the adrenal gland, kidney, liver, nervous system, and immune system. Toxaphene is mutagenic, causing chromosomal abnormalities. Workers exposed to toxaphene have developed genetic changes. The U. S. EPA classifies toxaphene as a probable human carcinogen. It caused liver tumors in animal studies and has estrogen-like effects on estrogen sensitive human breast cancer cells. 


\section{Cancer Effect Assumptions - Toxaphene Skin On Fillets}

\section{Assumptions:}

1) Slope Factor is 1.1 milligrams Toxaphene per kilogram per day

2) Average Meal Size is 227 grams or $1 / 2$ pound of uncooked fish.

3) Representative Consumer Body weight is 70 kilograms.

4) ARL is $10^{-4}$

5) Five Consumption Rates: Unrestricted 225 meals per year(140 g/day); One meal per week(32g/day); One meal per month(7.4 g/day); Six meals per year(3.7 g/day); No Consumption.

6) Assume meal preparation reduces residues by 50\% from raw skin off (catfish) fish fillets used to determine Toxaphene residue level.

\section{Cancer Effect Assumptions - Toxaphene Skin Off Fillets (Catfish)}

\section{Assumptions:}

1) Slope Factor is 1.1 milligrams Toxaphene per kilogram per day

2) Average Meal Size is 227 grams or $1 / 2$ pound of uncooked fish.

3) Representative Consumer Body weight is 70 kilograms.

4) ARL is $10^{-4}$

5) Five Consumption Rates: Unrestricted 225 meals per year(140 g/day); One meal per week(32g/day); One meal per month(7.4 g/day); Six meals per year(3.7 g/day); No Consumption.

6) Assume meal preparation reduces residues by $30 \%$ from raw skin off (catfish) fish fillets used to determine Toxaphene residue level. 


\section{Toxaphene Cancer Effect Advisory Groups - Skin On Fillets}

\section{GROUP 1}

Unrestricted Consumption or up to 225 meals per year (140 grams of sportfish per day)

Less than $0.091 \mathrm{ppm}$ Toxaphene in raw skin on fish fillet

\section{GROUP 2}

Up to 1 meal per week

(32 grams of sportfish per day)

$0.091 \mathrm{ppm}$ to $0.40 \mathrm{ppm}$ Toxaphene in raw skin on fish fillet

\section{GROUP 3}

Up to 1 meal per month

(7.4 grams of sportfish per day)

$0.40 \mathrm{ppm}$ to $1.72 \mathrm{ppm}$ Toxaphene in raw skin on fish fillet

\section{GROUP 4}

Up to 0.8 meals per year

(3.7 grams of sportfish per day)

$1.72 \mathrm{ppm}$ to $3.44 \mathrm{ppm}$ Toxaphene in raw skin on fish fillet

\section{GROUP 5}

DO NOT EAT

Greater than $3.44 \mathrm{ppm}$ Toxaphene in raw skin on fish fillet 
Toxaphene Cancer Effect Advisory Groups - Skin Off Fillets

\section{GROUP 1}

Unrestricted Consumption or up to 225 meals per year

(140 grams of sportfish per day)

Less than $0.065 \mathrm{ppm}$ Toxaphene in raw skin off (catfish) fish fillet

\section{GROUP 2}

Up to 1 meal per week

(32 grams of sportfish per day)

$0.065 \mathrm{ppm}$ to $0.28 \mathrm{ppm}$ Toxaphene in raw skin off (catfish) fish fillet

\section{GROUP 3}

Up to 1 meal per month

(7.4 grams of sportfish per day)

$0.28 \mathrm{ppm}$ to $1.23 \mathrm{ppm}$ Toxaphene in raw skin off (catfish) fish fillet

\section{GROUP 4}

Up to 0.8 meals per year

(3.7 grams of sportfish per day)

$1.23 \mathrm{ppm}$ to $2.46 \mathrm{ppm}$ Toxaphene in raw skin off (catfish) fish fillet

\section{GROUP 5 \\ DO NOT EAT}

Greater than $2.46 \mathrm{ppm}$ Toxaphene in raw skin off (catfish) fish fillet 


\section{Adult Advisory Assumptions -Toxaphene Skin On Fillet}

\section{Assumptions:}

1)RfD is 0.00036 micrograms Toxaphene per kilogram per day

2) Average Meal Size is 227 grams or $1 / 2$ pound of uncooked fish.

3) Representative Consumer Body weight is 70 kilograms.

4) Five Advisory Groups: Unrestricted or 225 meals per year; One meal per week; One meal per month; Six meals per year; No Consumption.

5) Assume meal preparation reduces residues by 50\% from raw skin on fish fillets used to determine Toxaphene residue level.

\section{Maximum Allowable Daily Toxaphene Ingestion Calculation}

0.36 micrograms per kilogram per day X 70 kilogram body weight $=25.2$ micrograms

Toxaphene allowed per day.

\section{Adult Advisory Assumptions -Toxaphene Skin Off Fillet}

\section{Assumptions:}

1)RfD is 0.00036 micrograms Toxaphene per kilogram per day

2) Average Meal Size is 227 grams or $1 / 2$ pound of uncooked fish.

3) Representative Consumer Body weight is 70 kilograms.

4) Five Advisory Groups: Unrestricted or 225 meals per year; One meal per week; One meal per month; Six meals per year; No Consumption.

5) Assume meal preparation reduces residues by $30 \%$ from raw skin off (catfish) fish fillets used to determine Toxaphene residue level.

Maximum Allowable Daily Toxaphene Ingestion Calculation

0.36 micrograms per kilogram per day X 70 kilogram body weight $=25.2$ micrograms

Toxaphene allowed per day. 


\section{Toxaphene Adult Advisory Groups Skin On Fillet}

\section{GROUP 1}

Unrestricted Consumption or up to 225 meals per year (140 grams of sportfish per day)

25.2 micrograms per day Toxaphene / 140 grams of fish per day /.5 preparation reduction

Less than $0.36 \mathrm{ppm}$ Toxaphene in raw skin on fish fillet

\section{GROUP 2}

Up to 1 meal per week

(32 grams of sportfish per day)

25.2 micrograms per day Toxaphene / 32 grams of fish per day / .5 preparation reduction

$0.36 \mathrm{ppm}$ to $1.58 \mathrm{ppm}$ Toxaphene in raw skin on fish fillet

\section{GROUP 3}

Up to 1 meal per month

(7.4 grams of sportfish per day)

25.2 micrograms per day Toxaphene / 7.4 grams of fish per day / .5 preparation reduction

$1.58 \mathrm{ppm}$ to $6.81 \mathrm{ppm}$ Toxaphene in raw skin on fish fillet

\section{GROUP 4}

Up to 6 meals per year (3.7 grams of sportfish per day)

25.2 micrograms per day Toxaphene / 3.7 grams of fish per day / .5 preparation reduction

$6.81 \mathrm{ppm}$ to $13.62 \mathrm{ppm}$ Toxaphene in raw skin on fish fillet

\section{GROUP 5}

DO NOT EAT

Greater than $13.62 \mathrm{ppm}$ Toxaphene in raw skin on fish fillet 


\section{Toxaphene Adult Advisory Groups Skin Off Fillet}

\section{GROUP 1}

Unrestricted Consumption or up to 225 meals per year

(140 grams of sportfish per day)

25.2 micrograms per day Toxaphene / 140 grams of fish per day /.7 preparation reduction

Less than $0.26 \mathrm{ppm}$ Toxaphene in raw skin off (catfish) fish fillet

\section{GROUP 2}

Up to 1 meal per week

(32 grams of sportfish per day)

25.2 micrograms per day Toxaphene / 32 grams of fish per day / .7 preparation reduction

$0.26 \mathrm{ppm}$ to $1.13 \mathrm{ppm}$ Toxaphene in raw skin off (catfish) fish fillet

\section{GROUP 3}

Up to 1 meal per month

(7.4 grams of sportfish per day)

25.2 micrograms per day Toxaphene / 7.4 grams of fish per day / .7 preparation reduction

$1.13 \mathrm{ppm}$ to $4.86 \mathrm{ppm}$ Toxaphene in raw skin off (catfish) fish fillet

\section{GROUP 4}

Up to 6 meals per year

(3.7 grams of sportfish per day)

25.2 micrograms per day Toxaphene / 3.7 grams of fish per day / .7 preparation reduction

$4.86 \mathrm{ppm}$ to $9.73 \mathrm{ppm}$ Toxaphene in raw skin off (catfish) fish fillet

\section{GROUP 5}

DO NOT EAT

Greater than 9.73 ppm Toxaphene in raw skin off (catfish) fish fillet 


\section{Child Advisory Assumptions -Toxaphene Skin On Fillet}

\section{Assumptions:}

1)RfD is 0.00036 micrograms Toxaphene per kilogram per day

2) Average Meal Size is 52.5 grams or 3 ounces of uncooked fish.

3) Representative Consumer Body weight is 14.5 kilograms.

4) Five Advisory Groups: Unrestricted or 225 meals per year; One meal per week; One meal per month; Six meals per year; No Consumption.

5) Assume meal preparation reduces residues by 50\% from raw skin on fish fillets used to determine Toxaphene residue level.

\section{Maximum Allowable Daily Toxaphene Ingestion Calculation}

0.36 micrograms per kilogram per day X 14.5 kilogram body weight $=5.22$ micrograms

Toxaphene allowed per day.

\section{Child Advisory Assumptions -Toxaphene Skin Off Fillet}

\section{Assumptions:}

1)RfD is 0.00036 micrograms Toxaphene per kilogram per day

2) Average Meal Size is 52.5 grams or 3 ounces of uncooked fish.

3) Representative Consumer Body weight is 14.5 kilograms.

4) Five Advisory Groups: Unrestricted or 225 meals per year; One meal per week; One meal per month; Six meals per year; No Consumption.

5) Assume meal preparation reduces residues by 30\% from raw skin off (catfish) fish fillets used to determine Toxaphene residue level.

\section{Maximum Allowable Daily Toxaphene Ingestion Calculation}

0.36 micrograms per kilogram per day X 14.5 kilogram body weight $=5.22$ micrograms Toxaphene allowed per day. 


\section{Toxaphene Child Advisory Groups Skin On Fillet}

\section{GROUP 1}

Unrestricted Consumption or up to 225 meals per year (52.5 grams of sportfish per day)

5.22 micrograms per day Toxaphene / 52.5 grams of fish per day /.5 preparation reduction

Less than $0.20 \mathrm{ppm}$ Toxaphene in raw skin on fish fillet

\section{GROUP 2}

Up to 1 meal per week

(12.13 grams of sportfish per day)

5.22 micrograms per day Toxaphene / 12.13 grams of fish per day / .5 preparation reduction

$0.20 \mathrm{ppm}$ to $0.86 \mathrm{ppm}$ Toxaphene in raw skin on fish fillet

\section{GROUP 3}

Up to 1 meal per month

(2.8 grams of sportfish per day)

5.22 micrograms per day Toxaphene / 2.8 grams of fish per day / .5 preparation reduction

$0.86 \mathrm{ppm}$ to $3.73 \mathrm{ppm}$ Toxaphene in raw skin on fish fillet

\section{GROUP 4}

Up to 6 meals per year (1.4 grams of sportfish per day)

5.22 micrograms per day Toxaphene / 1.4 grams of fish per day / .5 preparation reduction

$3.73 \mathrm{ppm}$ to $7.46 \mathrm{ppm}$ Toxaphene in raw skin on fish fillet

\section{GROUP 5}

DO NOT EAT

Greater than $7.46 \mathrm{ppm}$ Toxaphene in raw skin on fish fillet 


\section{Toxaphene Child Advisory Groups Skin Off Fillet}

\section{GROUP 1}

Unrestricted Consumption or up to 225 meals per year

(52.5 grams of sportfish per day)

5.22 micrograms per day Toxaphene / 52.5 grams of fish per day /.7 preparation reduction

Less than $0.14 \mathrm{ppm}$ Toxaphene in raw skin off (catfish) fish fillet

\section{GROUP 2}

Up to 1 meal per week

(12.13 grams of sportfish per day)

5.22 micrograms per day Toxaphene / 12.13 grams of fish per day / .7 preparation reduction

$0.14 \mathrm{ppm}$ to $0.61 \mathrm{ppm}$ Toxaphene in raw skin off (catfish) fish fillet

\section{GROUP 3}

Up to 1 meal per month

(2.8 grams of sportfish per day)

5.22 micrograms per day Toxaphene / 2.8 grams of fish per day / .7 preparation reduction

$0.61 \mathrm{ppm}$ to $2.66 \mathrm{ppm}$ Toxaphene in raw skin off (catfish) fish fillet

\section{GROUP 4}

Up to 6 meals per year (1.4 grams of sportfish per day)

5.22 micrograms per day Toxaphene / 1.4 grams of fish per day / .7 preparation reduction

$2.66 \mathrm{ppm}$ to $5.33 \mathrm{ppm}$ Toxaphene in raw skin off (catfish) fish fillet

\section{GROUP 5}

DO NOT EAT

Greater than $5.33 \mathrm{ppm}$ Toxaphene in raw skin off (catfish) fish fillet 


\section{Glossary}

ADI Acceptable Daily Intake - the amount of a chemical a person can be exposed to on a daily basis over an extended period of time(usually a lifetime) without suffering deleterious effects.

HPV Human protection Value - protective level developed by the Great Lakes Sport Fish Advisory Task Force for polychlorinated biphenyls using weight of evidence approach considering all existing toxicologic information.

LOAEL Lowest Observed Adverse Effects Level - the lowest exposure level at which there are statistically or biologically significant increases in frequency or severity of adverse effects between the exposed population and its appropriate control group.

MF Modifying Factor - A factor used in the derivation of a reference dose or concentration. The magnitude of the MF reflects the scientific uncertainties of the study and database not explicitly treated with standard uncertainty factors(e.g., the completeness of the overall database). A MF is greater than zero and less than or equal to 10 , and the default value for the MF is 1.

MRL Minimal Risk Level - An estimate of daily human exposure to a dose of a chemical that is likely to be without an appreciable risk of adverse noncancerous effects over a specified duration of exposure.

NOAEL No Observed Adverse Effects Level - highest exposure level at which there are no statistically or biologically significant increases in the frequency or severity of adverse effects between the exposed population and its appropriate control group; some effects may be produced at this level, but they are not considered adverse, nor precursors to adverse effects.

RfD Reference Dose - An estimate (with uncertainty spanning perhaps an order of magnitude) of a daily oral exposure to the human population (including sensitive subgroups) that is likely to be without an appreciable risk of deleterious effects during a lifetime. It can be derived from a NOAEL, LOAEL, or benchmark dose, with uncertainty factors generally applied to reflect limitations of the data used. Generally used in the EPA's noncancer health assessments.

SF Slope factor - An upper bound, approximating a 95\% confidence limit, on the increased cancer risk from a lifetime exposure to an agent. This estimate, usually expressed in units of proportion(of a population) affected per $\mathrm{mg} / \mathrm{kg} / \mathrm{day}$, is generally reserved for use in low-dose region of the dose-response relationship, that is, for exposures corresponding to risks less than 1 in 100 .

UF Uncertainty Factor - One of several, generally 10 -fold factors, used in operationally deriving the RfD and RfC from the experimental data. UF are intended to account for (1) the variation in sensitivity among members of the human population, i.e., intraspecies variability; (2) the uncertainty in extrapolating animal data to humans, i.e., interspecies variability; (3) the uncertainty in extrapolating from data obtained in a study with less-than-lifetime exposure to lifetime exposure, i.e., extrapolating from subchronic to chronic exposure; (4) the uncertainty in 
extrapolating from a LOAEL rather than a NOAEL; and (5) the uncertainty associated with extrapolation from animal data when the data base is incomplete.

(From USEPA 1999 and ATSDR 1999) 


\section{References}

Agency for Toxic Chemicals and Disease Registry. 1994. Toxicological Profile for 4,4'-DDT, 4,4'-DDE, 4,4'-DDD. ATSDR. TP-93/05, Atlanta, GA.

Agency for Toxic Chemicals and Disease Registry. 1993. Toxicological Profile for Aldrin/Dieldrin. ATSDR. TP-92/01, Atlanta, GA.

Agency for Toxic Chemicals and Disease Registry. 1997. Toxicological Profile for Cadmium Draft for Public Comment. ATSDR. Atlanta, GA.

Agency for Toxic Chemicals and Disease Registry. 1994. Toxicological Profile for Chlordane. ATSDR TP-93/03, Atlanta, GA.

Agency for Toxic Chemicals and Disease Registry. 1997. Toxicological Profile for Chlorpyrifos. ATSDR. Atlanta, GA.

Agency for Toxic Chemicals and Disease Registry. Toxicological Profile for Chlorinated Dibenzo-p- Dioxins - Draft for Public Comment. 1997. ATSDR. Atlanta, GA. 1997.

Agency for Toxic Chemicals and Disease Registry. 1995. Toxicological Profile for Disulfoton. ATSDR. Atlanta, GA.

Agency for Toxic Chemicals and Disease Registry. 1998. Toxicological Profile for Endosulfan Draft for Public Comment. ATSDR. Atlanta, GA.

Agency for Toxic Chemicals and Disease Registry. 1996. Toxicological Profile for Endrin and Endrin Aldehyde. ATSDR. Atlanta, GA.

Agency for Toxic Chemicals and Disease Registry.1998. Toxicological Profile for Ethion - Draft for Public Comment. ATSDR. Atlanta, GA.

Agency for Toxic Chemicals and Disease Registry. 1993. Toxicological Profile for Heptachlor/Heptachlor Epoxide. ATSDR. TP-92/11, Atlanta, GA.

Agency for Toxic Chemicals and Disease Registry. 1996. Toxicological Profile for Hexachlorobenzene. ATSDR. Atlanta, GA.

Agency for Toxic Chemicals and Disease Registry.1997. Toxicological Profile for Lead - Draft. ATSDR. Atlanta, GA.

Agency for Toxic Chemicals and Disease Registry.1997. Toxicological Profile for Mercury Draft. ATSDR. Atlanta, GA. 
Agency for Toxic Chemicals and Disease Registry. 1995. Toxicological Profile for Mirex and Chlordecone. ATSDR. Atlanta, GA.

Agency for Toxic Chemicals and Disease Registry.1998. Toxicological Profile for Polychlorinated Biphenyls - Draft for Public Comment. ATSDR. Atlanta, GA.

Agency for Toxic Chemicals and Disease Registry. 1996. Toxicological Profile for Selenium. ATSDR. Atlanta, GA.

Agency for Toxic Chemicals and Disease Registry. 1996. Toxicological Profile for Toxaphene. ATSDR. Atlanta, GA.

Agency for Toxic Chemicals and Disease Registry. 1999. ToxFAQs Hexachlorocyclohexane. ATSDR. Atlanta, GA. http://www.atsdr.cdc.gov/tfacts43.html

Agency for Toxic Chemicals and Disease Registry. 1999. ToxFAQs Toxaphene. ATSDR. Atlanta, GA. http://www.atsdr.cdc.gov/tfacts43.html

Agency for Toxic Chemicals and Disease Registry. 1996. Toxicological Profile for Toxaphene. U.S. Department of Health and Human Services ATSDR. Atlanta, GA.

Bentor, Yinon. Chemical Element.com - Cadmium. 1999. http:/www.chemicalselements.com/elements/cd.html

Bevelhimer, M.A. 1995. Recent Advances in Contaminant Assessment Offer Proactive Alternatives for Managing Contaminated Fisheries. Fisheries. 20(12):6-10.

Budavari, S., O' Neil, M.J., Smith, A., Heckelman, P.E. and J.F. Kinneary, J.F., editors. 1996. The Merck Index, An Encyclopedia of chemicals, Drugs, and Biologicals. Whitehouse Station: Merck and Company, Inc.

Cornell University. 1999. Extension Toxicology Network Pesticide Information Profiles Endosulfan.

http://pmep.cce.cornell.edu/profiles/extoxnet/dienochlor-glphosate/endosulfan.ext.html

Eisler, R. 1985. Cadmium Hazards to Fish, Wildlife, and Invertebrates: A Synoptic Review. U.S. Fish and Wildlife Service Biological Report 85(1.2).

Eisler, R. 1990. Chlordane Hazards to Fish, Wildlife, and Invertebrates: A Synoptic Review. U.S. Fish and Wildlife Service Biological Report 85(1.21).

Eisler, R. 1988. Chlorpyrifos Hazards to Fish, Wildlife, and Invertebrates: A Synoptic Review. U.S. Fish and Wildlife Service Biological Report 85(1.21).

Eisler, R. 1986. Diazinon Hazards to Fish, Wildlife, and Invertebrates: A Synoptic Review. U.S. Fish and Wildlife Service Biological Report 85(1.9). 
Eisler, R. 1986. Dioxin Hazards to Fish, Wildlife, and Invertebrates: A Synoptic Review. U.S. Fish and Wildlife Service Biological Report 85(1.2).

Eisler, R. 1988. Lead Hazards to Fish, Wildlife, and Invertebrates: A Synoptic Review. U.S. Fish and Wildlife Service Biological Report 85(1.14).

Eisler, R. 1987. Mercury Hazards to Fish, Wildlife, and Invertebrates: A Synoptic Review. U.S. Fish and Wildlife Service Biological Report 85(1.10).

Eisler, R. 1986. Polychlorinated Biphenyl Hazards to Fish, Wildlife, and Invertebrates: A Synoptic Review. U.S. Fish and Wildlife Service Biological Report 85(1.7).

Eisler, R. 1985. Selenium Hazards to Fish, Wildlife, and Invertebrates: A Synoptic Review. U.S. Fish and Wildlife Service Biological Report 85(1.10).

Foran, J.A. and D. Vander Ploeg. 1989. Consumption Advisories for Sport Fish in the Great Lakes Basin: Jurisdictional Inconsistencies. Journal of Great Lakes Research. 15(3):476-485.

Great Lakes Sport Fish Advisory Task Force. 1993. Protocol for a Uniform Great Lakes Sport Fish Consumption Advisory. GLSFAT, Madison, WI.

Hammond, P.B. and R.P. Beliles. 1980. Metals. In: Doull, J.; Klaassen, C.D. and M. O. Amdur, editors. Casareet and Doull's Toxicology, The Basic Science of Poisons. New York: Macmillan Publishing Company, Inc.

Harte, J., Holdren, C., Schneider, R., and C. Shirley. 1991. Toxics A to Z, A Guide to Everyday Pollution Hazards. Berkeley: University of California Press.

Humphrey, H.E.B. 1987. The Human Population - An Ultimate Receptor for Aquatic Contaminants. Hydrobiologia. 149: 75-80.

Khanna, N, Santerre, C.R, Xu, D., and Y. W. Huang. 1997. Changes in Dieldrin and p,p'-DDE Residues Following Cooking of Channel Catfish. 60(3): 300-304.

Leland, H.V. and J.S. Kuwabara. 1985. Trace Metals. In: Rand G.M.; Petrocelli S.R., editors. Fundamentals of Aquatic Toxicology. .New York: Hemisphere Publishing Corporation: pages 58 $-95$.

Milne, G.W.A., editor. 1995. CRC Handbook of Pesticides. Boca Raton: CRC Press.

Oregon State University. 1999. Extension Toxicology Network Pesticide Information Profiles Chlordane. http://ace.ace.orst.edu/info/extoxnet/pips/chlordan.htm

Oregon State University. 1999. Extension Toxicology Network Pesticide Information Profiles Chlorpyrifos. http://ace.ace.orst.edu/info/extoxnet/pips/chlordan.htm 
Oregon State University. 1999. Extension Toxicology Network Pesticide Information Profiles DDT. http://ace.ace.orst.edu/info/extoxnet/pips/ddt.htm

Oregon State University. 1999. Extension Toxicology Network Pesticide Information Profiles Disulfoton. http://ace.ace.orst.edu/info/extoxnet/pips/disufot.htm

Oregon State University. 1999. Extension Toxicology Network Pesticide Information Profiles Ethion. http://ace.ace.orst.edu/info/extoxnet/pips/ethion.htm

Oregon State University. 1999. Extension Toxicology Network Pesticide Information Profiles Heptachlor. http://ace.ace.orst.edu/info/extoxnet/pips/heptachl.htm

Oregon State University. 1999. Extension Toxicology Network Pesticide Information Profiles Hexachlorobenzene. http://ace.ace.orst.edu/info/extoxnet/pips/hexachlo.htm

Oregon State University. 1999. Extension Toxicology Network Pesticide Information Profiles Lindane. http://ace.ace.orst.edu/info/extoxnet/pips/lindane.htm

Pinkney AE, Logan DT and H.T. 1997.Wilson. Mercury Concentrations in Pond fish in Relation to a Coal-Fired Power Plant. Archives of Environmental Contamination And Toxicology; 33: $222-229$.

Reinert, R.E.; Knuth, B.A.; Kamrin, M.A. and Q.J. Stober. 1991. Risk Assessment, Risk Management, and Fish Consumption Advisories in the United States. Fisheries. 16(6): 5-12.

Reinert, R.E.; Knuth, B.A.; Kamrin, M.A. and Q.J. Stober. 1996. A review of the Basic Principles and Assumptions used to issue Fish Consumption Advisories. American Fisheries Society Symposium. 16:98-106.

Stow, C.; Carpenter, S.R.; Madenjian, C.P.; Eby, L.A. and L.J. Jackson. 1995. Fisheries Management to Reduce Contaminant Consumption. Bioscience. 45(11): 752-758.

Swartz, C.B. EPA Chemist [Memorandum to Nisenson, L and McNally, R., 1998. EPA Terbufos. List A Reregistration Case No.0109/Chemical IDNo. 105001. Chronic Dietary Risk Analysis Based on the 3/19/98 Anticipated Residues. NoMRID\#. DP Barcode No. D244364.

U.S. Bureau of the Census. 1998. 1990 Census of Population and Housing- West Virginia General Profile for West Virginia. http://govinfo.library.orst.edu/cgi-bin/buildit?1a-state.wvs

U.S. Bureau of the Census. 1998. 1990 Census of Population and Housing- West Virginia Income and Poverty Data for West Virginia. http://govinfo.library.orst.edu/cgi-bin/buildit?3istate.wvs 
U.S. Bureau of the Census. 1998. 1990 Census of Population and Housing- West Virginia Social Characteristics for West Virginia. http://govinfo.library.orst.edu/cgi-bin/buildit?3sstate.wvs

U.S. Environmental Protection Agency. 1995. Guidance for Assessing Chemical Contaminant Data for Use In Fish Consumption Advisories, Volume I: Fish Sampling and Analysis. USEPA, EPA 823-R-95-007, Washington, D.C.

U.S. Environmental Protection Agency. 1997. Guidance for Assessing Chemical Contaminant Data for Use In Fish Consumption Advisories, Volume II: Risk Assessment and Fish Consumption Limits. USEPA, EPA 823-B-97-009, Washington, D.C.

U.S. Environmental Protection Agency. 1996. Guidance for Assessing Chemical Contaminant Data for Use In Fish Consumption Advisories, Volume III: Overview of Risk Management. USEPA, EPA 823-B-96-006, Washington, D.C.

U.S. Environmental Protection Agency. 1995. Guidance for Assessing Chemical Contaminant Data for Use In Fish Consumption Advisories, Volume IV: Overview of Risk Management. USEPA, EPA 823-R-95-001, Washington, D.C.

U.S. Environmental Protection Agency. 1991. Methods for the Determination of Metals in Environmental Samples. USEPA, EPA 600491010, Washington, D.C.

U.S. Environmental Protection Agency. 1994. Methods for the Determination of Metals in Environmental Samples, Supplement 1. USEPA, EPA 600491010, Washington, D.C.

U.S. Environmental Protection Agency. 1998. R.E.D. Facts Dicofol. USEPA, EPA-738-F-98016. Washington, D.C.

U.S. Environmental Protection Agency. 1999. Technical Factsheet on: Dioxin (2,3,7,8 TCCDD). USEPA. Washington, D.C. http://www.epa.gov/OGWDW/dwh/t-soc/dioxin.html

U.S. Environmental Protection Agency. 1999. Technical Factsheet on: Lead. USEPA. Washington, D.C. http://www.epa.gov/OGWDW/dwh/t-ioc/lead.html

U.S. Environmental Protection Agency. 1999. Technical Factsheet on: Lindane. USEPA. Washington, D.C. http://www.epa.gov/OGWDW/dwh/t-soc/lindane.html

U.S. Environmental Protection Agency. 1999. Technical Factsheet on: Toxaphene. USEPA. Washington, D.C. http://www.epa.gov/OGWDW/dwh/t-soc/toxaphen.html

U.S. Food and Drug Administration. 1997. Pesticide Analytical Manual(PAM) Volume I. FDA, Washington, D.C.

U.S. Food and Drug Administration. 1997. Pesticide Analytical Manual(PAM) Volume II. FDA, Washington, D.C. 
West Virginia Division of Natural Resources. 1999. West Virginia Fishing, Favorite Fishing Waters. http://www.state.wv.us/dnr/wvfishing/waters.htm

Zabik, M.E., Zabik, M.J., Booren, A.M., Nettles, M, Song, J.H., Welch, R. and H. Humphrey. 1995. Pesticides and Total Polychlorinated Biphenyls in Chinook Salmon and Carp Harvested from the Great Lakes: Effects of Skin-on and Skin-off Processing and Selected Cooking Methods. Journal of Agriculture and Food Chemistry. 43: 993-1001.

Zabik M.E. and M.J. Zabik. 1996. Influence of Processing on Environmental Contaminants in Foods. Food Technology. May: 225 -229.

Zabik M.E. and M.J. Zabik. 1995. Tetrachlorodibenzo-p-dioxin Residue Reduction by Cooking/Processing of Fish Fillets Harvested from the Great Lakes. Bulletin of Environmental Contamination and Toxicology. 55: 264-269.

Zabik, M.E., Zabik, M.J., Booren, A.M., Daubenmire, S., Pascall, M.A., Welch, R. and H. Humphrey. 1995. Pesticides and Total Polychlorinated Biphenyls Residues in Raw and Cooked Walleye and White Bass Harvested from the Great Lakes. Bulletin of Environmental Contamination and Toxicology. 54: 396-402.

Zabik, M.E., Booren, A.M., Zabik, M.J., Welch, R. and H. Humphrey. 1996. Pesticide residues, PCBs and PAHs in Baked, Charbroiled, Salt Boiled and Smoked Great Lakes Lake Trout. Food Chemistry. 55(3): 213-239. 


\section{Table 1.Maximum Daily Ingestion for Compounds of Concern}

Compound
Cadmium
Chlordane
Chlorpyrifos
DDT/DDD/DDE
Diazinon
Dicofol
Dieldrin
Dioxin
Disulfoton
Endosulfan
Endrin
Ethion
Heptachlor Epoxide
Hexachlorobenzene
Lead
Lindane
Methylmercury
Mirex
PCB
PAH
Selenium
Terbufos
Toxaphene

Skin On Fillet

$\underline{\text { Screening Value }(\mathrm{ppm})^{*}}$

0.28

0.15

1.66

0.28

0.025

1.11

$0.0063 \$$

$0.000000552 \#$

0.011

1.66

0.166

0.14

0.007

$0.063 \$$

0

0.17

0.028

0.11

0.05@

$0.014 \$$

1.38

0.014

$0.091 \$$
Skin Off Fillet

Screening Value(ppm)*

0.28

0.11

1.18

0.20

0.025

1.10

$0.0045 \$$

$0.000000395 \#$

0.011

1.66

0.12

0.14

0.0051

$0.045 \$$

0

0.12

0.028

0.079

0.0357@

$0.010 \$$

1.38

0.014

$0.065 \$$

* Screening Value $=$ RfD x Body weight (70 kilograms)/Average Meal Size (.140 kilograms)/ Meal Preparation Reduction

@ Screening Value = HPV x Body weight (70 kilograms)/Average Meal Size (.140 kilograms)/ Meal Preparation Reduction

\# Screening Value $=$ MRL x Body weight (70 kilograms)/Average Meal Size (.140 kilograms) / Meal Preparation Reduction

$\$$ Screening Value $=\operatorname{ARL}\left(10^{-4}\right) \times$ Body weight $(70$ kilograms $) /$ Cancer Slope Factor*Maximum Allowable Consumption rate 
Table 2. Compound RfD, HPV, MRL and References

Compound

Cadmium $\quad 0.001^{1} \quad 10 \mathrm{H} \quad$ B1 probable- inhalation ${ }^{1}$

Chlordane $\quad 0.00015^{9}$
$3.5 \mathrm{mg} / \mathrm{kg} /$ day oral slope factor

Chlorpyrifos $\quad 0.003 \mathrm{mg} / \mathrm{kg} /$ day $^{1} \quad 10 \mathrm{H} \quad$ no data $^{1}$, no evidence ${ }^{2}$

Diazinon $\quad 0.00009 \mathrm{mg} / \mathrm{kg} / \mathrm{day}^{7,8} \quad$ no evidence $^{2}$

DDT/DDD/DDE $\quad 0.0005 \mathrm{mg} / \mathrm{kg} /$ day $^{1} \quad$ 10H 10A $\quad$ B2 probable $^{1}$, mixed $^{2}$ $.34 \mathrm{mg} / \mathrm{kg} /$ day Oral Slope factor

Dicofol $\quad 0.004 \mathrm{mg} / \mathrm{kg} / \mathrm{day}^{3} \quad \operatorname{mixed}^{2}$

Dieldrin $\quad 0.00005 \mathrm{mg} / \mathrm{kg} / \mathrm{day}^{1} \quad 100 \mathrm{H}, \mathrm{A} \quad$ B2 probable ${ }^{1}$,

$16 \mathrm{mg} / \mathrm{kg} /$ day oral slope factor

Dioxin $\quad 0.000000001 \mathrm{mg} / \mathrm{kg} / \mathrm{day}^{5} \quad 90 \mathrm{H}, \mathrm{A}, \mathrm{L} \quad$ probable $^{5}$

Disulfoton $\quad 0.00004 \mathrm{mg} / \mathrm{kg} /$ day $^{1} \quad 1000 \mathrm{H}, \mathrm{A}, \mathrm{L} \quad$ no data $^{1}$, no evidence ${ }^{2}$

Endosulfan $\quad 0.006 \mathrm{mg} / \mathrm{kg} /$ day $^{1} \quad 100 \mathrm{H}, \mathrm{A} \quad$ no data $^{1}$, not carcinogen ${ }^{2}$

Endrin $\quad 0.0003 \mathrm{mg} / \mathrm{kg} /$ day $^{1} \quad 100 \mathrm{H}, \mathrm{A} \quad$ D not classifiable ${ }^{1}$, not carcinogen ${ }^{2}$

Ethion $\quad 0.0005 \mathrm{mg} / \mathrm{kg} /$ day $^{1} \quad 100 \mathrm{H}, \mathrm{A} \quad$ no data $^{1}$, no evidence ${ }^{2}$

Heptachlor Epoxide $0.000013 \mathrm{mg} / \mathrm{kg} / \mathrm{day}^{1} 1000 \mathrm{H}, \mathrm{A}, \mathrm{L}$ B2 probable ${ }^{1}$, not enough data ${ }^{2}$ $9.1 \mathrm{mg} / \mathrm{kg} /$ day oral slope factor

Hexachlorobenzene $0.0008 \mathrm{mg} / \mathrm{kg} / \mathrm{day}^{1} \quad 100 \mathrm{H}, \mathrm{A} \quad$ B2 probable ${ }^{1}$, not enough data ${ }^{2}$ $1.6 \mathrm{mg} / \mathrm{kg} /$ day oral slope factor

Lead

No threshold

B2 probable ${ }^{1}$

No oral slope factor (Action Level $>0.015 \mathrm{mg} / 1(\mathrm{ppm})$ in $>10 \%$ of water samples)

Lindane $\quad 0.0003 \mathrm{mg} / \mathrm{kg} / \mathrm{day}^{1} \quad 1000 \mathrm{H}, \mathrm{A}, \mathrm{S}$ no data ${ }^{1}$, not enough data ${ }^{2}$ 
Table 2. Compound RfD, HPV, MRL and References(Cont.)

Methylmercury $\quad 0.0001 \mathrm{mg} / \mathrm{kg} /$ day $^{1} \quad 10 \mathrm{H}, \mathrm{D} \quad \mathrm{C}_{\text {possible }}{ }^{1}$

No oral slope factor

\begin{tabular}{|c|c|c|c|}
\hline Mirex & $0.0002 \mathrm{mg} / \mathrm{kg} / \mathrm{day}^{1}$ & $300 \mathrm{H}, \mathrm{A}, \mathrm{D}$ & no data ${ }^{1}$ \\
\hline PCB & $0.00005 \mathrm{mg} / \mathrm{kg} / \mathrm{day}^{6}$ & & \\
\hline PAH & no data ${ }^{1}$ & & B2 probable \\
\hline
\end{tabular}

$7.3 \mathrm{mg} / \mathrm{kg} /$ day oral slope factor

\begin{tabular}{|c|c|c|c|}
\hline Selenium & $0.005 \mathrm{mg} / \mathrm{kg} / \mathrm{day}^{1}$ & $3 \mathrm{H}$ & D not classifiable ${ }^{1}$ \\
\hline Terbufos & $0.00005 \mathrm{mg} / \mathrm{kg} / \mathrm{day}^{4}$ & $100 \mathrm{H}, \mathrm{A}$ & no evidence ${ }^{2}$ \\
\hline $\begin{array}{l}\text { Toxaphene } \\
1.1 \mathrm{mg} / \mathrm{kg} / \mathrm{da}\end{array}$ & $\begin{array}{l}0.00036 \mathrm{mg} / \mathrm{kg} / \mathrm{day}^{7} \\
\text { ope factor }\end{array}$ & & B2 probable \\
\hline $\begin{array}{l}1 \text { IRIS } \\
2 \text { ETN PIP } \\
3 \text { EPA-738-F } \\
4 \text { EPAOPP } 4 \\
5 \text { ATSDR } \\
6 \text { GLSFATF } \\
7 \text { EPA 823-B } \\
8 \text { Cholinester } \\
9 \text { Discussion }\end{array}$ & $\begin{array}{l}\text { oition End point } \\
\text { or Chlordane HPV }\end{array}$ & & \\
\hline
\end{tabular}


Table 3. West Virginia Sport Fish Consumption Cancer Contaminant Advisory Levels Summarized*

\begin{tabular}{|c|c|c|c|c|c|c|c|}
\hline Contaminant & Species & $\begin{array}{c}\text { Group } 1 \\
\text { Unrestricted }\end{array}$ & $\begin{array}{c}\text { Group } 2 \\
1 \text { meal/week }\end{array}$ & $\begin{array}{c}\text { Group } 3 \\
1 \text { meal/month }\end{array}$ & $\begin{array}{c}\text { Group } 4 \\
6 \text { meals/year }\end{array}$ & $\begin{array}{c}\text { Group } 5 \\
\text { Do Not Eat }\end{array}$ & Fat Soluble \\
\hline Chlordane & Scaled & $<0.29$ & 0.29 to 1.25 & 1.25 to 5.41 & 5.41 to 10.81 & $>10.81$ & Yes \\
\hline Chlordane & Catfish & $<0.20$ & 0.20 to 0.89 & 0.89 to 3.86 & 3.86 to 7.72 & $>7.72$ & Yes \\
\hline DDT & Scaled & $<0.29$ & 0.29 to 1.29 & 1.29 to 5.56 & 5.56 to 11.13 & $>11.13$ & Yes \\
\hline DDT & Catfish & $<0.21$ & 0.21 to 0.92 & 0.92 to 3.97 & 3.97 to 7.95 & $>7.95$ & Yes \\
\hline Dieldrin & Scaled & $<0.0063$ & 0.0063 to 0.027 & 0.027 to 0.12 & 0.12 to 0.24 & $>0.24$ & Yes \\
\hline Dieldrin & Catfish & $<0.0045$ & 0.0045 to 0.020 & 0.020 to 0.084 & 0.084 to 0.17 & $>0.17$ & Yes \\
\hline Dioxin & Scaled & $<0.00000064$ & $\begin{array}{c}0.00000064- \\
0.0000028\end{array}$ & $0.0000028-0.000012$ & $0.000012-0.000024$ & $>0.000024$ & Yes \\
\hline Dioxin & Catfish & $<0.00000045$ & $0.00000045-0.000002$ & $0.000002-0.0000086$ & $0.0000086-0.000017$ & $>0.000017$ & Yes \\
\hline Heptachlor Epoxide & Scaled & $<0.011$ & 0.011 to 0.048 & 0.048 to 0.21 & 0.21 to 0.42 & $>0.42$ & Yes \\
\hline Heptachlor Epoxide & Catfish & $<0.0078$ & 0.0078 to 0.034 & 0.034 to 0.15 & 0.15 to 0.30 & $>0.30$ & Yes \\
\hline Hexachlorobenzene & Scaled & $<0.063$ & 0.063 to 0.27 & 0.27 to 1.18 & 1.18 to 2.36 & $>2.36$ & Yes \\
\hline Hexachlorobenzene & Catfish & $<0.045$ & 0.045 to 0.20 & 0.20 to 0.84 & 0.84 to 1.69 & $>1.69$ & Yes \\
\hline PAHs & Catfish & $<0.010$ & 0.010 to 0.043 & 0.043 to 0.19 & 0.19 to 0.37 & $>0.37$ & Yes \\
\hline Toxaphene & Scaled & $<0.091$ & 0.091 to 0.40 & 0.40 to 1.72 & 1.72 to 3.44 & $>3.44$ & Yes \\
\hline Toxaphene & Catfish & $<0.065$ & 0.065 to 0.28 & 0.28 to 1.23 & 1.23 to 2.46 & $>2.46$ & Yes \\
\hline
\end{tabular}


Table 4. West Virginia Sport Fish Adult Consumption Contaminant Advisory Levels Summarized*

\begin{tabular}{|c|c|c|c|c|c|c|c|}
\hline Contaminant & Species & $\begin{array}{c}\text { Group } 1 \\
\text { Unrestricted }\end{array}$ & $\begin{array}{c}\text { Group } 2 \\
1 \text { meal/week }\end{array}$ & $\begin{array}{c}\text { Group } 3 \\
1 \text { meal/month }\end{array}$ & $\begin{array}{l}\text { Group } 4 \\
6 \text { meals/year }\end{array}$ & $\begin{array}{c}\text { Group } 5 \\
\text { Do Not Eat }\end{array}$ & Fat Soluble \\
\hline Cadmium & All Fish & $<0.5$ & 0.5 to 2.19 & 2.19 to 9.46 & 9.46 to 18.92 & $>18.92$ & No \\
\hline Chlordane & Scaled & $<0.15$ & 0.15 to 0.66 & 0.66 to 2.84 & 2.84 to 5.68 & $>5.68$ & Yes \\
\hline Chlordane & Catfish & $<0.11$ & 0.11 to 0.47 & 0.47 to 2.03 & 2.03 to 4.05 & $>4.05$ & Yes \\
\hline Chlorpyrifos & Scaled & $<3.0$ & 3.0 to 13.13 & 13.13 to 56.76 & 56.76 to 113.51 & $>113.51$ & Yes \\
\hline Chlorpyrifos & Catfish & $<2.14$ & 2.14 to 9.38 & 9.38 to 40.54 & 40.54 to 81.08 & $>81.08$ & Yes \\
\hline DDT & Scaled & $<0.5$ & 0.5 to 2.19 & 2.19 to 9.46 & 9.46 to 18.92 & $>18.92$ & Yes \\
\hline DDT & Catfish & $<0.36$ & 0.36 to 1.56 & 1.56 to 6.76 & 6.76 to 13.51 & $>13.51$ & Yes \\
\hline Diazinon & All Fish & $<0.045$ & 0.045 to 0.20 & 0.20 to 0.85 & 0.85 to 1.70 & $>1.70$ & No \\
\hline Dicofol & All Fish & $<2.0$ & 2.0 to 8.75 & 8.75 to 37.84 & 37.84 to 75.68 & $>78.68$ & No \\
\hline Dieldrin & Scaled & $<0.05$ & 0.05 to 0.22 & 0.22 to 0.95 & 0.95 to 1.89 & $>1.89$ & Yes \\
\hline Dieldrin & Catfish & $<0.036$ & 0.036 to 0.16 & 0.16 to 0.68 & 0.68 to 1.35 & $>1.35$ & Yes \\
\hline Dioxin & Scaled & $<1.0 \mathrm{E}-6$ & $1.0 \mathrm{E}-6$ to $4.38 \mathrm{E}-6$ & $4.38 \mathrm{E}-6$ to $1.89 \mathrm{E}-5$ & $1.89 \mathrm{E}-5$ to $3.78 \mathrm{E}-5$ & $>3.78 \mathrm{E}-5$ & Yes \\
\hline Dioxin & Catfish & $<7.14 \mathrm{E}-7$ & $7.14 \mathrm{E}-7$ to $3.13 \mathrm{E}-6$ & $3.13 \mathrm{E}-6$ to $1.35 \mathrm{E}-5$ & $1.35 \mathrm{E}-5$ to $2.7 \mathrm{E}-5$ & $>2.7 \mathrm{E}-5$ & Yes \\
\hline Disulfoton & All Fish & $<0.02$ & 0.02 to 0.09 & 0.09 to 0.38 & 0.38 to 0.76 & $>0.76$ & No \\
\hline Endosulfan & All Fish & $<3.0$ & 3.0 to 13.13 & 13.13 to 56.76 & 56.76 to 113.51 & $>113.51$ & No \\
\hline Endrin & Scaled & $<0.3$ & 0.3 to 1.31 & 1.31 to 5.68 & 5.68 to 11.35 & $>11.35$ & Yes \\
\hline Endrin & Catfish & $<0.21$ & 0.21 to 0.94 & 0.94 to 4.054 & 4.054 to 8.11 & $>8.11$ & Yes \\
\hline Ethion & All Fish & $<0.25$ & 0.25 to 1.09 & 1.09 to 4.73 & 4.73 to 9.46 & $>9.46$ & No \\
\hline Heptachlor Epoxide & Scaled & $<0.013$ & 0.013 to 0.057 & 0.057 to 0.24 & 0.24 to 0.49 & $>0.49$ & Yes \\
\hline Heptachlor Epoxide & Catfish & $<0.0093$ & 0.0093 to 0.041 & 0.041 to 0.18 & 0.18 to 0.35 & $>0.35$ & Yes \\
\hline Hexachlorobenzene & Scaled & $<0.80$ & 0.80 to 3.50 & 3.50 to 15.14 & 15.14 to 30.27 & $>30.27$ & Yes \\
\hline Hexachlorobenzene & Catfish & $<0.57$ & 0.57 to 2.50 & 2.50 to 10.81 & 10.81 to 21.62 & $>21.62$ & Yes \\
\hline Lindane & Scaled & $<0.30$ & 0.30 to 1.31 & 1.31 to 5.68 & 5.68 to 11.35 & $>11.35$ & Yes \\
\hline Lindane & Catfish & $<0.21$ & 0.21 to 0.94 & 0.94 to 4.05 & 4.05 to 8.11 & $>8.11$ & Yes \\
\hline Methylmercury & All Fish & $<0.05$ & 0.05 to 0.22 & 0.22 to 0.95 & 0.95 to 1.89 & $>3.78$ & No \\
\hline Mirex & Scaled & $<0.20$ & 0.20 to 0.88 & 0.88 to 3.78 & 3.78 to 7.56 & $>7.56$ & Yes \\
\hline Mirex & Catfish & $<0.14$ & 0.14 to 0.63 & 0.63 to 2.70 & 2.70 to 5.41 & $>5.41$ & Yes \\
\hline PCB & Scaled & $<0.05$ & 0.05 to 0.22 & 0.22 to 0.95 & 0.95 to 1.89 & $>1.89$ & Yes \\
\hline PCB & Catfish & $<0.036$ & 0.036 to 0.16 & 0.16 to 0.68 & 0.68 to 1.35 & $>1.35$ & Yes \\
\hline Selenium & All Fish & $<2.5$ & 2.5 to 10.94 & 10.94 to 47.30 & 47.30 to 94.59 & $>94.59$ & No \\
\hline Terbufos & All Fish & $<0.025$ & 0.025 to 0.11 & 0.11 to 0.47 & 0.47 to 0.95 & $>0.95$ & No \\
\hline Toxaphene & Scaled & $<0.36$ & 0.36 to 1.58 & 1.58 to 6.81 & 6.81 to 13.62 & $>13.62$ & Yes \\
\hline Toxaphene & Catfish & $<0.26$ & 0.26 to 1.13 & 1.13 to 4.86 & 4.86 to 9.73 & $>9.73$ & Yes \\
\hline
\end{tabular}


Table 5. West Virginia Sport Fish Children Advisory Consumption Contaminant Levels Summarized*

\begin{tabular}{|c|c|c|c|c|c|c|c|}
\hline Contaminant & Species & $\begin{array}{c}\text { Group } 1 \\
\text { Unrestricted }\end{array}$ & $\begin{array}{c}\text { Group } 2 \\
1 \text { meal/week }\end{array}$ & $\begin{array}{c}\text { Group } 3 \\
1 \text { meal } / \text { month }\end{array}$ & $\begin{array}{c}\text { Group } 4 \\
6 \text { meals/year }\end{array}$ & $\begin{array}{c}\text { Group } 5 \\
\text { Do Not Eat }\end{array}$ & Fat Soluble \\
\hline Cadmium & All Fish & $<0.28$ & 0.28 to 1.2 & 1.20 to 5.18 & 5.18 to 10.36 & $>10.36$ & No \\
\hline Chlordane & Catfish & $<0.11$ & 0.11 to 0.47 & 0.47 to 2.03 & 2.03 to 4.05 & $>4.05$ & Yes \\
\hline Chlorpyrifos & Scaled & $<1.66$ & 1.66 to 7.17 & 7.17 to 31.07 & 31.07 to 62.14 & $>62.14$ & Yes \\
\hline Chlorpyrifos & Catfish & $<1.18$ & 1.18 to 5.12 & 5.12 to 22.19 & 22.19 to 44.39 & $>44.39$ & Yes \\
\hline DDT & Scaled & $<0.28$ & 0.28 to 1.20 & 1.20 to 5.18 & 5.18 to 10.36 & $>10.36$ & Yes \\
\hline Diazinon & All Fish & $<0.025$ & 0.025 to 0.108 & 0.108 to 0.47 & 0.47 to 0.93 & $>0.93$ & No \\
\hline Dicofol & All Fish & $<1.10$ & 1.10 to 4.78 & 4.78 to 20.71 & 20.71 to 41.43 & $>41.43$ & No \\
\hline Dieldrin & Scaled & $<0.028$ & 0.028 to 0.120 & 0.120 to 0.52 & 0.52 to 1.036 & $>1.036$ & Yes \\
\hline Dieldrin & Catfish & $<0.020$ & 0.020 to 0.085 & 0.085 to 0.37 & 0.37 to 0.74 & $>0.74$ & Yes \\
\hline Dioxin & Scaled & $<5.52 \mathrm{E}-7$ & $5.52 \mathrm{E}-7$ to $2.39 \mathrm{E}-6$ & $2.39 \mathrm{E}-6$ to $1.04 \mathrm{E}-5$ & $1.04 \mathrm{E}-5$ to $2.07 \mathrm{E}-5$ & $>2.07 \mathrm{E}-5$ & Yes \\
\hline Dioxin & Catfish & $<3.95 \mathrm{E}-7$ & $3.95 \mathrm{E}-07$ to $1.71 \mathrm{E}-6$ & $1.71 \mathrm{E}-6$ to $7.4 \mathrm{E}-6$ & $7.4 \mathrm{E}-6$ to $1.48 \mathrm{E}-5$ & $>1.48 \mathrm{E}-5$ & Yes \\
\hline Disulfoton & All Fish & $<0.011$ & 0.011 to 0.048 & 0.048 to 0.21 & 0.21 to 0.41 & $>0.41$ & No \\
\hline Endosulfan & All Fish & $<1.66$ & 1.66 to 7.17 & 7.17 to 31.07 & 31.07 to 62.14 & $>62.14$ & No \\
\hline Endrin & Scaled & $<0.17$ & 0.17 to 0.72 & 0.72 to 3.11 & 3.11 to 6.21 & $>6.21$ & Yes \\
\hline Heptachlor Epoxide & Scaled & $<0.0072$ & 0.0072 to 0.031 & 0.031 to 0.13 & 0.13 to 0.27 & $>0.27$ & Yes \\
\hline Heptachlor Epoxide & Catfish & $<0.0051$ & 0.0051 to 0.022 & 0.022 to 0.096 & 0.096 to 0.19 & $>0.19$ & Yes \\
\hline Hexachlorobenzene & Scaled & $<0.44$ & 0.44 to 1.91 & 1.91 to 8.29 & 8.29 to 16.57 & $>16.57$ & Yes \\
\hline Hexachlorobenzene & Catfish & $<0.32$ & 0.32 to 1.37 & 1.37 to 5.92 & 5.92 to 11.84 & $>11.84$ & Yes \\
\hline Lindane & Scaled & $<0.17$ & 0.17 to 0.72 & 0.72 to 3.11 & 3.11 to 6.21 & $>6.21$ & Yes \\
\hline Lindane & Catfish & $<0.12$ & 0.12 to 0.51 & 0.51 to 2.22 & 2.22 to 4.44 & $>4.44$ & Yes \\
\hline Methylmercury & All Fish & $<0.028$ & 0.028 to 0.12 & 0.12 to 0.52 & 0.52 to 1.036 & $>1.036$ & No \\
\hline Mirex & Scaled & $<0.11$ & 0.11 to 0.49 & 0.49 to 2.071 & 2.071 to 4.14 & $>4.14$ & Yes \\
\hline Mirex & Catfish & $<0.079$ & 0.079 to 0.34 & 0.34 to 1.48 & 1.48 to 2.96 & $>2.96$ & Yes \\
\hline PCB & Scaled & $<0.05$ & 0.05 to 0.22 & 0.22 to 0.95 & 0.95 to 1.89 & $>1.89$ & Yes \\
\hline $\mathrm{PCB}$ & Catfish & $<0.036$ & 0.036 to 0.16 & 0.16 to 0.68 & 0.68 to 1.35 & $>1.35$ & Yes \\
\hline Selenium & All Fish & $<1.38$ & 1.38 to 5.98 & 5.98 to 25.89 & 25.89 to 51.79 & $>51.79$ & No \\
\hline Terbufos & All Fish & $<0.014$ & 0.014 to 0.060 & 0.060 to 0.26 & 0.26 to 0.52 & $>0.52$ & No \\
\hline Toxaphene & Scaled & $<0.20$ & 0.20 to 0.86 & 0.86 to 3.73 & 3.73 to 7.46 & $>7.46$ & Yes \\
\hline Toxaphene & Catfish & $<0.14$ & 0.14 to 0.61 & 0.61 to 2.66 & 2.66 to 5.33 & $>5.33$ & Yes \\
\hline
\end{tabular}




\title{
Chapter 2: Mercury Levels in Fish Fillets from Selected West Virginia Fisheries
}

\author{
Abstract \\ Mercury is a toxic heavy metal present in the environment with no known biological \\ function. Mercury can bioconcentrate through the aquatic food chain into aquatic organisms and \\ is rapidly and almost completely absorbed when ingested by humans. Fish samples from ten \\ West Virginia sites ( 5 previously identified as contaminated, 5 previously identified as \\ uncontaminated) were collected, processed and analyzed for total mercury concentration. Mean \\ fillet sample mercury levels were compared to composite sample levels and found to require the \\ same level of consumption advisory. All samples from the ten sites had mercury levels above \\ West Virginia Sportfish Consumption Advisory Guide screening levels.
}

\section{Introduction}

Mercury has been mined since $415 \mathrm{BC}$ and has been used in gold extraction, in mirrors, to make felt hats, for electrodes to produce chlorine, in electrical components, as an antiseptic, in plastic manufacturing, as a slimicide in the pulp and paper industry, and as an agricultural fungicide. Mercury is widespread in the environment from both natural and human sources. Combustion of fossil fuels, especially coal, is currently the largest contributor of mercury into the environment. Combustion of coal is estimated to contribute $50 \%$ of the anthropogenic mercury to the atmosphere (Pinkney et al. 1997).

Coal has been a major factor in the development of Appalachia and West Virginia, since the first commercial mine opened in 1810 near Wheeling, WV. The Appalachian Region is responsible for $41 \%$ of the total U.S. coal production and $40 \%$ of the estimated atmospheric 
mercury pollution. West Virginia has traditionally been one of the top coal producing states in the nation, ranked number two in production only behind Wyoming in 1998 (Energy Information Administration 1998). West Virginia has a total of 346 active coal mines located in 29 counties and 9 of the top fifty producing coal mines in the nation. West Virginia has 15 coal burning power plants that produced a combined 92.8 million megawatt hours and released an estimated 4,155.4 kilograms of mercury into the environment in 1998 (NRDC 1999).

Mercury has no known metabolic function in organisms. Biological and chemical processes in the environment transform low toxicity forms of mercury into forms with high toxicity. Methylmercury (MeHg), like many compounds, can be bioconcentrated through the food chain. Fish consume mercury in food and can also absorb it through the gills.

Methylmercury levels in predator fish average seven million times higher than the concentrations of methylmercury found in surrounding waters (USEPA 1999). Methylmercury is lipophilic, but also binds to protein and can be found in considerable amounts in fish tissue. Eighty to ninety five percent of total mercury found in fish is in the form of methylmercury (Eisler 1987, Kannan et al. 1998, Ward et al. 1999).

Humans rapidly and almost completely absorb methylmercury. Methylmercury is of great concern for pregnant women and women in their child bearing years. Pregnant women exposed to methylmercury in their diets bore children with nervous system damage at levels producing only minor effects in the mothers. Chronic, low dose prenatal MeHg exposure from mothers consuming fish has been linked to poor performance on neurobehavioral tests, particularly on tests of fine-motor function, language, visual-spatial abilities, and verbal memory (National Research Council 2000). The developing nervous system of the fetus is the most sensitive human organ or system when exposed to mercury, and therefore the pregnant woman 
and her developing child is the most sensitive human subpopulation. Children are the next in sensitivity due to their greater food consumption as a percentage of body weight and their decreased ability to eliminate mercury from their bodies (USEPA 1999).

Methylmercury is listed as a possible human carcinogen by the U.S. Environmental Protection Agency (EPA) (USEPA 1997). Male mice had higher levels of kidney tumors after being dosed with methylmercury and animal studies have reported $\mathrm{MeHg}$ is mutagenic causing chromosome damage (USEPA 1998). Mercury exposure has also been linked to cardiovascular, immune and reproductive system effects (ATSDR 1997). Chronic effects from the human exposures in Japan and Iraq include impaired vision, numbness, lost coordination, slurred speech, damaged hearing, inability to walk and dementia.

Unfortunately, most state mercury fish consumption advisories and the U.S. Food and Drug Administration's (FDA) action level are calculated based on adult exposures or body weights and may not adequately protect the youngest portion of the population that is most susceptible. The West Virginia Sport Fish Consumption Advisory's lowest screening value is calculated using the EPA's reference dose and a child's body weight of 14.5 kilograms, as apposed to many advisories using higher adult body weights or action levels.

The objectives of this study were: 1) to find the mercury levels present in fish from the selected sites, 2) to determine if a fish consumption advisory is triggered for the selected sites based on composite $\mathrm{Hg}$ levels and Screening Values from the West Virginia Sport Fish Consumption Advisory Guide (the guide), and 3) to compare right fillet composite sample residue levels with mean left fillet individual sample residue levels to determine if the $\mathrm{Hg}$ levels are similar. 


\section{Methods and Materials}

\section{Fish Collection}

Ten sites, five with known contamination and five with unknown contamination selected by the West Virginia Department of Environmental Protection (WVDEP), were sampled in 1999 using experimental mesh gill nets, electroshocking gear or rotenone to collect fish samples for tissue analysis (Figure 1). The West Virginia Division of Natural Resources selected the species of fish collected at each site. A sample consisted of a minimum of six predator fish of the same species and size class or six bottom feeding fish of the same species and size class. Samples were collected from each of the ten sites for analysis, with 22 samples collected and analyzed. A size class is defined where the smallest individual is no less than 75 percent of the total length of the largest individual in a sample (USEPA 1995). The New River had bottom feeders collected from Bluestone Lake above the dam and predators collected from the river below the dam. Two sites, the North Branch of the Potomac River and Cranberry River, did not produce the minimum number of predator fish of the same size class. The Monongahela River had a total of five samples collected, three predator and two bottom feeder. The Kanawha River had 3 samples collected, one predator and two bottom feeder. The fish were weighed, measured for total length and handled and processed according to EPA procedures (USEPA 1995).

\section{Fish Processing and Analysis}

The samples were analyzed for total mercury using hot acid digestion and cold vapor atomic absorption according to the methods of Evans et al. (1986). Scaled fish, hybrid striped bass (Morone chrysops, saxatilis), spotted bass (Micropterus punctulatus), smallmouth bass (Micropterus dolomieu), white bass (Morone chrysops), sauger (Stizostedion canadense), walleye (Stizostedion vitreum), white sucker (Catostomus commersoni), and golden redhorse sucker (Moxostoma erythrurum) had scales removed with the skin remaining on the fillets. 
Channel Catfish (Ictalurus punctatus) were skinned prior to filleting. The right fillet from each sample was combined into a composite sample and analyzed while the left fillet from each sample was analyzed for individual residue levels. Homogenized fish fillet samples of 2 to 3 grams were placed in a digestion tube and $10 \mathrm{ml}$ of concentrated nitric acid was added. Samples were heated on a hotplate and digested at $125^{\circ} \mathrm{C}$ for four hours and then cooled to room temperature. Samples were diluted with distilled water, then analyzed using a Varian SpectrAA 300 atomic absorption unit with a Varian Model 76 Vapor Generation Accessory (Palo Alto, CA).

Standards were prepared using mercuric chloride in a nitric acid solution. Calibration was checked with a commercially available Ultra Scientific independent standard (North Kingstown, RI) . Fish samples and blanks were analyzed for quality assurance. Recovery of $\mathrm{MeHg}$ standards from control fish was eighty one percent with 75 to 125 percent considered a standard recovery range (MASCO 2002, ANL 2002).

\section{Statistical Analysis}

Screening values from the West Virginia Sport Fish Consumption Advisory Guide (the Guide) were used for comparison of residue levels found in fish fillets (Tables 1 and 2). The Guide was written as a document to assist the West Virginia government issue risk based fish consumption advisories. A screening value is a concentration of a target analyte in fish tissue that poses potential public health risk, in this case the level that would trigger the lowest level of a fish consumption advisory. Samples with mean levels above the next higher fish consumption advisory level were also compared. A Student's T-test was used to test mean sample residue levels with screening values and composite sample residue levels. An $\alpha$ of 0.05 was used in all tests. 


\section{Results}

Mercury levels in all nine composite samples collected at the five sites with no previously known contamination, were greater than the screening value of $0.028 \mathrm{ppm}$ (Table 1) set in the Guide (Warnick and Mazik 2000). All thirteen composite samples collected at the five sites with known contamination also exceeded the screening value. Composite mercury sample values ranged from a low of $0.05 \mathrm{ug} / \mathrm{g}$ in the North Branch of the Potomac River for white suckers to a high of $0.57 \mathrm{ug} / \mathrm{g}$ in the Tygart Reservoir for walleye. All composite sample levels exceeded the screening value of $0.028 \mathrm{ug} / \mathrm{g}$ (Table 1) and the adult level of $0.05 \mathrm{ug} / \mathrm{g}$ (Table 2), which would trigger one meal a week consumption advisories. Twelve composite sample levels were greater than or equal to the children's next higher advisory value of $0.12 \mathrm{ug} / \mathrm{g}$, and nine were greater than the next adult's advisory value of $0.22 \mathrm{ug} / \mathrm{g}$ which would prompt one meal per month consumption advisories.

Four of the twenty-two composite values were significantly different than the mean of individual fillet levels (Table 3). Three composite levels were significantly less than their individual mean and one was significantly greater than its mean. The individual fillet mean and composite samples would dictate the same level of fish consumption advisory in each case. Due to this observation, composite samples will only be discussed in this chapter.

\section{Discussion}

Composite mercury samples from the sites without previously known contamination, Cranberry River, New River, the South Branch of the Potomac River, Summersville Lake and Tygart Lake all exceeded the screening value to implement a fish consumption advisory set by 
the Guide. None of these sites is located near a city or industrialized area. The contaminated sites, Flat Fork Creek, Kanawha River, Monongahela River, North Branch of the Potomac River and the Ohio River are all near cities an industrialized area or both. The contaminated sites received more scrutiny in environmental sampling due to their locations. Localized pollution could explain the results from these sites, but not at Cranberry River, New River, the South Branch of the Potomac River, Summersville Lake and Tygart Lake. Atmospheric deposition of fossil fuel combustion, the chief cause of mercury bioaccumulation in fish, (Pinkney et al. 1997, EDC 1999, Mahaffey 1999) is most likely the cause of the elevated levels found in this study. West Virginia and its neighboring states rank high in coal production and atmospheric release of mercury from power plants (Table 5). Fish consumption is responsible for the vast majority of methyl mercury ingested by humans (U.S. EPA 1999, Mahaffey 1999), and forty states including Pennsylvania, Ohio, Kentucky, Maryland, and Virginia have already implemented some form of mercury based fish consumption advisory. Seventeen states have statewide mercury advisories including Kentucky, Maryland, Ohio and Pennsylvania (U. S. EPA 2002).

There has been debate concerning appropriate levels for mercury consumption advisories in fish (NRC 2000, Mahaffey 1999, Egeland and Middaugh 1997). Three United States agencies, the Agency for Toxic Substances and Disease Registry (ATSDR), EPA, and FDA have set 3 different levels for oral consumption of methyl mercury. The FDA action level of 1 ppm for fish in commerce is used by some states to set fish consumption advisories. This action level is based on a $0.5 \mathrm{ug} / \mathrm{kg} /$ day intake with an endpoint of paresthesis or numbness, prickling or tingling sensation in adults. However, the FDA cautions that pregnant women and women of childbearing age not to consume more than an average of 340 grams of fish per week from commercial sources (USFDA 2001). The ATSDR's minimal risk level (MRL) of $0.3 \mathrm{ug} / \mathrm{kg} / \mathrm{day}$ 
and EPA's reference dose (RfD) of $0.1 \mathrm{ug} / \mathrm{kg} / \mathrm{day}$ are both based on the neurotoxic effects on the developing fetus, making them more protective of early life stages than the FDA level. The ATSDR and EPA both used similar methods to set their limits, but also use different studies and uncertainty factors in their calculations. The National Research Council's Committee of Toxicological Effects of Methyl Mercury was tasked with reviewing mercury data and the EPA RfD. The committee determined the EPA RfD is scientifically justifiable for the protection of public health, but recommended a newer study conducted in the Faroe Islands to be the basis of the calculation (NRC 2000).

Previously, the State of West Virginia has used the FDA action level of $1 \mathrm{ppm}$ in the edible portion of the fish to establish mercury-based fish consumption advisories. Since 1978, when the WVDEP began collecting data on residues in fish tissues, only a single fish analyzed exceeded the FDA mercury limit. The State has now moved to risk-based fish consumption advisories, which requires a much lower screening value of $0.028 \mathrm{ppm}$.

Currently there are no mercury fish consumption advisories in place in West Virginia; however each composite sample tested from each site exceeds the screening value for a children's consumption advisory according to the Guide (Warnick and Mazik 2000). All twenty two samples analyzed exceed the screening value for the establishment of a mercury fish consumption advisory according to the Guide. The results are in agreement with past data compiled by the DEP from other sites in West Virginia. In 1996, thirty-six samples were collected and analyzed from 14 sites (WVDEP 1998). All of the samples would trigger a children's advisory under the Guide. Twenty-two samples were at mercury levels requiring a one meal per week advisory and the remaining 14 would require a one meal per month advisory. Eighty one percent of those same samples would trigger an adult advisory at ten sites. Twenty- 
seven samples would require a one meal per week and two would require one meal per month adult advisories. In 1997, forty-three samples from ten sites were collected (WVDEP 1998) and again all would activate a children's advisory with 23 one meal per week and 20 one meal per month. Ninety-five percent of the 1997 samples would cause adult consumption advisory with thirty-four one meal per week and seven one meal per month adult advisories at eight sites. In 1998, twenty-six samples were collected at four Ohio River Sites (WVDEP 1998), and $100 \%$ would require both children's and adult consumption advisories, ten one meal per week and sixteen one meal per month children's advisories and twenty-two one meal per week and 4 one meal per month advisories for adults.

Composite samples are often used for fish consumption advisories because of the greater cost of analyzing several individual samples from a site (USEPA 1995). One fillet from the fish making up a composite could be placed frozen storage for a period of time in case further analysis is indicated. When resources are scarce, the question of composite versus individual samples can restrict the number of water bodies a state or agency examines for advisories. Four of the twenty two composite residue levels were significantly different than their mean levels of the individual fish samples (Table 3), however all composite samples analyzed would dictate the same consumption advisory be instituted as the individual means for each site. The composite samples would provide the public with the same level of protection at a much lower cost per site. This would allow for testing of more fishing areas, providing greater protection for the public over a larger part of the state.

Mercury levels, in all but one sample of West Virginia sport fish were significantly greater than the screening value set in the West Virginia Sport Fish Consumption Advisory Guide (Warnick and Mazik 2000). Because of the history of mining and industry in West 
Virginia and surrounding Appalachia, it is not unlikely that the majority of sport fish found in West Virginia's waters may contain levels of mercury in excess of the new screening values set by the state. All fish samples contained composite mercury levels greater than the screening value of $0.28 \mathrm{ug} / \mathrm{kg}$, The Guide indicates a consumption advisory should be implemented on both the five sites previously identified as uncontaminated as well as the five sites previously identified as contaminated.

More intensive studies should be performed when contaminants are found in excess of screening values (EPA 1995). Expanded sampling and analysis could determine the extent and range of pollution. Future research including sampling and analyzing fish from all West Virginia watersheds to determine the extent of mercury contamination should be conducted. Since atmospheric contamination is most likely the source, mercury levels exceeding the screening value are probably widespread. 


\section{References}

Agency for Toxic Chemicals and Disease Registry. 1997. Toxicological Profile for Mercury Draft. ATSDR. Atlanta, GA.

Argonne National Lab. 1995. Site Environmental Report 7.2 Chemical Analysis February 18, 2002.

Egeland, GM and J.P. Middaugh. 1997. Balancing Fish Consumption Benefits with Mercury Exposure. Science. 278:1904 - 1905.

Eisler, R. 1987. Mercury Hazards to Fish, Wildlife, and Invertebrates: A Synoptic Review. U.S. Fish and Wildlife Service Biological Report 85(1.10).

Evans S.J., Johnson MS, and R. T. Leah. 1986. Determination of Mercury in Fish Tissue, a Rapid, Automated Technique for Routine Analysis. Varian Instruments at Work. AA-60: 1 -6.

Energy Information Administration. 1998. Coal Industry Annual 1998. DOE/EIA-0584(98), Washington, D.C.

Environmental Working Group. 1999. Mercury Falling: An analysis of mercury pollution from coal-burning power plants. EWG. Washington, D.C.

Foulke, J.E. 1994. Mercury in Fish: Cause for Concern? FDA Consumer. 9:5-8.

Mahaffey, M.R. 1999. Mercury Exposure Risks. Public Health Reports. 114:397 - 413.

MASCO. Attachment B- Analytical Method for Mercury in Wastewater February 18, 2002.

National Research Council. Toxicological Effects of Methylmercury. 2000. 289p. National Academy Press. Washington, DC

Pinkney A.E., Logan D.T. and H.T. Wilson. 1997. Mercury Concentrations in Pond fish in Relation to a Coal-Fired Power Plant. Archives of Environmental Contamination And Toxicology. 33: 222 - 229.

U.S. Environmental Protection Agency. 1995. Guidance for Assessing Chemical Contaminant Data for Use In Fish Consumption Advisories, Volume I: Fish Sampling and Analysis. USEPA, EPA 823-R-95-007, Washington, D.C.

U.S. Environmental Protection Agency. 1997. Guidance for Assessing Chemical Contaminant Data for Use In Fish Consumption Advisories, Volume II: Risk Assessment and Fish Consumption Limits. USEPA, EPA 823-B-97-009, Washington, D.C. 
U.S. Environmental Protection Agency. 1998. Integrated Risk Information System Methylmercury (MeHg) CARSRN 22967-92-6.

http://www.epa.gov/ngispgm3/iris/subst/0073.htm

U.S. Environmental Protection Agency. 1999. Mercury Update: Impact on Fish Consumption Advisories. USEPA, EPA-823-F-99-016, Washington, D.C.

U.S. Environmental Protection Agency. 2002. Update: National Listing of Fish and Wildlife Advisories. USEPA, EPA-823-F-02-007, Washington, D.C.

U.S. Food and Drug Administration. 2001. Consumer Advisory: An Important Message For Pregnant Women And Women of Childbearing Age Who May Become Pregnant About The Risks of Mercury In Fish. FDA, Rockville, MD.

Ward, S.M. and R. M. Neumann. 1999. Seasonal Variations in Concentrations of Mercury in Axial muscle Tissue of Largemouth Bass. North American Journal of Fisheries Management. 19:89-96.

Warnick, W.A. and P.M. Mazik. 2000. West Virginia Sport Fish Consumption Advisory Guide. 173p.Available from : West Virginia Division of Environmental Protection, Charleston, WV.

West Virginia Department of Environmental Protection. 1998. A:/fish.dbf Fish Tissue Data Base $1974-1998$.

West Virginia Office of Miners' Health Safety and Training. 2000. A Brief History of Coal and Safety Enforcement in West Virginia. http://www.state.wv.us/mhst/History.htm 
Figure 1. West Virginia Sport Fish Consumption Advisory Sampling Sites

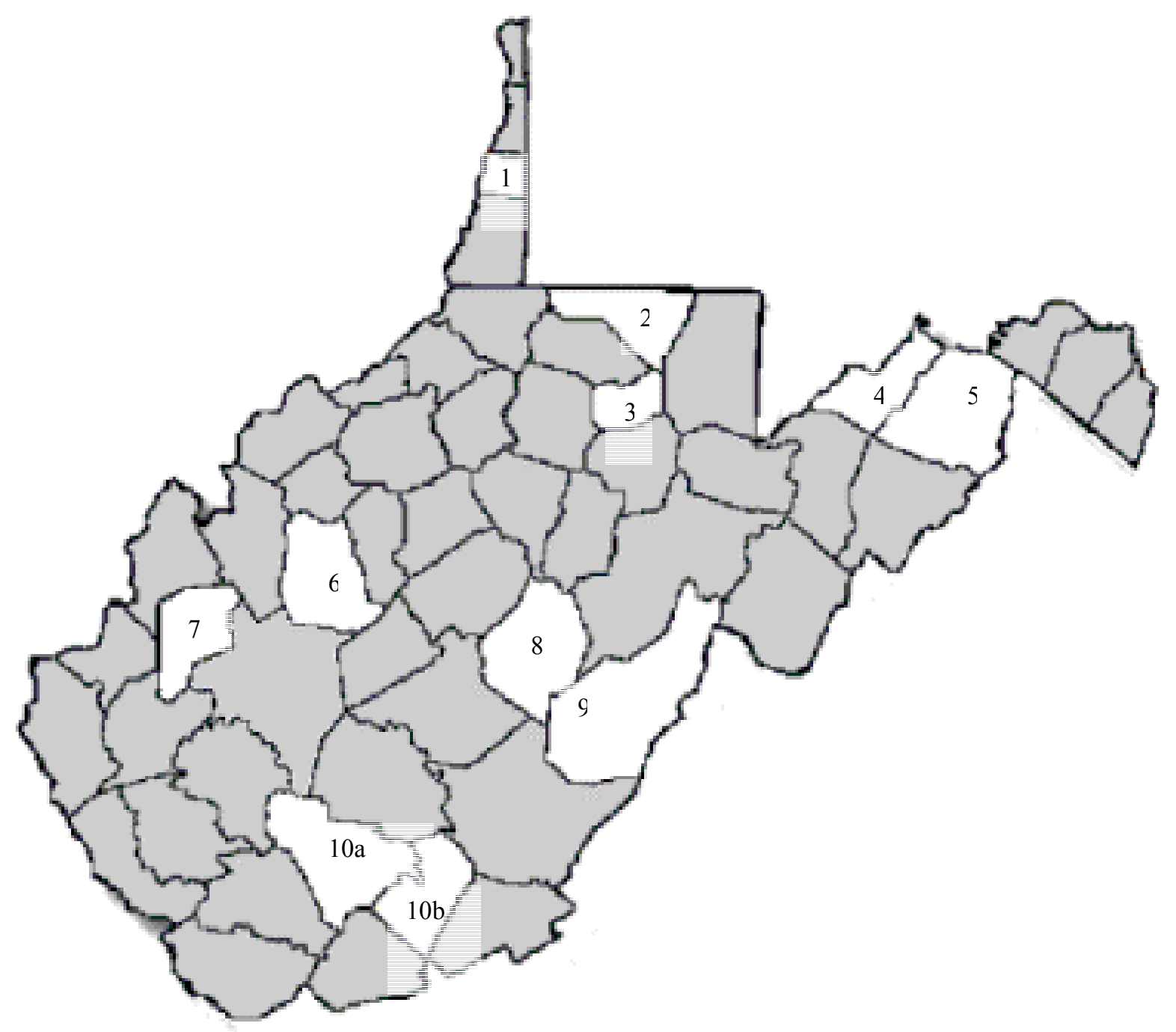

Known Contamination

1) Ohio River, Ohio County

2) Monongahela River, Monongalia County

4) North Branch of the Potomac River, Mineral County

6) Flat Fork Creek, Roane County

7) Kanawha River, Putnam County
Unknown Contamination

3) Tygart Lake, Taylor County

8) Summersville Lake, Nicholas County

5) South Branch of the Potomac River, Hampshire County

9) Cranberry River, Pocahontas County

10a) New River, Raleigh County

10b) Bluestone Lake, Summers County 
Table 1. Methylmercury Child Advisory Groups

Consumption Advisory Group

Group 1 Unrestricted Consumption or 225 meals per year

Group 2 One meal per week

Group 3 One meal per month

Group 4 Six meals per year

Group 5 DO NOT EAT
Mercury level

$<0.028 \mathrm{ppm}^{*}$

$>0.028 \mathrm{ppm}$ to $0.12 \mathrm{ppm}$

$>0.12 \mathrm{ppm}$ to $0.52 \mathrm{ppm}$

$>0.52 \mathrm{ppm}$ to $1.036 \mathrm{ppm}$

$>1.036 \mathrm{ppm}$

* = screening value for mercury consumption advisory 
Table 2. Methylmercury Adult Advisory Groups

\begin{tabular}{lc}
\hline Consumption Advisory Group & Mercury level \\
\hline Group 1 Unrestricted Consumption or 225 meals per year & $<0.05 \mathrm{ppm}$ \\
Group 2 One meal per week & $0.05 \mathrm{ppm}$ to $0.22 \mathrm{ppm}$ \\
Group 3 One meal per month & $>0.22 \mathrm{ppm}$ to $0.95 \mathrm{ppm}$ \\
Group 4 Six meals per year & $>0.95 \mathrm{ppm}$ to $1.89 \mathrm{ppm}$ \\
Group 5 DO NOT EAT & $>1.89 \mathrm{ppm}$ \\
\hline
\end{tabular}


Table 3. Results of Students T-Test comparing Mean Hg levels and Composite Hg levels in fish samples at Ten West Virginia sites.

\begin{tabular}{|c|c|c|c|c|c|c|}
\hline Site & $\begin{array}{c}\text { Contaminated/ } \\
\text { Uncontaminated }\end{array}$ & Species & $\begin{array}{l}\text { Mean Fish } \\
\text { length } \mathrm{cm} .\end{array}$ & $\begin{array}{c}\text { Composite } \mathrm{Hg} \\
\text { level ug/g }\end{array}$ & $\begin{array}{c}\text { Mean } \mathrm{Hg} \text { level } \\
\text { ug/g }\end{array}$ & Significance \\
\hline Cranberry River & $\mathrm{UC}$ & White Sucker & 23.2 & 0.16 & 0.15 & NS \\
\hline Flat Fork Creek & $\mathrm{C}$ & $\begin{array}{l}\text { Golden } \\
\text { Redhorse } \\
\text { Sucker }\end{array}$ & 26.7 & 0.44 & 0.38 & 0.02 \\
\hline Flat Fork Creek & $\mathrm{C}$ & Spotted Bass & 22.9 & 0.46 & 0.44 & NS \\
\hline Kanawha River & $\mathrm{C}$ & Channel Catfish & 34.8 & 0.08 & 0.07 & NS \\
\hline Kanawha River & $\mathrm{C}$ & Channel Catfish & 46.8 & 0.32 & 0.16 & 0.010 \\
\hline Kanawha River & $\mathrm{C}$ & $\begin{array}{l}\text { Hybrid Striped } \\
\text { Bass }\end{array}$ & 32.9 & 0.10 & 0.11 & NS \\
\hline Monongahela River & $\mathrm{C}$ & Channel Catfish & 36.6 & 0.10 & 0.12 & NS \\
\hline Monongahela River & $\mathrm{C}$ & Channel Catfish & 45.3 & 0.10 & 0.12 & NS \\
\hline Monongahela River & $\mathrm{C}$ & Sauger & 36.4 & 0.23 & 0.21 & NS \\
\hline Monongahela River & $\mathrm{C}$ & Sauger & 36.3 & 0.18 & 0.11 & 0.01 \\
\hline Monongahela River & C & White Bass & 32.9 & 0.11 & 0.18 & 0.05 \\
\hline New River & $\mathrm{UC}$ & Channel Catfish & 40.5 & 0.05 & 0.07 & NS \\
\hline New River & UC & $\begin{array}{l}\text { Smallmouth } \\
\text { Bass }\end{array}$ & 27.4 & 0.08 & 0.10 & NS \\
\hline $\begin{array}{l}\text { North Branch of the } \\
\text { Potomac }\end{array}$ & $\mathrm{C}$ & White Sucker & 23.6 & 0.05 & 0.11 & NS \\
\hline Ohio River & $\mathrm{C}$ & Channel Catfish & 41.5 & 0.07 & 0.07 & NS \\
\hline Ohio River & $\mathrm{C}$ & $\begin{array}{l}\text { Hybrid Striped } \\
\text { Bass }\end{array}$ & 40.0 & 0.12 & 0.22 & NS \\
\hline $\begin{array}{l}\text { South Branch of the } \\
\text { Potomac }\end{array}$ & $\mathrm{UC}$ & $\begin{array}{l}\text { Golden } \\
\text { Redhorse } \\
\text { Sucker }\end{array}$ & 48.9 & 0.33 & 0.34 & NS \\
\hline $\begin{array}{l}\text { South Branch of the } \\
\text { Potomac }\end{array}$ & $\mathrm{UC}$ & $\begin{array}{l}\text { Smallmouth } \\
\text { Bass }\end{array}$ & 29.2 & 0.47 & 0.33 & NS \\
\hline Summersville Lake & $\mathrm{UC}$ & $\begin{array}{l}\text { Golden } \\
\text { Redhorse } \\
\text { Sucker }\end{array}$ & 44.8 & 0.26 & 0.27 & NS \\
\hline Summersville Lake & $\mathrm{UC}$ & $\begin{array}{l}\text { Smallmouth } \\
\text { Bass }\end{array}$ & 30.0 & 0.44 & 0.46 & NS \\
\hline Tygart Lake & $\mathrm{UC}$ & Channel Catfish & 47.2 & 0.08 & 0.10 & NS \\
\hline Tygart Lake & UC & Walleye & 39.3 & 0.57 & 0.49 & NS \\
\hline
\end{tabular}


Table 4. Composite Hg levels compared to children's one meal per week screening value of $0.028 \mathrm{ug} / \mathrm{g}$, one meal per month value of $0.12 \mathrm{ug} / \mathrm{g}$, adult's one meal per week value of $0.05 \mathrm{ug} / \mathrm{g}$ and one meal per month value of $0.22 \mathrm{ug} / \mathrm{g}$.

\begin{tabular}{|c|c|c|c|c|c|c|}
\hline Site & $\begin{array}{l}\text { Contaminated/ } \\
\text { Uncontaminated }\end{array}$ & Species & $\begin{array}{l}\text { Mean Fish } \\
\text { length } \mathrm{cm} .\end{array}$ & $\begin{array}{c}\text { Composite } \mathrm{Hg} \\
\text { level ug/g }\end{array}$ & $\begin{array}{l}\text { Child Advisory } \\
\text { Level } \\
\text { One meal per }\end{array}$ & $\begin{array}{c}\text { Adult Advisory } \\
\text { Level } \\
\text { One meal per }\end{array}$ \\
\hline Cranberry River & UC & White Sucker & 23.2 & 0.16 & Month & Week \\
\hline Flat Fork Creek & $\mathrm{C}$ & $\begin{array}{l}\text { Golden } \\
\text { Redhorse } \\
\text { Sucker }\end{array}$ & 26.7 & 0.44 & Month & Month \\
\hline Flat Fork Creek & $\mathrm{C}$ & Spotted Bass & 22.9 & 0.46 & Month & Month \\
\hline Kanawha River & $\mathrm{C}$ & Channel Catfish & 34.8 & 0.08 & Week & Week \\
\hline Kanawha River & $\mathrm{C}$ & Channel Catfish & 46.8 & 0.32 & Month & Month \\
\hline Kanawha River & $\mathrm{C}$ & $\begin{array}{l}\text { Hybrid Striped } \\
\text { Bass }\end{array}$ & 32.9 & 0.10 & Week & Week \\
\hline Monongahela River & $\mathrm{C}$ & Channel Catfish & 36.6 & 0.10 & Week & Week \\
\hline Monongahela River & $\mathrm{C}$ & Channel Catfish & 45.3 & 0.10 & Week & Week \\
\hline Monongahela River & $\mathrm{C}$ & Sauger & 36.4 & 0.23 & Month & Month \\
\hline Monongahela River & $\mathrm{C}$ & Sauger & 36.3 & 0.18 & Month & Week \\
\hline Monongahela River & $\mathrm{C}$ & White Bass & 32.9 & 0.11 & Week & Week \\
\hline New River & $\mathrm{UC}$ & Channel Catfish & 40.5 & 0.05 & Week & Week \\
\hline New River & UC & $\begin{array}{l}\text { Smallmouth } \\
\text { Bass }\end{array}$ & 27.4 & 0.08 & Week & Week \\
\hline $\begin{array}{l}\text { North Branch of the } \\
\text { Potomac }\end{array}$ & $\mathrm{C}$ & White Sucker & 23.6 & 0.05 & Week & Week \\
\hline Ohio River & $\mathrm{C}$ & Channel Catfish & 41.5 & 0.07 & Week & Week \\
\hline Ohio River & $\mathrm{C}$ & $\begin{array}{l}\text { Hybrid Striped } \\
\text { Bass }\end{array}$ & 40.0 & 0.12 & Month & Week \\
\hline $\begin{array}{l}\text { South Branch of the } \\
\text { Potomac }\end{array}$ & UC & $\begin{array}{l}\text { Golden } \\
\text { Redhorse } \\
\text { Sucker }\end{array}$ & 48.9 & 0.33 & Month & Month \\
\hline $\begin{array}{l}\text { South Branch of the } \\
\text { Potomac }\end{array}$ & UC & $\begin{array}{l}\text { Smallmouth } \\
\text { Bass }\end{array}$ & 29.2 & 0.47 & Month & Month \\
\hline Summersville Lake & $\mathrm{UC}$ & $\begin{array}{l}\text { Golden } \\
\text { Redhorse } \\
\text { Sucker }\end{array}$ & 44.8 & 0.26 & Month & Month \\
\hline Summersville Lake & UC & $\begin{array}{l}\text { Smallmouth } \\
\text { Bass }\end{array}$ & 30.0 & 0.44 & Month & Month \\
\hline Tygart Lake & UC & Channel Catfish & 47.2 & 0.08 & Week & Week \\
\hline Tygart Lake & UC & Walleye & 39.3 & 0.57 & Month & Month \\
\hline
\end{tabular}


Table 5. 1998 National Ranking of Coal Production and Power Plant Mercury Release Rankings for West Virginia and Surrounding States

\begin{tabular}{lcc}
\hline State & $\begin{array}{c}\text { Coal Production* } \\
\text { National Ranking }\end{array}$ & $\begin{array}{c}\text { Estimated Mercury Air Pollution } \\
\text { National Ranking** }\end{array}$ \\
\hline Kentucky & 3 & 8 \\
Maryland & 18 & 18 \\
Ohio & 13 & 3 \\
Pennsylvania & 4 & 1 \\
Virginia & 9 & 7 \\
West Virginia & 2 & 7 \\
* Energy Information Administration 2000. & & \\
$* *$ Environmental Working Group 1999. & & \\
\hline
\end{tabular}




\title{
Chapter 3: Aroclor 1260 levels in Fish Fillets from Selected West Virginia Sites
}

\begin{abstract}
Polychlorinated Biphenyls (PCBs) are persistent toxic, carcinogenic environmental contaminants. They can bioaccumulate through the aquatic food chain into fish to levels from 2000 to over a million times greater than the ambient water (EPA 1999). Twenty one samples of fish from ten West Virginia sites (5 previously identified as contaminated, 5 previously identified as uncontaminated) were collected, processed and analyzed for Aroclor residue concentrations. Aroclor 1260 was the only PCB formulation isolated from the samples. Ten composite samples had concentrations greater than the lowest screening value used to trigger a fish consumption advisory according to the West Virginia Sport Fish Consumption Advisory Guide. Composite Aroclor 1260 levels were compared to individual means and found to provide the same or in one case a more protective level of consumption advisory.
\end{abstract}

\section{Introduction}

Polychlorinated biphenyls (PCBs) are a group of 209 isomers of synthetic halogenated hydrocarbons invented in 1881. They were used for heat transfer agents, lubricant, dielectric agents, flame retardants, plasticizers, and waterproofing materials (Eisler 1986). Since 1971, PCBs have been used only for insulation or cooling in closed electrical components. The Toxic Substances Control Act of 1979 banned the manufacture processing, distribution, and use of PCBs except in totally enclosed systems because they are fat soluble, extremely persistent and 
will bioaccumulate in the environment. However, due to indiscriminate disposal and atmospheric transport, PCB residues are found worldwide.

PCBs are absorbed through the gastrointestinal tract at a rate of $75 \%$ to $90 \%$ and stored in fatty tissue including the liver, and skin (EPA 1999). PCBs are transferred through the placenta and through milk in mothers who consume contaminated fish (U.S. Public Health Service et al. 1999, Mendola et al.1995, Swain 1988). Acute doses have caused death in animals, although no human deaths have been documented due to PCB exposure. Chronic exposures in animal studies include hepatic, gastrointestinal, hematological, dermal, endocrine, immunological, reproductive, and developmental effects (ATSDR 1998). One human study showed lower birth weight, smaller head circumference, and shorter gestational age (Fein et al. 1988). Age four children had deficits in weight gain, depressed responsiveness and reduced performance on the visual recognition-memory test (U.S. Public Health Service et al. 1999). At age 11 the children with prenatal exposure had lower full scale and verbal IQ scores (EPA 1997a). Most mutagenicity tests produced negative results (EPA 1997b). Workers with occupational exposures of $10-25$ years have increased chromosomal abnormalities and increased sister chromatid exchange (EPA 1997a). PCBs are listed as a probable human carcinogen by the U.S. EPA and have been shown to produce liver cancers in rats (ATSDR 1998).

There has been confusion concerning appropriate levels for PCB consumption advisories in fish. Three United States agencies, the Agency for Toxic Substances and Disease Registry (ATSDR), EPA, and FDA have set different levels for oral consumption of PCBs or Aroclors. The FDA has set an action level of 2 parts per million (ppm) for all PCB residues and combinations, while the EPA has set reference doses (RfD) for some individual Aroclor mixtures. The Agency for Toxic Substances and Disease Registry (ATSDR) has set a minimal 
risk level (MRL) for Aroclor 1254. The Great Lakes Task Force produced a Human Protection Value (HPV) of $0.05 \mathrm{ug} / \mathrm{kg} /$ day for all PCBs to standardize fish consumption advisories in the Great Lakes. The Great Lakes HPV was used for PCB advisories in the West Virginia Sport Fish Consumption Advisory Guide (the Guide).

The objectives of this study were: 1) to find the PCB levels present in fish from the selected sites, 2) to determine if a fish consumption advisory is triggered for the selected sites based on composite PCB levels and Screening Values from the West Virginia Sport Fish Consumption Advisory Guide (the guide), and 3) to compare right fillet composite sample residue levels with mean left fillet individual sample residue levels to determine if the PCB levels are similar.

\section{Methods and Materials}

\section{Fish Collection}

Ten sites, five with known contamination and five with unknown contamination selected by the West Virginia Department of Environmental Protection (WVDEP), were sampled in 1999 using experimental mesh gill nets, electroshocking gear or rotenone to collect fish samples for tissue analysis (Figure 1). The West Virginia Division of Natural Resources selected the species of fish collected at each site. A sample consisted of a minimum of six predator fish of the same species and size class or six bottom feeding fish of the same species and size class.

Samples were collected from each of the ten sites for analysis, with 21 samples collected and analyzed. A size class is defined where the shortest fish is not less than $75 \%$ of the total length of the longest fish (USEPA 1995). The New River had bottom feeders collected from Bluestone Lake above the dam and predators collect from the river below the dam. Two sites, the North Branch of the Potomac River and Cranberry River, did not produce the minimum 
number of predator fish of the same size class. The Monongahela River had a total of four samples collected and analyzed, two predator and two bottom feeder. The Kanawha River had 3 samples, one predator and two bottom feeder. The fish were weighed, measured for total length and handled and processed according to EPA's Guidance for Assessing Chemical Contaminant Data for Use in Fish Advisories, Volume I Fish Sampling and Analysis (USEPA 1995).

\section{Fish Processing and Analysis}

The samples were analyzed for Aroclor residues according to the FDA's Pesticide Analytical Manual (PAM) (USFDA 1997). Scaled fish, hybrid striped bass (Morone chrysops, saxatilis), spotted bass (Micropterus punctulatus), smallmouth bass (Micropterus dolomieu), white bass (Morone chrysops), sauger (Stizostedion canadense), walleye (Stizostedion vitreum), white sucker (Catostomus commersoni), and golden redhorse sucker (Moxostoma erythrurum) had scales removed with the skin remaining on the fillets. Channel Catfish (Ictalurus punctatus) were skinned prior to filleting. The right fillet from each sample was combined into a composite sample and analyzed. When composites samples exceeded the screening value, the left fillets from corresponding fish were individually analyzed. Homogenized fish fillet samples of 25 grams were extracted with acetonitrile and filtered through a florisil column with an ethyl ether/petroleum ether mixture. The extract solution was then concentrated in a Kuderna-Danish concentrator. The concentrated extracts were then analyzed twice, using either a Varian model 3700 Gas Chromatograph (Palo Alto, CA) or a Waters Dimension I Gas Chromatograph (Milford, MA) both with Hewlett Packard 3390A Integrators (Palo Alto, CA). Calibration was checked with EPA standards. Spiked fish samples and blanks were analyzed for quality assurance. Recovery for the composite samples was $102 \%$ and recovery for the individual fillets was 79\%. Acceptable recoveries range from 50\% to 130\% (NOAA 1996). 


\section{Statistical Analysis}

Screening values from the Guide (Warnick and Mazik 2000) were used for comparison of residue levels found in fish fillets (Tables 1 and 2). A screening value is a concentration of a target analyte in fish tissue that poses potential public health risk, in this case the level that would trigger the lowest level of a fish consumption advisory. Samples with mean levels above the next higher fish consumption advisory level were also compared. A Student's T-test was used to test mean sample residue levels with screening values and composite sample residue levels with the minimum $\alpha$ of 0.05 used in all tests.

\section{Results}

Aroclor 1260 levels in one sample collected at a site with no previously known contamination were greater than the screening value of $0.036 \mathrm{ppm}$ for skin off fillets (Table 1) set in the Guide (Warnick and Mazik 2000). Nine of the twelve composite samples collected at sites with previously known contamination exceeded screening values for skin on fillets or skin off fillets (Table 1). Two composite samples collected at contaminated sites had no Aroclor residues detected. One composite sample at a contaminated site had Aroclor 1260 detected but at a level lower than the screening value.

One of the ten composite samples, with aroclor levels that exceeded the screening value, was significantly different from the mean of individual fillet levels (Table 2), although the composite and mean levels would dictate the same level of advisory. Due to this, composite samples will only be discussed in this chapter.

Composite sample values ranged from a low of $0.03 \mathrm{ug} / \mathrm{g}$ in the Kanawha River for channel catfish to a high of $0.55 \mathrm{ug} / \mathrm{g}$ in the Ohio River for hybrid striped bass. Three of the five skin on fillets composites exceeded the one meal per week advisory level of 0.05 ppm and two 
exceeded the one meal per month level of $0.22 \mathrm{ppm}$ (Table 3). Three of the five skin off fillets composites exceeded the one meal per week advisory level of $0.036 \mathrm{ppm}$ and two exceeded the one meal per month level of 0.16 ppm (Table 4).

\section{Discussion}

One composite sample from a site with no previously known contamination, the New River, exceeded the screening value to implement a fish consumption advisory set by the Guide. None of the sites with no previously known contamination, the Cranberry River, New River, South Branch of the Potomac River, Summersville Lake and Tygart lake, are located near a city or industrialized area. The contaminated sites, Flat Fork Creek, Kanawha River, Monongahela River, North Branch of the Potomac River and the Ohio River are all relatively near a city, an industrialized area or both. The contaminated sites have received more scrutiny in environmental sampling due to their locations. The levels of PCBs found in the composites with Aroclor residues are most likely due to industrial contamination or improper disposal.

Our results would indicate that PCB contamination is a problem at least in some waters of the State of West Virginia. Bluestone Lake, the only site with out previously know contamination with PCB residues found in fish, does not have an advisory and has not had PCB residues detected in previous sampling. Catfish collected from Bluestone Lake had levels of Aroclor 1260 (Table 4) which fall into the one meal per week advisory range. The remaining sites, Cranberry River, New River, South Branch of the Potomac, Summersville Lake and Tygart Lake had no Aroclor residues detected.

Fish from five of the ten sites sampled were positive for PCB residues (Tables 3 and 4). Two of the sites, the Ohio River (Table 5), and Flat Fork Creek, currently have PCB fish consumption advisories. The analysis of the Ohio River hybrid striped bass (Morone chrysops $x$ 
saxatilis) agrees with the current advisory allowing up to one meal per month. The results for the Ohio River channel catfish (Ictalurus punctatus) disagree with the advisory in place. The current advisory allows six meal a year of Ohio River Catfish less than 43.18 centimeters while the levels found in this study indicate up to one meal per month is acceptable. West Virginia has implemented a uniform advisory for the entire Ohio River, which explains the difference between the advisory in place and the results of this study. The uniform advisory for the Ohio River issued by West Virginia and Ohio prevents confusion from anglers from the two states fishing the same areas. Sampling of the entire river has found higher levels of PCBs in the same size class of Channel Catfish and led to the more conservative advisory for West Virginia's portion of the Ohio River (DEP 1998). Flat Fork Creek currently has a "do not eat" advisory on all bottom feeders including suckers. Golden redhorse suckers (Maxostoma erythrurum) collected there had no Aroclor residues detected. Flat Fork Creek spotted bass (Micropterus punctulatus), a predator species, had a level of $0.06 \mathrm{ppm}$ which would dictate an advisory to eat no more than one meal per week. The EPA reported higher concentrations of Aroclor 1260 are found in predators compared to bottom feeders (USEPA 1999) which agrees with these findings. The Kanawha River is under a more strict consumption advisory for dioxin than the Aroclor 1260 levels would impose. All four samples analyzed for the Monongahela River carried levels that require consumption advisories according to the Guide. Fish tissues from the Monongahela River have had PCBs detected in the past but does not currently have a consumption advisory (DEP 1998). In 1990, three samples were collected near Morgantown with levels that ranged from $0.34 \mathrm{ppm}$ in spotted bass to $1.2 \mathrm{ppm}$ in golden redhorse suckers. The 1990 levels would result in two one meal per week advisories and one six meals per year advisory under the Guide. The Monongahela was sampled in 1993 near Morgantown and three samples ranged from 
$0.07 \mathrm{ppm}$ in spotted bass to $1.11 \mathrm{ppm}$ in carp (Cyprinus carpio), these results would also produce two one meal per week advisories and one six meals per year advisory (DEP 1998). The last sample collected previous to this study, was in 1995, where white bass had a level of .16 dictating a one meal per week study according to the Guide. Pennsylvania has a one meal per month advisory for carp in place based on PCB residues at the border with West Virginia. The fish collected for the West Virginia samples were collected at Hildebrand Lock and Dam and Morgantown Lock and Dam, 17.2 and 11.2 river miles from Point Marion where the Pennsylvania advisory takes effect (USACOE 2002). The Monongahela River channel catfish samples both contained residue levels indicating an advisory of no more than one meal per week. The white bass levels indicate an advisory of no more than one meal per week and the sauger results would require a one meal per month advisory.

Disagreement on acceptable levels of PCBs in fish exists between the responsible federal agencies. The ATSDR, EPA and FDA have set different levels for oral consumption of PCB's. The ATSDR set an MRL for Aroclor 1254 of $0.00002 \mathrm{ppm} /$ day based on immunologic effects in female rhesus monkeys (Macaca mulatta) (ATSDR 1999). The FDA action level is for fish in interstate commerce has been and is used by some states to set fish consumption advisories, even though the FDA stated that economic impacts to the commercial fishing industry was a consideration when setting its current limit of 2 parts per million (ppm) (USFDA 1984). The EPA has set reference doses (RfD) for individual Aroclor mixtures 1016 and 1254, but is still reviewing the limit for 1260 (EPA 2000). No EPA RfD was set for Aroclor 1248 due to death of a rhesus monkey at the lowest tested dose (EPA 2002). The differing information from these agencies prompted the Great Lakes Task Force to use a weight of evidence approach. They considered not one but all the available studies when they set their Health Protection Value 
(HPV) of $0.05 \mathrm{ug} / \mathrm{kg} /$ day. The HPV incorporates acceptable cancer, reproductive and developmental risk. The Task Force reasoned that by considering all the available information and distilling it into a single HPV, the most robust and stable HPV possible would emerge (GLSFATF 1993).

Until 1996 the State of West Virginia has used the FDA action level of 2 ppm in the edible portion of the fish to establish all PCB based fish consumption advisories. Since then, West Virginia's PCB fish consumption advisories on the Ohio River have been issued according to the risk based GLSFATF protocol. With the acceptance of the Guide by the State of West Virginia, all PCB advisories issued should use a HPV of $0.00005 \mathrm{ppm} /$ day resulting in a screening value of $0.036 \mathrm{ppm}$ in skin off fillets (catfish) and $0.05 \mathrm{ppm}$ in skin on fillets.

Composite samples are often used for fish consumption advisories because of the greater cost of analyzing several individual samples from a site (USEPA 1995). One fillet from each fish making up a composite could be placed frozen storage for a period of time in case further analysis is indicated. When resources are scarce, the question of composite versus individual samples can restrict the number of water bodies a state or agency examines for advisories. Ten composite samples from five sites exceed the lowest screening values set in the Guide. One sample channel catfish from Bluestone Lake revealed contamination where none was previously reported. Compositing fish samples would err on the side of caution and provide the public with the same or greater level of protection at a much lower cost per site. This would allow for testing of more fishing areas, providing greater protection for the public over a larger part of the state.

More intensive studies should be performed to determine the extent of the contamination in the water body and different species of fish, in cases where pollutants are found in excess of screening values (EPA 1995). Sampling and analysis should be performed on fish samples from 
different areas of the Monongahela River and Bluestone Lake where levels in excess of screening values were found and no fish consumption advisory exists. These studies could determine if contamination is more widespread or localized in the two water bodies. Sampling and analysis of fish from all watersheds in West Virginia should be performed to screen as much of the fishable waters as possible for water borne contaminants in order to protect the health of anglers. 


\section{References}

Agency for Toxic Chemicals and Disease Registry. 1998. Toxicological Profile for Polychlorinated Biphenyls - Update. ATSDR. Atlanta, GA.

Eisler R. 1986. Polychlorinated Biphenyls Hazards to Fish, Wildlife, and Invertebrates: A Synoptic Review. U.S. Fish and Wildlife Service Biological Report 85(1.7).

Fein G.G., J.L. Jacobson, S.W. Jacobson, P.M. Schwartz and J.K. Dowler.1984. Prenatal Exposure to Polychlorinated Biphenyls: Effects on Birth Size and Gestational Age. The Journal of Pediatrics; 105(2):315 - 320.

Great Lakes Sport Fish Advisory Task Force. 1993. Protocol for a Uniform Great Lakes Sport Fish Consumption Advisory. GLSFAT, Madison, WI.

Humphrey, H.E.B. 1987. The Human Population - An Ultimate Receptor for Aquatic Contaminants. Hydrobiologia. 149: 75-80.

National Oceanic and Atmospheric Administration Great Lakes Environmental Laboratory. 1996. Analysis of Polychlorinated Biphenyls and Chlorinated Pesticides by Gas Chromatography with Electron Capture Detection. NOAA, Ann Arbor, MI.

Mendola P., G.M. Buck, J.E. Vena, M. Zielezny and L.E. Sever.1995. Consumption of PCBContaminated Sport Fish and Risk of Spontaneous Fetal Death. Environmental Health Perspectives; 103(5):498 - 502.

Pennsylvania Department of Environmental Protection. 2002. Commonwealth of Pennsylvania Public_Health Advisory - Fish Consumption. http://www.dep.state.pa.us/dep/deputate/watermgt/Wqp/WQStandards/FishAdvis/fishadvisory02 .pdf

Reinert, R.E., Knuth, B.A., Kamrin, M.A. and Q.J. Stober. 1991. Risk Assessment, Risk Management, and Fish Consumption Advisories in the United States. Fisheries. 16(6): 5-12.

Reinert, R.E., Knuth, B.A., Kamrin, M.A. and Q.J. Stober. 1996. A review of the Basic Principles and Assumptions used to issue Fish Consumption Advisories. American Fisheries Society Symposium. 16:98-106.

Swain, W.R.1988. Human Health Consequences of Consumption of Fish Contaminated with Organochlorine Compounds. Aquatic Toxicology.11:357 - 377.

U.S. Army Corps Of Engineers. 2002. Monongahela River Mileage Chart. http://www.lrp.usace.army.mil/mrmile.pdf 
U.S. Environmental Protection Agency. 1995. Guidance for Assessing Chemical Contaminant Data for Use In Fish Consumption Advisories, Volume I: Fish Sampling and Analysis. USEPA, EPA 823-R-95-007, Washington, D.C.

U.S. Environmental Protection Agency. 1997a. Guidance for Assessing Chemical Contaminant Data for Use In Fish Consumption Advisories, Volume II: Risk Assessment and Fish Consumption Limits. USEPA, EPA 823-B-97-009, Washington, D.C.

U.S. Environmental Protection Agency. 1997b. Integrated Risk Information System Polychlorinated biphenyls (PCBs) CARSRN 1336-36-3. http://www.epa.gov//iris/subst/0294.htm

U.S. Environmental Protection Agency. 1999. Polychlorinated Biphenyls (PCBs) Update: Impact on Fish Consumption Advisories. USEPA, EPA-823-F-99-019, Washington, D.C.

U.S. Food and Drug Administration. 1998. Fish and Fisheries Products Hazards and Controls Guide. 2nd ed. FDA, Rockville, MD.

U.S. Food and Drug Administration.1997. Pesticide Analytical Manual (PAM) Volume I $3^{\text {rd }}$ Edition. FDA. Washington, D.C.

U.S. Food and Drug Administration. 1984. Polychlorinated biphenyls (PCBs) in fish and shellfish: reduction of tolerances; Final decision. Federal Register 49; 10:21514 21520.Washington, D.C.

U.S. Public Health Service, The Agency for Toxic Substances and Disease Registry, U.S. Department of Health and Human Services and the U.S. Environmental Protection Agency. 1999. Public health Implications Of Exposure To Polychlorinated Biphenyls (PCBs). http://www.epa.gov/OST/fish/pcb99.html

Warnick, W.A. and P. Mazik. West Virginia Sport Fish Consumption Advisory Guide. 2000. 173p.Available from: West Virginia Division of Environmental Protection, Charleston, WV.

West Virginia Division of Natural Resources. 2002. West Virginia Fishing, Favorite Fishing Waters. http://www.dnr.state.wv.us/wvfishing/waters.htm. 
Figure 1. West Virginia Sport Fish Consumption Advisory Sampling Sites

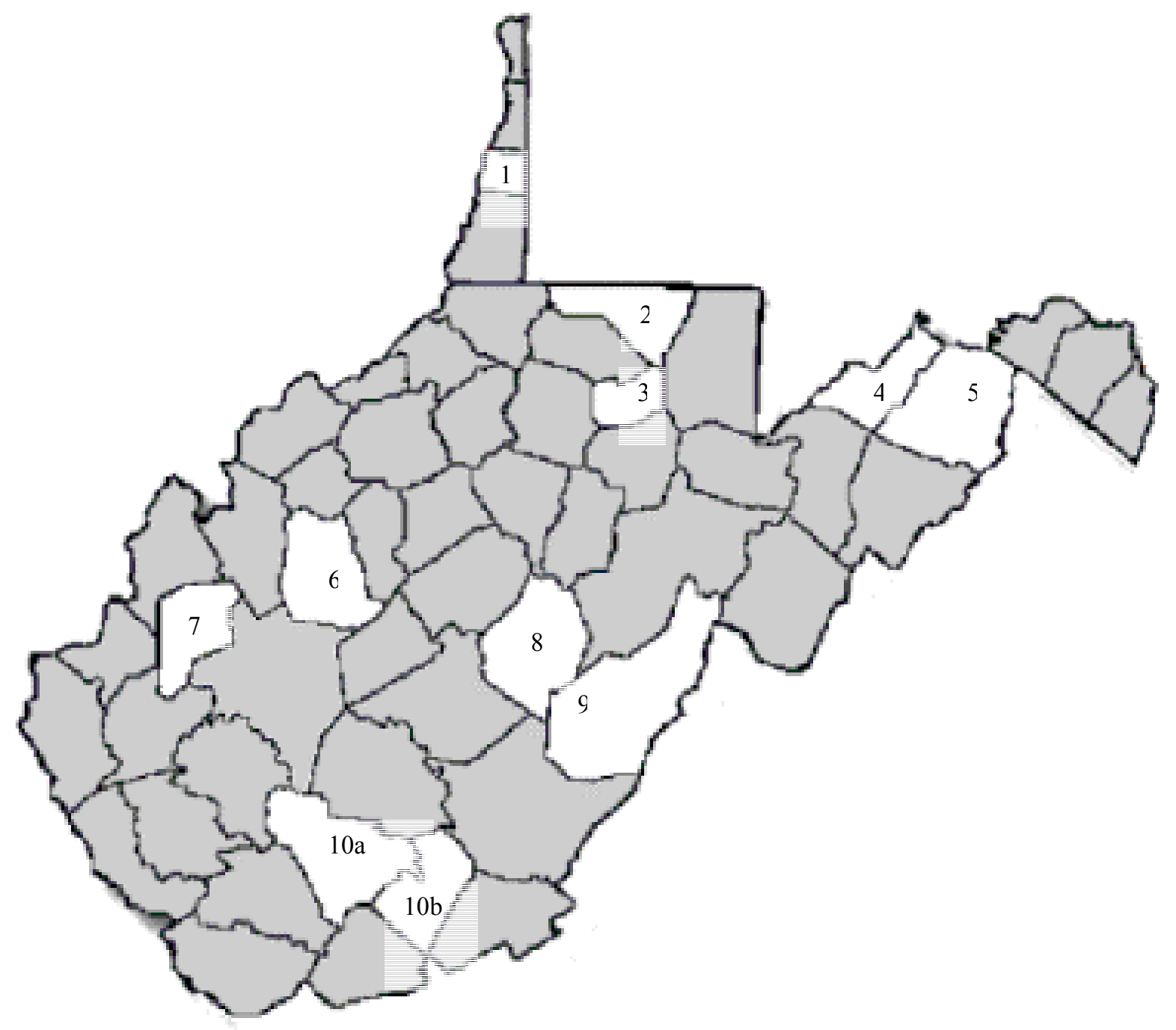

Known Contamination

1) Ohio River, Ohio County

2) Monongahela River, Monongalia County

4) North Branch of the Potomac River, Mineral County

6) Flat Fork Creek, Roane County

7) Kanawha River, Putnam County
Unknown Contamination

3) Tygart Lake, Taylor County

8) Summersville Lake, Nicholas County

5) South Branch of the Potomac River, Hampshire County

9) Cranberry River, Pocahontas County

10a) New River, Raleigh County

10b) Bluestone Lake, Summers County 
Table 1. PCB Advisory Groups - Skin Off Fillet and Skin On Fillet

\begin{tabular}{lcc}
\hline Consumption Advisory Group & Skin Off Fillet & Skin On Fillet \\
\hline Group 1 Unrestricted Consumption & $<0.036 \mathrm{ppm} *$ & $<0.05 \mathrm{ppm}$ \\
Group 2 One meal per week & $0.036 \mathrm{ppm}$ to $0.16 \mathrm{ppm}$ & $>0.05 \mathrm{ppm}$ to $0.22 \mathrm{ppm}$ \\
Group 3 One meal per month & $>0.16 \mathrm{ppm}$ to $0.68 \mathrm{ppm}$ & $>0.22 \mathrm{ppm}$ to $0.95 \mathrm{ppm}$ \\
Group 4 Six meals per year & $>0.68 \mathrm{ppm}$ to $1.35 \mathrm{ppm}$ & $>0.95 \mathrm{ppm}$ to $1.89 \mathrm{ppm}$ \\
Group 5 DO NOT EAT & $>1.35 \mathrm{ppm}$ & $<1.89 \mathrm{ppm}$ \\
\hline
\end{tabular}


Table 2. Results of Students T-Test comparing Mean Aroclor levels and Composite Aroclor levels in fish samples at West Virginia Sites.

\begin{tabular}{|c|c|c|c|c|c|c|}
\hline Site & $\begin{array}{c}\text { Contaminated/ } \\
\text { Uncontaminated }\end{array}$ & Species & $\begin{array}{l}\text { Mean Fish } \\
\text { length } \mathrm{cm} .\end{array}$ & $\begin{array}{c}\text { Composite } \mathrm{Hg} \\
\text { level ug/g }\end{array}$ & $\begin{array}{c}\text { Mean } \mathrm{Hg} \text { level } \\
\text { ug/g }\end{array}$ & Significance \\
\hline Cranberry River & $\mathrm{UC}$ & White Sucker & 23.2 & ND & - & - \\
\hline Flat Fork Creek & $\mathrm{C}$ & $\begin{array}{l}\text { Golden } \\
\text { Redhorse } \\
\text { Sucker }\end{array}$ & 26.7 & ND & - & - \\
\hline Flat Fork Creek & $\mathrm{C}$ & Spotted Bass & 22.9 & 0.06 & 0.08 & NS \\
\hline Kanawha River & $\mathrm{C}$ & Channel Catfish & 34.8 & 0.03 & - & - \\
\hline Kanawha River & $\mathrm{C}$ & Channel Catfish & 46.8 & 0.41 & 0.40 & NS \\
\hline Kanawha River & $\mathrm{C}$ & $\begin{array}{l}\text { Hybrid Striped } \\
\text { Bass }\end{array}$ & 32.9 & 0.21 & 0.23 & NS \\
\hline Monongahela River & $\mathrm{C}$ & Channel Catfish & 36.6 & 0.12 & 0.08 & 0.010 \\
\hline Monongahela River & $\mathrm{C}$ & Channel Catfish & 45.3 & 0.12 & 0.20 & NS \\
\hline Monongahela River & $\mathrm{C}$ & Sauger & 36.3 & 0.25 & 0.10 & NS \\
\hline Monongahela River & $\mathrm{C}$ & White Bass & 32.9 & 0.15 & 0.11 & NS \\
\hline New River & $\mathrm{UC}$ & Channel Catfish & 40.5 & 0.05 & 0.03 & NS \\
\hline New River & $\mathrm{UC}$ & $\begin{array}{l}\text { Smallmouth } \\
\text { Bass }\end{array}$ & 27.4 & ND & - & - \\
\hline $\begin{array}{l}\text { North Branch of the } \\
\text { Potomac }\end{array}$ & $\mathrm{C}$ & White Sucker & 23.6 & ND & - & - \\
\hline Ohio River & $\mathrm{C}$ & Channel Catfish & 41.5 & 0.06 & 0.05 & NS \\
\hline Ohio River & $\mathrm{C}$ & $\begin{array}{l}\text { Hybrid Striped } \\
\text { Bass }\end{array}$ & 40.0 & 0.24 & 0.18 & NS \\
\hline $\begin{array}{l}\text { South Branch of the } \\
\text { Potomac }\end{array}$ & $\mathrm{UC}$ & $\begin{array}{l}\text { Golden } \\
\text { Redhorse } \\
\text { Sucker }\end{array}$ & 48.9 & ND & - & - \\
\hline $\begin{array}{l}\text { South Branch of the } \\
\text { Potomac }\end{array}$ & $\mathrm{UC}$ & $\begin{array}{l}\text { Smallmouth } \\
\text { Bass }\end{array}$ & 29.2 & ND & - & - \\
\hline Summersville Lake & $\mathrm{UC}$ & $\begin{array}{l}\text { Golden } \\
\text { Redhorse } \\
\text { Sucker }\end{array}$ & 44.8 & ND & - & - \\
\hline Summersville Lake & $\mathrm{UC}$ & $\begin{array}{l}\text { Smallmouth } \\
\text { Bass }\end{array}$ & 30.0 & ND & - & - \\
\hline Tygart Lake & $\mathrm{UC}$ & Channel Catfish & 47.2 & ND & - & - \\
\hline Tygart Lake & $\mathrm{UC}$ & Walleye & 39.3 & ND & - & - \\
\hline
\end{tabular}


Table 3. Composite Aroclor levels compared to one meal per week screening value $0 \mathrm{f} 0.05 \mathrm{ug} / \mathrm{g}$ - Skin on Fillet and one meal per month value 0 f $0.22 \mathrm{ug} / \mathrm{g}$ - Skin on Fillet

\begin{tabular}{|c|c|c|c|c|c|}
\hline Site & $\begin{array}{c}\text { Contaminated } \backslash \\
\text { Uncontaminated }\end{array}$ & Species & $\begin{array}{l}\text { Mean Fish } \\
\text { length } \mathrm{cm} .\end{array}$ & $\begin{array}{c}\text { Composite A- } \\
1260 \text { level ug/g }\end{array}$ & $\begin{array}{l}\text { Advisory Level } \\
\text { One meal per }\end{array}$ \\
\hline Cranberry River & $\mathrm{UC}$ & White Sucker & 23.2 & ND & Unlimited \\
\hline $\begin{array}{l}\text { South Branch of the } \\
\text { Potomac }\end{array}$ & UC & $\begin{array}{l}\text { Golden } \\
\text { Redhorse Sucker }\end{array}$ & 48.9 & ND & Unlimited \\
\hline $\begin{array}{l}\text { South Branch of the } \\
\text { Potomac }\end{array}$ & $\mathrm{UC}$ & $\begin{array}{l}\text { Smallmouth } \\
\text { Bass }\end{array}$ & 29.2 & ND & Unlimited \\
\hline Summersville Lake & $\mathrm{UC}$ & $\begin{array}{l}\text { Golden } \\
\text { Redhorse Sucker }\end{array}$ & 44.8 & ND & Unlimited \\
\hline Summersville Lake & UC & $\begin{array}{l}\text { Smallmouth } \\
\text { Bass }\end{array}$ & 30.0 & ND & Unlimited \\
\hline Tygart Lake & UC & Walleye & 39.3 & ND & Unlimited \\
\hline Flat Fork Creek & $\mathrm{C}$ & $\begin{array}{l}\text { Golden } \\
\text { Redhorse Sucker }\end{array}$ & 26.7 & ND & Unlimited \\
\hline Flat Fork Creek & $\mathrm{C}$ & Spotted Bass & 22.9 & 0.06 & Week \\
\hline Kanawha River & $\mathrm{C}$ & $\begin{array}{l}\text { Hybrid Striped } \\
\text { Bass }\end{array}$ & 38.9 & 0.21 & Week \\
\hline Monongahela River & $\mathrm{C}$ & Sauger & 36.3 & 0.25 & Month \\
\hline Monongahela River & $\mathrm{C}$ & White Bass & 32.9 & 0.15 & Week \\
\hline New River & $\mathrm{C}$ & $\begin{array}{l}\text { Smallmouth } \\
\text { Bass }\end{array}$ & 27.4 & ND & Unlimited \\
\hline $\begin{array}{l}\text { North Branch of the } \\
\text { Potomac }\end{array}$ & $\mathrm{C}$ & White Sucker & 23.6 & ND & Unlimited \\
\hline Ohio River & $\mathrm{C}$ & $\begin{array}{l}\text { Hybrid Striped } \\
\text { Bass }\end{array}$ & 40.0 & 0.55 & Month \\
\hline
\end{tabular}


Table 4. Composite Aroclor levels compared to one meal per week screening value 0f $0.036 \mathrm{ug} / \mathrm{g}$ - Skin off Fillet and one meal per month value of $0.16 \mathrm{ug} / \mathrm{g}$.

\begin{tabular}{lccccc}
\hline \multicolumn{1}{c}{ Site } & $\begin{array}{c}\text { Contaminated } \backslash \\
\text { Uncontaminated }\end{array}$ & Species & $\begin{array}{c}\text { Mean Fish } \\
\text { length cm. }\end{array}$ & $\begin{array}{c}\text { Composite A- } \\
\text { 1260 level ug/g }\end{array}$ & $\begin{array}{c}\text { Advisory Level } \\
\text { One meal per }\end{array}$ \\
\hline New River & $\mathrm{UC}$ & $\begin{array}{l}\text { Channel } \\
\text { Catfish }\end{array}$ & 40.5 & 0.05 & Week \\
Tygart Lake & $\mathrm{UC}$ & $\begin{array}{l}\text { Channel } \\
\text { Catfish } \\
\text { Channel } \\
\text { Catfish } \\
\text { Channel }\end{array}$ & 34.8 & ND & Unlimited \\
Kanawha River & $\mathrm{C}$ & 46.8 & 0.03 & Unlimited \\
Kanawha River & $\mathrm{C}$ & $\begin{array}{l}\text { Catfish } \\
\text { Channel }\end{array}$ & 36.6 & 0.12 & Month \\
$\begin{array}{l}\text { Catfish } \\
\text { Channel } \\
\text { River }\end{array}$ & $\mathrm{C}$ & 45.3 & 0.12 & Week \\
$\begin{array}{l}\text { Catfish } \\
\text { River } \\
\text { Ohio }\end{array}$ & $\mathrm{C}$ & 41.5 & 0.24 & Month \\
Catfish & $\mathrm{C}$ & &
\end{tabular}


Table 5. Ohio River Fish Consumption Advisory

\begin{tabular}{ll}
\hline Fish Species & Restrict Meals to: \\
\hline Largemouth bass, smallmouth bass, and sauger & One meal a week (52 meals/year) \\
White bass, hybrid striped bass, and freshwater drum & One meal a month (12 meals/year) \\
Flathead catfish Channel catfish less than 17 inches & Six meals a year (one meal every two months) \\
Channel catfish more than 17 inches Carp & DO NOT EAT \\
\hline
\end{tabular}

